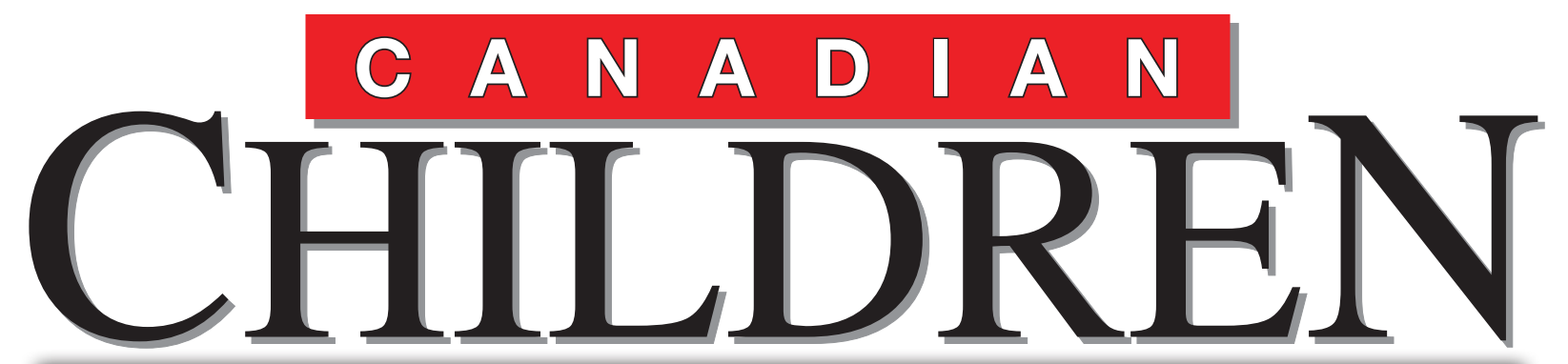

JOURNAL OF THE CANADIAN ASSOCIATION FOR YOUNG CHILDREN

FALL 2014 / AUTOMNE 2014

Vol. 39 No. 3
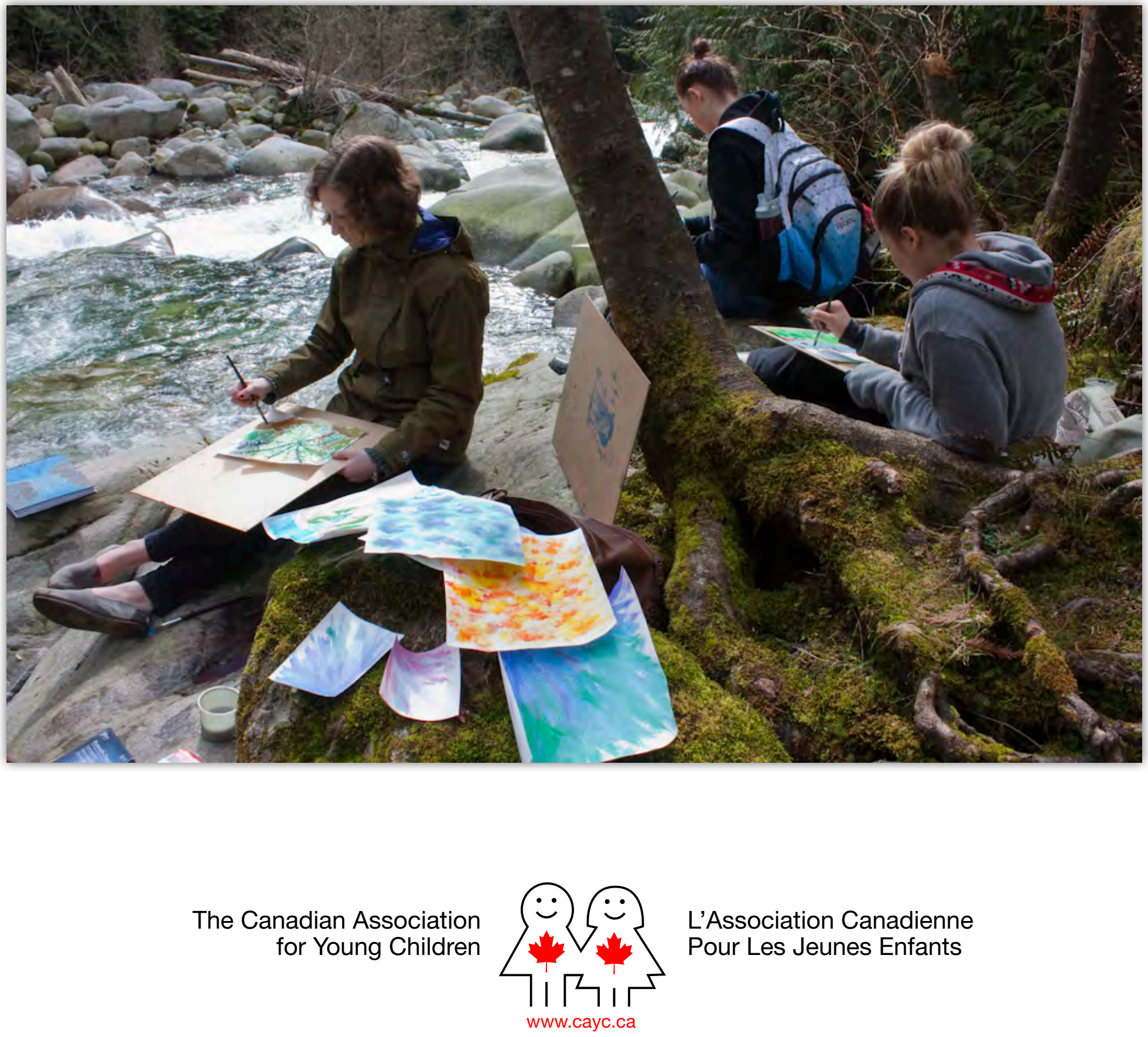


\section{THE CANADIAN ASSOCIATION FOR YOUNG CHILDREN}

\section{WHAT IS THE CAYC?}

The Canadian A ssociation for Young Children (CAYC) grew out of the Council for Childhood Education and was officially recognized in 1974 by the granting of a Federal Charter. It is the only national association specifically concerned with the well-being of children, birth through age nine, at home, in preschool settings and at school. Members of the multidisciplinary association include parents, teachers, caregivers, administrators, students and all those wishing to share ideas and participate in activities related to the education and welfare of young children.

\section{MISSION STATEMENT}

CAY C exists to provide a Canadian voice on critical issues related to the quality of life of all young children and their families.

\section{THE AIMS OF THE CAYC}

1. To influence the direction and quality of policies and programs that affect the development and well-being of young children in Canada.

2. To provide a forum for the members of Canada's early childhood community to support one another in providing developmentally appropriate programs for young children.

3. To promote and provide opportunities for professional development for those charged with the care and education of young children.

4. To promote opportunities for effective liaison and collaboration with all those responsible for young children.

5. To recognize outstanding contributions to the well-being of young children.

\section{IMPLEMENTING THE AIMS OF THE CAYC}

\section{The National Conference:}

The National Conference is a highlight of the CAY C. The program includes lectures by internationally renowned authorities on children, workshops, discussion groups, displays, demonstrations, school visits and tours.

\section{Provincial and Regional Events:}

The organization of members at the local and provincial level is encouraged to plan events to deal with the issues and concerns pertaining to young children. These events may take the form of lectures, seminars or a local conference.

\section{The J ournal:}

A n outstanding multidisciplinary journal is published twice yearly. Articles by nationally and internationally known experts in early childhood education and child rearing are presented in the Journal of the CAYC. Inside CAYC provides information on A ssociation activities.

\section{SUBSCRIPTIONS AND MEMBERSHIP}

M embership fees are payable on application and renewable annually on an evergreen basis. To be considered a voting member, fees must be paid no later than 60 days prior to the A nnual General M eeting.

CAYC members receive two issues of Canadian Children as well as favourable rates for national and regional conferences.

Regular $\$ 55.00,2$ Y ear Regular $\$ 100.00$, association/institution $\$ 120.00$, student/senior $\$ 30.00$, international $\$ 135.00$ (CA).

\section{CAYC}

31 Pinedale Drive

Prospect Bay, Nova Scotia B3T 1 Z6

membership@cayc.ca
ASSOCIATION CANADIENNE POUR LES JEUNES ENFANTS

QU'EST CE QUE L'ACJE

L'A ssociation Canadienne pour les J eunes Enfants, issue du Council for Childhood Education, a reçu sa charte fédérale en 1974. Elle demeure la seule association nationale vouée exclusivement au bien-être des enfants, de la naissance jusqu'à l'âge de neuf ans, dans leur foyer, à la garderie et à l'école primaire. L'A CJE est composée de parents, $d^{\prime}$ 'enseignants, de professionnels de la petite enfance, d'administrateurs et d'étudiants, ainsi que de tous ceux et celles qui sont intéressés à partager leurs idées en participant à des activités liées au bien-être et à l'éducation des jeunes enfants.

\section{SA MISSION}

L'A CJE s'est donné comme mandat de faire entendre une voix canadienne sur les questions essentielles ayant trait à la qualité de vie de tous les jeunes enfants et de leur famille.

\section{SE S OBJECTIFS}

1. Jouer un rôle sur le plan des orientations et sur la qualité des politiques et des programmes touchant au développement et au bien-être des jeunes enfants canadiens.

2. Créer un forum pour les membres de la communauté canadienne oeuvrant dans le domaine de la petite enfance afin de susciter une collaboration active dans l'élaboration de programmes appropriés au développement des jeunes enfants.

3. Encourager et offrir des possibilités de perfectionnement professionnel au personnel responsable du bien-être et de l'éducation des jeunes enfants.

4. Promouvoir des occasions pour une meilleure coordination et collaboration entre tous les responsables des jeunes enfants.

5. Récompenser et souligner les contributions exceptionnelles faites en faveur des jeunes enfants.

\section{EXÉCUTION DES OBJECTIFS DE L'ACJE \\ 1. Le congrès national:}

II constitue le grand évènement de l'A CJE. Des sommités de renommée internationale en matière de petite enfance y prononcent des conférences et on y participe à des ateliers, des débats, des expositions, des démonstrations, et à des visites guidées d'écoles.

\section{Les évènements provinciaux et locaux:}

L'ACJE encourage ses membres à organiser des conférences, des séminaires ou des congrès au niveau local et régional afin de débattre des problèmes relatifs aux jeunes enfants.

3. La revue:

Publication bisannuelle et multidisciplinaire de premier ordre, la revue regroupe des articles traitant de questions d'éducation et de formation des jeunes enfants. On y retrouve également des articles écrits par des experts de renommée nationale et internationale. $L$ a rubrique Inside CA Y C renseigne les lecteurs sur les activités de l'A ssociation.

\section{ABONNEMENT ET COTISATION DES MEMBRES}

Les cotisations doivent être réglées au moment de l'adhésion et celle-ci doit être renouvelée chaque année. Pour se prévaloir de son droit de vote, tout membre doit acquitter sa cotisation au moins 60 jours avant I'A ssemblée Générale annuelle.

Les members de l'A CJE reçoivent la revue, et bénéficient de tariffs spéciaux pour participer au congrès national et aux évènements régionaux.

Tarif des cotisations annuelles: général; 55 \$, général 2 année $100 \$$, étudiants/aîné: 30 \$, associations : 120 \$, international : 135 \$ (CA)

\section{ACJE}

31 Pinedale Drive

Prospect Bay, Nova Scotia B $3 T 1 Z 6$

membership@ cayc.ca 


\section{CHILDREN}

JOURNAL OF THE CANADIAN ASSOCIATION FOR YOUNG CHILDREN

SPRING / PRINTEMPS 2014

Vol. 39 No. 2

\section{EDITORS' DESK}

Dr. Laurie Kocher

Douglas College, Coquitlam, British Columbia

Dr. Veronica Pacini-Ketchabaw

University of Victoria, Victoria, British Columbia

\section{PUBLICATIONS CHAIRPERSON}

\author{
Dr. Iris Berger \\ University of British Columbia \\ Vancouver, British Columbia
}

\section{DR. ANNE CARR \\ University of Cuenca Ecuador}

DR. ALLIE CLEGHORN

Concordia University

Montreal, QC

DR. ENID ELLIOT

Camosun College

Victoria, BC

\section{SUSAN FRASER}

Author/Consultant

West Vancouver, BC

DR. MARTHA GABRIEL

University of Prince Edward Island

Charlottetown, PEI

DR. RACHEL HEYDON

University of Western Ontario London, ON

DR. LUIGI IANNACCI

Trent University

Peterborough, ON

DR. SYLVIA KIND

Capilano University

North Vancouver, BC

\section{DR. RACHEL LANGFORD}

Ryerson University Toronto, ON

\section{DR. PATRICK LEWIS}

University of Regina Regina, SK

DR. LARRY PROCHNER

University of Alberta Edmonton, $\mathrm{AB}$

DR. CARMEN RODRIGUEZ DE FRANCE

University of Victoria Victoria, BC

DR. SHERRY ROSE University of New Brunswick Fredericton, NB

DR. WAYNE SEREBRIN

University of Manitoba Winnipeg, MB

DR. PATRICIA TARR

University of Calgary Calgary, $A B$

\section{DR. AFFRICA TAYLOR}

University of Canberra

Canberra, Australia

DR. PAM WHITTY

University of New Brunswick Fredericton, NB

DR. CAROL ANNE WIEN York University Toronto, ON
EXCEPT WHERE NOTED ON THE ARTICLE: Reproduction of material in this publication is hereby authorized, provided the use of the material is both noncommercial and educational, and the number of copies does not exceed 100 . Permission to reprint articles must be obtained in writing from the Editor (or the original source, where noted). Opinions exp original soure. where noted). Opinions expressed in the atic and do not necessarily represent the views of the editors or the members of CAYC.

(c) 1996: The Canadian Association for Young Children ISSN: 0833-7519 Graphics \& Printing by The Printing House, Vancouver, BC

\section{VISIT OUR WEBSITE: www.cayc.ca} In search of printable articles? Please refer to EBSCO-host.
2 Guidelines for $A$ uthors

3 From the Editors' Desk

By Laurie Kocher and Veronica Pacini-K etchabaw

\section{CHILD STUDY}

$5 \quad$ Young Children Representing Numbers: W hat Does the Literature Say?

By Gabriela Arias de Sanchez

15 Voices From the Field: Full-day Kindergarten Teams in O ntario Share Their Wisdom

By M onica M CG lynn-Stewart and Kimberly Bezaire

24 U sing Play as a Key to Unlocking the Silence for Children with Selective M utism

By Poling Bork, Debra Harwood, and Sheila M. Bennett

34 21st Century Vision U sing a 20th Century Curriculum: Examining B ritish Columbia's K indergarten Curriculum Package By Laura Teichert

42 A re We Ready? Early Childhood Educator Students and Perceived Preparedness for School-B ased Special Education

By Kimberly Maich and $\mathrm{C}$ armen $\mathrm{H}$ all

\section{DIRECTIONS AND CONNECTIONS}

53 B eyond Red Week: Working with Inquiry in Early Years Settings By Kim Atkinson

58 Seeking the O therwise: A ttending to the Complexities of Listening By Vanessa Clark and Deanna Elliott

\section{PROFESSIONAL RESOURCES}

64 Conversations B ehind E arly Childhood Pedagogical Documentation. Edited by A Ima Fleet, Catherine Patterson, and Janet Robertson

By Sydney Gurewitz Clemens

Cover Photo by: Sylvia Kind 
Canadian Children is the journal of the Canadian Association for Young Children (CAYC), the only national association specifically concerned with the well-being of children of preschool and elementary age in Canada. The journal is published twice yearly and contains articles, book reviews and announcements of professional conferences.

Canadian Children is a multidisciplinary journal concerned with child development, child studies and early childhood education. A uthors from across $C$ anada, and el sewhere, are invited to submit articles and book reviews which reflect the variety and extent of both research and practice in early childhood education and child well-being.

\section{CONTENT:}

Submissions should appeal to an audience that includes parents, professionals in the field of childhood education and child services, as well as teachers and researchers. M ost issues are multi-theme in nature and the editor will attempt to balance articles that are research related with articles of a practical nature relating to programming, curriculum, classroom practice or child well-being.

\section{FORM, LENGTH, AND STYLE:}

- Articles may be of varying length, written in a readable style. Style should be consistent with the Publication Manual of the A merican Psychological A ssociation (6th Edition).

- Articles should be sent as an e-mail attachment to the email address below.

- All submissions should be accompanied by a copy of the signed permission form available at the website (cayc.ca)

- Authors are to obtain releases for use of photographs prior to e-mailing the manuscript. Signed permissions must be included in the submission.

- Please include a brief biographical sketch (4-5 sentences) including the author(s) full name, title, professional affiliation, and other relevant information.

- An abstract should be included at the start of the manuscript, and should not exceed 100 words.

- In order to enable blind review, manuscripts must be anonymized. No author information should be included in the manuscript.

- All author information (including full name, mailing address and biographical information) must be included in a separate document.

- It is expected that authors will not submit articles to more than one publisher at a time.

\section{ACCEPTANCE AND PUBLICATION:}

The editors will acknowledge receipt and will review all solicited and unsolicited manuscripts received. The final publication decision rests with the editors, and will be communicated within three months.

DEADL INE S: Submissions for publication are considered in February \& A ugust.
Canadian Children est la revue de I'A ssociation canadienne pour jeunes enfants $(A C J E)$, la seule association vouée exclusivement au bien-être des enfants de niveau préscolaire et primaire au Canada. Cette revue publiée deux fois I'an regroupe des articles, des comptes rendus de livres et des avis de conférences professionnelles.

Canadian Children est une revue multidisciplinaire axée sur le développement de l'enfant, les études de l'enfant et l'éducation à I'enfance. L es auteurs du C anada et d' ailleurs sont invités à soumettre des articles et des comptes rendus de livres mettant en évidence la vari été et l'étendue de la recherche et de la pratique dans le domaine de l'éducation à la petite enfance et du bien-être de l'enfant.

\section{CONTENU:}

Les articles doivent s' adresser à un public composé de professionnels des domaines de l'éducation à l'enfance et des services à l'enfance, de parents, d'enseignants et de chercheurs. La plupart des numéros traitent $d^{\prime}$ une multitude de thèmes et le rédacteur en chef tentera $d^{\prime} y$ inclure tant des articles portant sur la recherche que des articles portant sur des aspects pratiques de l'éducation, comme la gestion et la mise en œuvre de programmes d'études, de méthodes d'enseignement en salle de classe et de techniques utilisées pour assurer le bien-être des enfants.

\section{FOR ME, L ONG UE UR ET STYLE:}

- Les articles peuvent être de longueur variée et doivent être rédigés dans un style accessible à tous les lecteurs. La présentation doit être conforme aux normes du Publication Manual (6e édition) de I'A merican Psychological A ssociation.

- Les articles devront être joints à un courrier électronique et envoyés à l'adresse de courriel indiquée ci-dessous.

- Toutes les soumissions devront être accompagnées d'une copie signée du formulaire d'autorisation disponible sur notre site Web (www.cayc.ca).

- Les auteurs devront obtenir une autorisation de publier pour I'utilisation de photographies avant de nous faire parvenir le manuscrit par courriel. L es autorisations signées doivent être incluses dans la soumission.

- Veuillez inclure une brève notice biographique (4 ou 5 phrases) comprenant le nom complet, le titre et l'affiliation professionnelle de I'auteur ou des auteurs, ainsi que tout autre renseignement pertinent. - Un résumé de maximum 100 mots devra être inclus au début du manuscrit.

- Afin de permettre un examen aveugle des manuscrits, ceux-ci doivent être anonymes. A ucune information relative à l'auteur ne doit être présente dans le manuscrit.

- Tous les renseignements relatifs à l'auteur (y compris le nom complet, l'adresse postale et l'information biographique) doivent être inclus dans un document à part.

- Il est entendu que les auteurs ne soumettront leurs articles qu'à une seule revue à la fois.

\section{ACCE PTATION ET PUBLICATION}

Les rédacteurs en chef accuseront réception et tiendront compte de tous les manuscrits reçus, qu'ils aient été sollicités ou non. La décision définitive de publier un article relève de la responsabilité des rédacteurs en chef, et elle sera communiquée à l'auteur dans un délai de trois mois.

É C HÉ ANCE : L es soumissions sont acceptées en tout temps.

\section{Please send all publication correspondence for consideration to: \\ Co-Editors, Laurie Kocher \& Veronica Pacini-Ketchabaw CANADIAN CHILDREN JOURNAL cdnchildren@gmail.com}




\section{EDITORS}

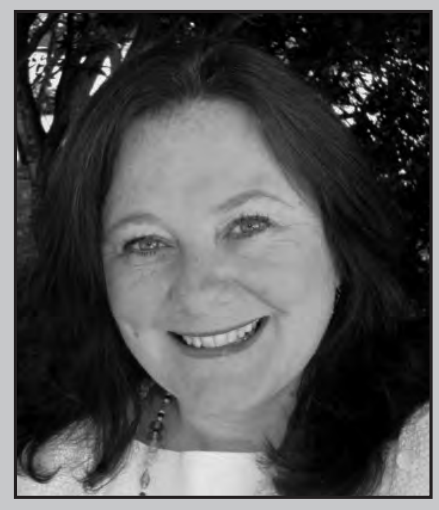

Dr. Laurie Kocher

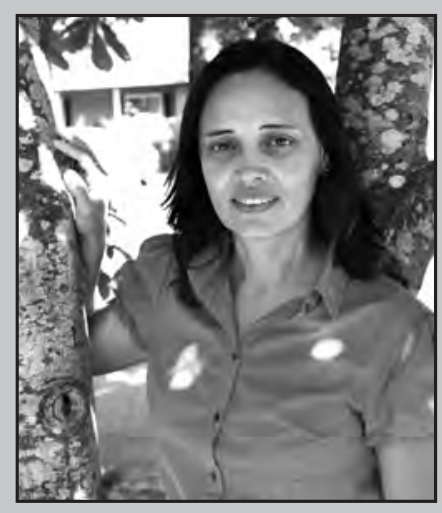

Dr. Veronica Pacini-Ketchabaw

It's been an uncommonly beautiful spell of weather here on the west coast of Canada. Vancouver's reputation as a grey and dismal place is so undeserved! As we roll into fall weather, a season of sitting by the fire with a warm of mug of cider and good reading at hand seems in order. This issue of Canadian Children brings you a fascinating range of articles.

Gabriela A rias de Sanchez, in her article Young Children Representing Numbers, summarizes a body of research in the area of symbolic and numeric development in young children that is supported by socio-constructivist ideas. De Sanchez invites readers to reflect on pedagogical principles and conceptual frameworks that support current early childhood mathematics education.

In Voices F rom the F ield: F ull-day Kindergarten Teams in 0 ntario Share Their Wisdom, authors M onica M cGlynn-Stew art and K imberly B ezaire examine the perspectives of teaching teams with varying backgrounds and status as they implement innovative approaches to full day, school-based early years education for 4-5 year olds. Re-establishing roles is one of their key findings.

Poling B ork, Debra Harwood, and Sheila M. B ennett consider U sing Play as a K ey to U nlocking the Silence for Children with Selective M utism In this article, the authors propose that play is a valuable and necessary medium to meet the needs of the child with selective mutism, foster resiliency, and promote well-being. Play provides a much-needed context to lessen the anxieties associated with being seen or heard speaking.

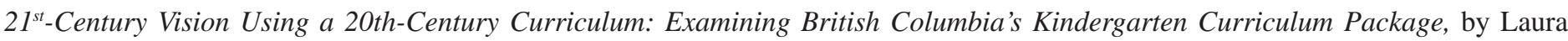
Teichert, provides a critical analysis of British Columbia's early learning curricula concerning 21st-century education and the role of digital technology in the early years. As children navigate an increasingly digital world, one with blurred lines between content and advertising, critical thinking and critical analysis skills are essential in order for children to effectively manage the vast amounts of information available to them. Educators and policy makers, through curricula developed reflecting digital media use, can play an important role in educating young, technologically engaged students.

K imberly $\mathrm{M}$ aich and Carmen $\mathrm{H}$ all, in their contribution A re We Ready? E arly Childhood E ducator Students and Perceived P reparedness for School-Based Special Education, describe a small-scale, single-region research project to investigate early childhood educator (ECE) students' understanding of special education in the kindergarten context that has been in place in Ontario schools since 2010. The perceived preparedness of ECE students on placement in kindergarten classrooms is evaluated and suggestions for ECE preparedness and ECE curriculum changes are made.

K im A tkinson draws on her own experience and that of her colleagues in Beyond Red Week: Working with Inquiry in Early Years Settings. This article explores moving from a theme-based curriculum in early years settings to an inquiry-based approach. N ew possibilities for doing curriculum are described as educators challenge themselves to engage in processes of critical reflection, enact democratic principles, and adopt an inquiry as a focal point for discussion among children, colleagues, and families.

Vanessa Clark and Deanna Elliott, in Seeking the 0 therwise: Attending to the Complexities of Listening, attempt to move beyond both 
developmental and Reggio Emilia guidelines for listening. Situating their efforts within a wounded colonial context- what is now called Victoria, B ritish Columbia - they consider listening within unequal spaces of power, and wonder what ethics such arrangements might require.

Sydney Gurewitz Clemens brings us a review of the Australian volume, Conversations: Behind Early Childhood Pedagogical D ocumentation, edited by A Ima Fleet, Catherine Patterson, and Janet Robertson. As Sydney says, "I haven't felt this excited by a teaching book in some years!" The thoughtful, critically minded authors gathered in this book present nontrivial thinking about ideas educators are learning from Reggio Emilia.

The publication of this journal represents a labour of love on the part of many authors, reviewers, and volunteers. A very significant, long-term contributor to this effort has been Dr. Carol A nne Wien. We wish to express our deep appreciation to Carol A nne as she steps down from the editorial board to take up some new, some familiar interests in her retirement.

Carol A nne has been a valued member of the editorial board of Canadian Children for 17 years. Her work as a professor at York University has made her a significant mentor for many educators in Ontario, and her willingness to travel to work with groups in other provinces has elevated her impact to the national level. Throughout her academic career, Carol A nne has ensured that she kept in contact with the experience of children and educators, and as such, her thinking is informed by practice. Carol Anne has also influenced the development of curriculum frameworks, either directly or through colleagues and former students. She has been a keynote speaker at major conferences across the country and in the U nited States, and her long-standing interest in the Reggio experience and emergent curriculum has led her to author books and articles that have been influential throughout North America. Two titles, in particular, that will be familiar to readers of this journal are E mergent Curriculum in the Primary Classroom (Teachers College Press), and The Power of Emergent Curriculum (NAEY C). A new book, D ocumentation as Relationship: "I am in your eye", co-authored by Jason Avery, Carol A nne and fellow CAY C board member K aryn Callaghan, is soon to be published by Davis A rt.

Canadian Children has benefitted from Carol Anne's wisdom, and we wish her well on her retirement--and at the same time hope to see her name on upcoming publications and conference rosters. A nd if you happen to hear the some jazz riffs tickling the ivories, look for Carol Anne. She has an uncommon ability to find a piano just about anywhere!

Grazie mille for your generous contribution to the quality of Canadian Children.

*A special online version of Canadian Children will be available for CAY C members at the website: cayc.ca This special issue will focus on Professionalism in the Canadian Early Childhood Education and Care sector. Look for it in February. 


\title{
Young Children Representing Numbers: What Does the L iterature Say?
}

\author{
Gabriela A rias de Sanchez
}

G abriela A rias de Sanchez has a degree in early childhood from the U niversity of Rio Cuarto, A rgentina. In 2010, she completed the master in education and leadership at the University of Prince Edward Island. She is currently a SSHRC doctoral student at UPEI. Her research interests include early years pedagogy, particularly early childhood mathematics education. Prior to completing her MEd, Gabriela worked in the early years for more than two decades as an educator and director as well as teaching at the postsecondary level. Email: gsanchez@ upei.ca

Children are exposed to written numerals from a very young age, and the practice of using written numerals is encouraged in early childhood educational settings. Further, many mathematical assessments are based on young children's understanding of conventional numerals. Supported by socio-constructivist ideas, this review summarizes a body of research in the areas of symbolic and numeric development in young children, providing a synthesis for early childhood educators and teachers. This work is an invitation to reflect on both the pedagogical principles that underline "pencil-pushing practices" and the conceptual frameworks that support current early childhood mathematics education.
Maria hurried into the early childhood centre. The child's preschool classroom was noisy and everybody was busy. Some children were building, others were drawing on large posters, and others were dressing up. "M aria," said her teacher, "could you go to the kitchen and ask for five spoons? There are not enough for the snack table."

Returning from the kitchen, Maria realized she had only four spoons in her hand. She went back to the kitchen and asked the cook for one more. Then M aria chose to play in the dramatic play area. She played teacher with her friends and everybody seemed enthusiastic. "There are 10 boys in the class today" said Maria, printing seven tally marks on the whiteboard. Later, during work time, Maria received a pencil and a sheet. Her teacher asked her

to count the objects on the page and to write the number inside the empty square. Looking at the page, Maria could see a flower, butterflies, and something she was not sure about- "maybe flies?" Beside each picture she could see the empty square at which the teacher kept pointing. Maria took a long time to complete the activity. Her eyes roved the classroom and her face was tense. She finally traced a big square around the smaller, empty one, passed the sheet quickly to the teacher, and ran outside to the playground.

As an early childhood educator (ECE) in A rgentina and Canada for more than two decades, I have observed situations like the one above in many different early childhood settings. A ttitudes similar to M aria's were expressed by many young children in both countries. It seemed to me that when young children printed numbers and the printing was not influenced by adults' expectations, the notations and the attitudes w ere quite different. Like M aria, most children's responses to formal requests were fragile and lacked enthusiasm, as if they did not know anything about mathematics.

My interest in mathematics and young children's development caused me to question why young children's strategies changed so drastically in routines like the ones described above. Why were children's responses, including their body language, so different from one situation to the other? W hy had M aria printed numeric ideas when she played teacher, yet was not able to respond when the educator asked her to write numerals?

Early childhood mathematical and cognitive studies have shown that young children use their own notations to represent quantities (Bialystok \& Codd, 1996; Carruthers \& Worthington, 2006; Hughes, 1986; M unn, 2008; Sinclair, Siegrist, \& Sinclair, 1983; Teubal \& Dockrell, 2004). This issue was also explored by well-known researchers in the early childhood field, such as Constance Kamii, who, with other researchers, showed that young children represent numbers in their own way according to their levels of abstraction (K ato, Kamii, Ozaki, \& Nagahiro, 2002). However, using conventional mathematical symbols in their spoken (rote counting) or written form (numerals) are mathematical practices that generally receive considerable attention in early childhood mathematics education (ECM E). In general, there appears to be a tendency to rush children into using symbols in the name of "academic learning," whereby young children are expected to practice and master the use of numerals (e.g.,1, 25, 100) before they enter school (Brosseau, 2006; Ginsburg, Sun Lee, \& B oyd, 2008). Hughes (1986) argues that asking young children to print conventional numerals is equival ent to asking them to replace their use of informal ways of representing numbers (e.g., tally marks) with a system that is contrived and has no meaning to 
them. One curriculum department in the U.S. calls these practices pencil pushing and argues that "pencil pushing has helped produce generations of people who see mathematics as little else" (Plainfield Board of Education, 2006, p. 24).

In my teaching experience, I have observed that many children are exposed to conventional numerals from a very young age, and children are expected to print numbers earlier and earlier. Furthermore, many mathematical assessments are based on young children's understanding of numerals. A re these kinds of exercises necessary to build foundational mathematics knowledge? Do these assessments lead children to learn the meaning of numbers ? Do they inform educators about what children can really do? Sadly, pencil-pushing activities are completed most of the time by young children with no opportunity to explore and comprehend the meaning of numbers.

This review summarizes a body of research that focuses on early symbolic and numeric development. The review invites educators and early childhood policy makers to reflect on the pedagogical principles that underlie pencil-pushing practices in early childhood settings.

\section{Background to the Study}

A literature review, as a reflective summary of previous knowledge and ideas, is fundamental to understanding current issues in research. Literature reviews provide research evidence and facilitate the possibility of critically examining what others have done in a particular area of endeavour.

This literature review is informed by the idea that knowledge construction does not happen in isolation but within culturally shared understandings and practices (Cobb, 1994; Rogoff, 1990, 2003; Vygotsky, 1978). This socio-constructivist perspective suggests that mathematical learning is a process of individual active construction that occurs when individuals engage in mathematical practices with others. Symbols appear to play a particular role within the socio-constructivist framew ork because they carry a shared social meaning that individuals have to construct. From a constructivist perspective, mathematical knowledge evolves through different phases in which individuals understand and make sense of the world in ever more complex ways.

Research-based evidence about the value of foundational mathematics teaching has been accumulating in the last decades (A nderson, A nderson, \& Thauberger, 2008; B aroody \& Li, 2009; Gifford, 2003; 2004; Kamii, 2000; Siegler \& Booth; 2004). However, more studies are needed to align this evidence with meaningful early childhood mathematical practices (Clements \& Sarama, 2009; Ginsburg \& Golbeck, 2004; Sophian, 2009). Likewise, the processes that young children appear to follow when developing their ideas of numbers and numerals have been extensively explored (Bialystok \& Codd, 1996; Carruthers \& Worthington, 2006; DeLoache, 1995a, 1995b; Gifford, 2005; Hughes, 1986; Kato et al., 2002; Munn, 2008; Piaget, 1952; Piaget \& Inhelder, 1971, 1983; Sinclair et al., 1983). Yet, most early mathematics teaching regarding the use of numerals has been oriented to school preparation with a tendency to teach content rather than to scaffold mathematical process (Ginsburg et al., 2008). I believe that many misconceptions about young children's mathematical learning and a lack of pedagogical research about this matter have been guiding early childhood educators to rely, in some cases, on practices that are not appropriate and that lack clear mathematical intentionality.

The purpose of this paper is to highlight research that has focused on exploring the trajectories followed by children ages 2 to 5 when they print numbers. This review also proposes a context for discussion about mathematical practices throughout the early years and challenges us to reflect on the ways that pencil pushing happens in isolation during a time when young children are discovering their world.

\section{Methods}

A review of relevant literature was conducted via keyboard searches using various electronic databases. These included A cademic Search Complete, ERIC, Google Scholar, M athSciNet, PsycINFO, and SA GE Premier collection. Practice-oriented texts, researchbased texts, reports, and research-based peer-reviewed articles were selected according to four main topics: children's mathematical learning trajectories, children's number learning trajectories, individuals' use of symbols, and approaches to early childhood mathematics education. The selection criterion was that the resources had to address at least one of the above-mentioned areas. The selection was focused on children ages 2 to 5 . However, resources that explored children's developmental ages 0 to 8 were also included when findings reported children's numeric and symbolic trajectories within this age range.

A total of 71 resources were selected for review. The final selection included the following: (a) 5 practice-oriented texts; (b) 12 researchbased texts; (c) 49 research-based peer-reviewed articles; (d) 4 reports; and (e) 1 conference proceeding. Studies that highlighted children's cognitive development and children's mathematical competences were explored in depth. The selected resources involved 
both qualitative and quantitative research-based investigations. Resources were written in English with the exception of one book written in Spanish.

\section{Data Analysis}

The selected resources were read independently and summarized in tables. The tables included author, title, purpose of the study, context of the study, findings, and conclusions. By using a thematic analysis approach (Joffe \& Yardley, 2004), I explored in depth trends, similarities, and differences across the summary tables. Recurring consistencies and inconsistencies (Patton, 2002) were then identified and organized in four main descriptive findings related to the previously chosen search areas: children's mathematical learning trajectories, children's number learning trajectories, individuals' use of symbols, and approaches to early childhood mathematics education.

\section{Findings}

Four themes emerged as a result of this literature review: (a) understanding early childhood mathematics education (ECME); (b) the meaning of symbols; (c) using symbols to represent numbers; and (d) children's knowledge. I discuss each of these themes below.

Understanding early childhood mathematics education (ECME)

Mathematics in the early childhood field appears to be widely influenced by the ideas of the constructivist school. For Kamii (1985), constructivism is the theory according to which children build their own knowledge "from the inside, through [their] own mental activity, in interaction with the environment" (p. 6). Constructivists believe that knowledge is not directly transmitted from the teacher, but that teachers can facilitate knowledge acquisition.

The vision of the child as an active learner, capable of understanding abstract concepts through exploration and manipulation, grew tremendously in the early childhood field during the 1980s, especially in opposition to the passivity often related to the traditional school system. These ideas were mainly supported by Piaget's theory and the three kinds of knowledge he described: physical, social, and logico-mathematical (Piaget, 1953, 1962). Each kind of knowledge is related to the others and, according to Piaget and Inhelder (1971, 1983), empirical and constructivist abstraction facilitates their acquisition. Empirical abstraction supports the individual's focus on different properties of the objects (e.g., colour, size, and weight) while constructivist abstraction involves mental relationships that the individual makes among objects (e.g., two, the same, and different).

With a constructivist approach, play and hands-on activities became the main strategy used to facilitate young children's learning. Hands-on activities and manipulation were related to free exploration and oriented toward facilitating empirical abstraction. However, misconceptions of abstraction led those in the field to believe that young children could learn abstract mathematical ideas by just touching objects (Kamii, L ewis, \& K irkland, 2001; Williams \& K amii, 1986). Consequently, these types of activities lacked clear mathematical intentionality, and the educator's role was limited to providing objects and observing (K amii et al., 2001; Williams \& Kamii, 1986)

The idea of exploration, mostly related to play, is still very important in the field. The environment and the presence of various manipulatives are considered key components of mathematical learning. However, the variety of manipulatives and free exploration do not necessarily facilitate or guarantee learning (Williams \& Kamii, 1986). When talking about the value of play, Kamii and Kato (2005) suggest that "play has al ways been valued in early childhood education; it is important for educators to know precisely why a playful activity is educational and what the teacher can do to maximize its value" (p. 382). The latest mathematical research emphasizes that the only way manipulation can become meaningful in a rich environment is if it is guided through reflection and problem solving (Brosseau, 2006; Clements \& Sarama, 2009; Van de Walle, 2001). In other words, empirical abstraction should be supported by a challenging environment where constructive abstraction is encouraged, challenged, and scaffolded.

The meaning of symbols

It is interesting to observe that ECME has primarily related the use of symbols to what is known in the field as "academic learning." $M$ athematics has often been lumped with literacy under this label (Sun L ee \& Ginsburg, 2007), and many early mathematics outcomes that involve the use of symbols have been oriented to school preparation. In the case of mathematics, it appears that "academic learning" mainly related to the use of mathematical symbols in their written or spoken form. Thus, intensive practice on paper to write numerals and represent sets was required in many early childhood settings during the 1970s and 1980s. As in the example of M aria that opened this article, these "ready-made" activities (Sun Lee \& Ginsburg, 2007, p. 135), also called worksheets, were given to children from a very young age. Sun Lee and G insburg (2007) report that, in general, early childhood educators who expressed a strong commitment to academic education were the ones who approved the use of these kinds of activities. 
Writing numerals is a practice that still receives considerable attention, formally and informally, during early years education. The practice involves young children using symbols and symbolic notations.

The studies chosen for this review that focused on investigating the role of symbols in children's cognitive development showed the same understandings when referring to the term symbol. Overall, these studies agreed in defining symbol as a tool that enables humans to represent ideas. Vygotsky (1978) differentiated between a first and second order symbolic system. For him, first order symbols convey a pictorial message, where the symbol can be decoded just by looking at it (i.e., a picture of a cat resembles a cat). The second order symbolic system uses a graphic form that represents an abstract unit of meaning, like a phoneme or a quantity. It is in these situations where, even by looking at the form, the conventional meaning will not be revealed (e.g., "100," "A," "casita"). A ccording to Vygotsky, understanding the meaning of conventional notations is more difficult than understanding the meaning of pictures. For DeLoache (2004), the child needs to understand the social intention of different symbolic systems. For example, the child needs to understand what the printed notations " 12 ," "MOM," or " 58 " mean. This idea implies that the meaning of symbols is grounded in social patterns and patterns of communication.

According to DeLoache (2004), "symbols are a characteristic of humans. A vital function of symbols is to enable humans to acquire information without direct experience. Our vast store of cultural knowledge exists because we can learn through symbolic representation" (p. 68). For this researcher, intention and communication are the basis of symbols, and children need to figure out how people intend symbols to be interpreted. DeL oache suggests that symbols can represent, are general, and are intentional: symbols represent because they denote; they are about something. A ccording to D eL oache, anything can be used to represent, including numbers, words, sounds, fingers, blocks, maps, and many other possibilities. She states that the intentionality of symbols is grounded in social contexts; therefore, there has to be a person who intends to represent. The same approach was suggested by Piaget $(1953,1962)$ when he explained that it is people who represent, not symbols.

For Hobson (2000), intentionality is the foundation of symbols: "Intention is at the heart of symbolization" (p. 2). He describes this intention as an intention-to-refer and intention-to-mean where there is a mental relationship between the symbol and what it represents. This mental relationship between the symbols and what they signify is the unique dual nature of symbols (Uttal, Scudder, \& DeL oache, 1997). Based on her theoretical model, DeLoache (1995a; 1995b) calls this relationship between a symbol and what it represents dual representation. She explains that dual representation allows individuals to understand, for example, the abstract relation between the idea of "5" and the word "five," the numeral "5," or the notation "IIIII." This ability implies mentally representing the concrete object itself and its abstract relation to what it stands for. A clear example is provided by MacConnell and Daehler (2004), who state that a child is capable of dual representation when s/he is capable of perceiving a model train as both a toy and a representation of an actual train. MacDonnell and Daehler (2004) refer to the capability to use dual representation as symbolic insight. For Piaget (1952, 1962), the individual has to "see" an idea mentally to be able to represent it.

Researchers agree that dual representation is an important cognitive milestone that children need to achieve to understand symbols (Bialystok, 2000; Bialystok \& Codd, 1996; DeLoache, 1995a, 1995b, 2004; DeLoache \& Burns, 1994; DeLoache \& Marzolf, 1992; DeL oache et al., 1997; Huttenlocher, Vasilyeva, N ewcombe, \& Duffy, 2008; K lein \& Bisanz, 2000). Researchers also concur that dual representation is learned progressively following age-based developmental trajectories. Therefore, the younger the child, the more difficulties $\mathrm{s} /$ he will have in understanding dual representation.

\section{U sing symbols to represent numbers}

According to McCloskey (1992), it is important to distinguish between numbers and numerals. A number is an abstract entity, the domain of knowledge. A numeral is defined as the conventional written form for numbers (e.g., "1," "5," "77"). A numeral is an abstract symbol that stands for a certain quantity, for example, 6 apples, 10 fingers, 20 crayons. To be meaningful, the numeral has to be linked to a number in terms of cardinality. Cardinality is a complex issue in number development that takes time to develop (B ermejo, 1996; Bermejo, Morales, \& Garcia de Osuna, 2004; Zhou \& Wang, 2004). While ordinality refers to the order of natural numbers (e.g., $1^{\text {st }}$, $4^{\text {th }}, 10^{\text {th }}$ ), cardinality refers to the classificatory meaning of natural numbers (e.g., 1 refers to all classes containing 1 thing; 6 refers to all classes containing 6 things). Cardinality and ordinality are both aspects of number (Piaget \& Inhelder, 1983). Cardinality, according to Bermejo (1996) "is a way to quantify the items in a set" (p. 263). According to Piaget (1952), the cardinal principle implies the largest number word in a set. In other words, to understand cardinality, children need to understand that " 6 " includes " 1 ," " 2 ," " 3 ," " 4 ," " 5 ," and "6." A dditionally, children need to understand that " 6 " is always " 6 " whether the numeral represents 6 balls, cars, or dolls, and so on. The last number's word is the spoken symbol used to identify the size of the set (e.g., "seven," "fifty," and "twelve"). By extension, it could be suggested that numerals are the written symbols to communicate the total amount in a set (e.g., "7," 50," and "12"). In other words, both the oral word and the written symbol serve the same function, which is to represent the total amount of items in a set. 
Some researchers maintain that conceptual mathematical knowledge should precede children's exposure to the use of symbols (K amii, 1986; Kato et al., 2002; Teubal \& Dockrell, 2005). These researchers argued that numerals are not relevant for the child without a conceptual understanding of number and, as result, young children should have a solid foundation of mathematical concepts before using numerical symbols. Other researchers argue instead that there is a parallel development between conceptual understanding and children's different forms of representing, such as drawing or invented spelling (Bowers, 2000, cited in Teubal \& Dockrell, 2005; Carruthers \& Worthington, 2006; Sfard, 2000). With this approach, numerals become relevant as the child has the opportunity to write the idea of sets in many different forms.

\section{Children's knowledge}

Young children are surrounded by a world of symbols. F rom a young age, children need to deal simultaneously with a variety of symbols, such as letters, numbers, signs, and pictures. In order to participate in their own societies, children are expected to learn about different symbol systems and how they function. Today, as DeLoache (2004) states, "children must learn to use more varieties of symbols than ever before" (p. 66).

Exposure to this tremendous variety of symbols happens even before children enter the formal school system. During the early years, the quality of this exposure will facilitate, or not, children's understanding of these symbols (i.e., letters, numbers, and what they mean). Children then need to explore what social intention these symbols have in their social context. Children's use of symbols progresses from a general symbolic ability (DeLoache, 2004) to a more conventional and intentional ability. For example, the use of sounds to label objects at 13 months changes to a preference for using words at around 18 months (DeLoache, 2004); the use of scribbles while drawing at 2 years of age changes to intentional drawing by 5 years of age. For Teubal and Dockrell (2005), children's numeric notations could be considered in terms of quality and accuracy. For example, if the child uses a perfectly executed " 3 " to represent the number " 6, " the quality is good, but the accuracy is not. Accuracy and quality, according to these researchers, are important elements in the development of number notations.

This review has identified three major research trends investigating how young children write numeric ideas. An early trend in cognitive research highlighted that children's numeric representations follow developmental trajectories that appear to be related to children's ages (Sinclair et al., 1983; Hughes, 1986; M unn, 2008). These previous studies, which were mostly conducted in clinical contexts, suggested that with age children produce more accurate representations and use digits more often. A more recent research trend that has examined children's forms of numeric representations acknowledges the value of understanding children's developmental trajectories, but highlights the idea that children's trajectories are impacted not only by age but by children's learning contexts (including home and formal education), the types of experiences those contexts provide, and children's emotional and physical development (Carruthers \& Worthington, 2005; Gifford, 2005). For example, a recent study conducted in the UK by Carruthers and Worthington (2005) collected 700 children's number representation samples in scenarios such as home, school, and

\section{Terminology}

The extensive body of research investigating how young children develop numeric ideas defines and explains key terms and concepts with different nuances of meaning. To clarify the terminology used throughout this review, a brief list of terms is provided below.

Number: an abstract entity of knowledge. Piaget maintained that number is constructed in close relation with an understanding of a system of inclusions (that relates to classes). For Piaget, number is at the same time both class and order. Understanding numbers implies, for example, that 6 includes 1, 2, 3, 4, 5, and 6 . For Piaget (1952), this understanding is constructed by individuals through different developmental stages.

Cardinal meaning: the value of the number in terms of quantity. Cardinality, according to B ermejo (1996), is a way of quantifying all the items of a set. Cardinality responds to the question "how many?" and refers to the fact that the last number counted is the total amount of items in a set (e.g., three [3] refers to one [1], two [2], and three [3]).

Numerals: conventional written symbols used to represent a number (e.g., "6," "100," or "35"; Kato et al., 2002). Numerals are the conventional written symbols that communicate the total amount in a set.

Numeric notations: children's own written ways to represent numbers(Teubal \& Dockrell, 2005), such as tally marks. Accuracy and quality of the representation is sometimes not contemplated. For example, a child might represent "five" by printing four tally marks, or a perfectly drawn 3 (Teubal \& Dockrell, 2005, p. 259).

Marks: children's forms of representation on paper. According to Carruthers and Worthington (2006), marks represent "identities, events, objects, and meanings of their world" (p. 7). 
outdoor activities. These samples were collected during children's spontaneous play as well as in direct teaching situations. Carruthers and Worthington (2005) describe how children represent numbers as "common forms of graphical marks" (p. 15), thus providing a broader meaning that is not restricted to age when describing children's trajectories. Table 1 below summarizes the main findings of Sinclair, Siegrist, and Sinclair (1983), Hughes (1986), and Carruthers and Worthington (2006). To hel p the reader, I have organized the summary table into four representational forms that emerged through the review: scribbles, pictures, one-to-one correspondence, and conventional forms. A $n$ example of these forms of representation is also provided.

Table 1. Summary of findings reported by Sinclair, Siegrist, and Sinclair (1983), Hughes (1986), and Carruthers and Worthington (2005).

\begin{tabular}{|c|c|c|c|}
\hline Findings reported by & $\begin{array}{c}\text { Sinclair, Siegrist, \& Sinclair } \\
\text { (1983) }\end{array}$ & $\begin{array}{l}\text { Hughes } \\
(1986)\end{array}$ & $\begin{array}{l}\text { Carruthers and Worthington } \\
\text { (2005) }\end{array}$ \\
\hline \multicolumn{4}{|c|}{ Representation type } \\
\hline Scribbles & & $\begin{array}{l}\text { Idiosyncratic: } \\
\text { The representations are } \\
\text { ambiguous and do not } \\
\text { relate to quantity. }\end{array}$ & $\begin{array}{l}\text { Dynamic: } \\
\text { Graphics that are } \\
\text { characterized by change and/ } \\
\text { or activity. }\end{array}$ \\
\hline Pictures & $\begin{array}{l}\text { Representation of the object- } \\
\text { kind: } \\
\text { The representation focuses on } \\
\text { the qualitative aspect of the } \\
\text { set. }\end{array}$ & $\begin{array}{l}\text { Pictographic: } \\
\text { The responses represent } \\
\text { the quantity as well as } \\
\text { the characteristics of the } \\
\text { objects, such as shape, } \\
\text { position, colour, or size. }\end{array}$ & $\begin{array}{l}\text { Pictographic: } \\
\text { Graphics that represent } \\
\text { something that is present to } \\
\text { the child. }\end{array}$ \\
\hline One-to-one representations & $\begin{array}{l}\text { One-to-one correspondence } \\
\text { with symbols: } \\
\text { This is the first notation type in } \\
\text { which numerical ideas appear. } \\
\text { One-to-one correspondence } \\
\text { with numerals: } \\
\text { The child represents each } \\
\text { object separately. }\end{array}$ & $\begin{array}{l}\text { Iconic: } \\
\text { The responses marks } \\
\text { are in one-to-one } \\
\text { correspondence with the } \\
\text { objects. }\end{array}$ & $\begin{array}{l}\text { Iconic: } \\
\text { Graphics that represent sets } \\
\text { one by one. }\end{array}$ \\
\hline $\begin{array}{l}\text { Conventional representations } \\
\text { Mili's representation of " } 3 \text { " }\end{array}$ & $\begin{array}{l}\text { Cardinal value alone: } \\
\text { The child uses conventional } \\
\text { numerals. } \\
\text { Cardinal value and object- } \\
\text { kind: } \\
\text { Notations represent the child's } \\
\text { ability to think simultaneously } \\
\text { about numeric quantity and } \\
\text { object type. }\end{array}$ & $\begin{array}{l}\text { Symbol responses: } \\
\text { Consist of the use of } \\
\text { conventional numerals or } \\
\text { written number words }\end{array}$ & $\begin{array}{l}\text { Written: } \\
\text { Graphics that represent using } \\
\text { words or invented spelling to } \\
\text { denote sets. } \\
\text { Symbolic: } \\
\text { Graphics that use standard } \\
\text { forms. }\end{array}$ \\
\hline
\end{tabular}

A third research trend was found in a series of studies that clinically explored the relationship between children's use of numerals and their ability to understand what those numerals represent (Bialystok \& Codd, 1996; K ato et al., 2002). These studies have shown that even when young children knew how to write numbers, the children did not use this understanding and instead used their own forms of numeric notations. Why? The researchers agreed that the numerals, as a resource to communicate and gather mathematical information, were not fully understood. For example, in Bialystok and Codd's study (1996), children ages 3 to 6 were individually asked to represent small sets and subsequently read their own representations. The researchers found that although children were screened about their 
knowledge of counting and number recognition, their knowledge was limited when they were asked to represent and read three different tasks that involved quantities. Overall, these studies suggest that familiarity with symbols does not guarantee that young children understand the mental relationships represented by the symbols, and there is a general tendency to believe that children have mastered the numerical domain because they are familiar with some structures of the domain (e.g., counting up to 20 or " $1,2,3 \ldots$...G !")

\section{Implications}

The major focus of this review was to explore the theoretical ideas and research frameworks that refer to number printing during the early years, particularly with children ages 2 to 5 .

The review strongly shows that before they use numerals, children use their own ways to represent numbers. Both studies conducted in control settings and studies conducted in the field concurred. And even though these investigations name children's trajectories differently, the progressions they describe follow similar paths. The studies show that a pattern of development exists for children's numeric representations that progresses from global marks into symbols that involve notions of quantity. However, the studies differ in how the researchers understand the meaning of children's writing of numeric ideas. Earlier studies (Hughes, 1986; M unn, 2008; Sinclair et al., 1983) asked children to write numeric ideas and explored these marks' accuracy and quality (Teubal \& Dockrell, 2005). In other words, the studies investigated how well those representational forms aligned or did not align with conventional forms. And even though children's trajectories were described in depth, the studies had a general tendency to stress what children could not do. M ost recent investigations (Carruthers \& Worthington, 2006; Gifford, 2005) considered children's marks as a social practice and explored how they happened in children's most meaningful environments: home and school. For this line of research, these marks constitute a valid representational form because they show how children make meaning of their realities. Furthermore, this latest research proposes that it is the practice of using invented marks that helps children make sense of numbers and symbols. The development of how symbols work, according to these studies, is parallel to understanding what the symbols are intended to represent. According to Zhou and Wang (2004), "invented symbols provide a foundation for children's learning of written number symbols" (p. 254).

Some studies (Bialystok, 2000; Bialystok \& Codd, 1996; DeLoache, 1995a, 1995b; DeLoache \& Burns, 1994; DeLoache \& Marzolf, 1992; D eL oache et al., 1997) found that the understanding of quantity (cardinality) and the understanding of how symbols work devel op gradually during the first years of life. However, the exploration of pedagogical approaches in early childhood settings (Sun Lee \& Ginsburg, 2007) highlighted a tendency to rush children into the use of conventional symbols. Based on this line of thought, it could be suggested that what was emphasized in those educational practices was the accuracy and quality (Teubal \& Dockrell, 2005) of children's marks rather than the progressions that young children follow.

An important finding of this review refers to what DeLoache (1995a; 1995b) defines as dual representation. This researcher highlights dual representation as an important milestone that al lows individuals to understand how symbols work and what they mean. DeL oache's research explains that dual representation develops gradually and that young children need time to understand this relationship. If at young ages children are still not aware of the relationship between numeric and symbolic domains, providing practices where they are asked, for example, to relate a set of flowers with a numeral instead of printing what they know about flowers seems pedagogically inappropriate. This review indicates that children's forms of representing numbers cannot be ignored. Therefore, early childhood mathematical practices cannot be supported by approaches that aim for production of conventional printing of numbers only, especially during a time in life when key domains (mathematical and symbolic) are still developing.

The research evidence provided in this review supports the idea that children's marks are not inaccurate or developmentally wrong but are instead a representational form that shows how children think of numbers and quantities. As such, they could become a tremendous source of information for early childhood educators. Based on the research findings presented in this review, paying close attention to children's marks could facilitate educators (a) better understanding of how each of their students thinks about numbers and numerals; (b) scaffolding a child's current level of numeric understanding; and (c) enriching mathematical activities regarding numbers and numerals.

\section{Final Thoughts}

The meanings of numeric symbols are part of a sociocultural heritage. According to Geary (1995, cited in Bialystok \& Codd, 2000), the meaning of conventional symbols is something that children need to learn. A dults play a valuable role in teaching and sharing this knowledge. Under this framework, early childhood educators' role in supporting children's understanding of numbers and numerals is crucial. 
From a sociocultural constructivist perspective, educators provide scaffolds for children's learning processes and facilitate children's processes of enculturation (which involves, for example, understanding the conventional meaning of numerals). Scaffolding and guiding children through the process of number construction and number representation requires an adult with a solid understanding of the mathematical processes generally followed by children (Franke \& K azemi, 2001). K nowing this sequence and knowing what children can do is crucial for early childhood pedagogical practices. The research findings shared in this review illustrate that consideration of young children's thinking processes is critical for early childhood educators.

This review reveals that the numeric notations children use to represent numeric ideas are the main source of information about how children understand numbers. The observation of, documentation of, and, most of all, respect for these representational responses are essential for meaningful and appropriate early childhood mathematical practices. After all, early childhood mathematics education should be for young children.

It is my aim that this review will contribute to early childhood education and expand previous mathematical and cognitive studies about the developmental process of number printing. As an early childhood educator, it is my hope that my review will both encourage and challenge early childhood mathematical practices, especially those regarding number printing. Reflections about the way we do math in the early years, in particular reflecting about the rationale of certain practices, could lead ECEs to the valuable consideration of young children's mathematical thinking processes.

\section{Epilogue}

The educator came closer. She wanted to see the pictures of the lighthouses M aria had posted on the bulletin board.

"Can you see this one?" said Maria. "Can you see how tall it is? It is the tallest lighthouse in the world... this one, the small one had lots of windows."

The educator looked at the pictures and asked, "Could you tell me something else about the light houses? Could you write something about them?"

M aria went to the art shelf and took some large paper and a bucket full of markers. She worked for a long period while her friends were getting ready to go outside. When she finished, she showed her teacher what she had done: several tally marks with yellow circles on top.

"We saw lots of lighthouses," she said. "We saw seven."

Then, she added blue for the ocean and one bigger bright yellow circle.

"It was sunny," she said to the teacher.

Maria and her teacher posted the picture on the bulletin board for everybody to see. Maria smiled with pride.

\section{References}

A nderson, A., A nderson, J., \& Thauberger, C. (2008). M athematics learning and teaching in the early years. In B. Spodek \& 0 . Saracho (Eds.), Handbook of research on the education of young children (Vol. 2, pp. 95-132). New Jersey, NJ: Erlbaum.

Baroody, A. J. \& Li, X. (2009). Mathematics instruction that makes sense for 2 to 5 year olds. In E. L. Essa \& M. M. Burnham (Eds.), D evelopment and education: Research reviews from young children (pp. 119-135). New York, NY: National Association for the Education of Young Children.

Bermejo, V. (1996). Cardinality development and counting. D evelopmental Psychology, 32(2), 263-68.

Bermejo, V., Morales, S., \& Garcia de Osuna, J. (2004). Supporting children's development of cardinality understanding. Learning and Instruction, 14(4), 381-398. doi:10.1016/j.learninstruc.2004.06.010

Bialystok, E. (2000). Symbolic representation across domains in preschool children. J ournal of Experimental Child Psychology, 76(3), 173-189. doi: 10.1006/jecp.1999.2548

Bialystok, E., \& Codd, J. (1996). Developing representations of quantity. Canadian J ournal of Behavioural Science, 28(4), 281.

Bialystok, E., \& Codd, J. (2000). Representing quantity beyond whole numbers: Some, none, and part. Canadian J ournal of Experimental P sychology, $54(2), 117$. 
B rosseau, G. (2006). M athematics, didactical engineering, and observation. Proceedings of the 30 th conference of the International G roup for the Psychology of M athematics Education, Czech Republic, 1, 1-3. doi: 20.132.48.254/PDFS/ED496931

Carruthers, E., \& Worthington, M. (2005). Making sense of mathematical graphics: The development of understanding abstract symbolism. European Early Childhood Education Research, 13(1), 57-79.

Clements, D. H., \& Sarama, J. (2009). Learning and teaching early math. The learning trajectory approach. N ew York, NY: Routledge.

Cobb, P. (1994). Where is the mind? Constructivist and sociocultural perspectives on mathematical development. Educational Research, 23(7), 13-20.

DeLoache, J. (1995a). Early symbolic understanding and use. The psychology of learning and motivation, 33, 65-114.

DeLoache, J. (1995b) Early symbolic understanding and use. Current Directions in Psychological Science, 4,109-113.

DeLoache, J. (2004). Becoming symbol-minded. Trends in Cognitive Sciences, 8(2), 66-70. doi:10.1016/j.tics.2003.12.004

DeLoache, J., \& Burns, N. (1994). Symbolic functioning in preschool children. Journal of Applied Developmental Psychology, 15(4), 513-527. doi: 10.1016/01933973(94)90020-5

DeL oache, J., \& M arzolf, D. (1992). When a picture is not worth a thousand words: Young children's understanding of pictures and models. Cognitive D evelopment, 7(3), 317-329. doi:10.1016/0885-2014(92)90019-N

DeL oache, J., M iller, K., \& Rosengren, K. (1997). The credible shrinking room: Very young children's performance with symbolic and non-symbolic relations. Psychology Science, 8, 329-338.

Franke, M ., \& K azemi, E. (2001). Learning to teach mathematics: Focus on student thinking. Theory into Practice, 40(2),103-109

Gifford, S. (2003). How should we teach mathematics to 3- and 4-year-olds? Pedagogical principles and practice for the foundation stage. Mathematics Teaching, $184,33-38$.

Gifford, S. (2004). A new mathematical pedagogy for the early years: In search of principles for practice. International J ournal of Early Years E ducation, 12 (2), 1-18.

Gifford, S. (2005). Teaching mathematics 3-5: D eveloping learning in the foundation stage. Berkshire, UK: O pen University Press.

Ginsburg, H., Sun Lee, J., \& Boyd, J. (2008). Mathematics education for young children: What it is and how to promote it. Social policy report: Giving child and youth development knowledge away. Society for Research in Child D evelopment, 21(1), 3-23.

Ginsburg, H., \& Golbeck, S. (2004). Thoughts on future research on mathematics and science learning and education. Early Childhood Research Q uarterly, 19, 190-200.

Hobson, P. (2000). The grounding of symbols: A social-developmental account. In P. M itchell \& K. Riggs (Eds.), Children's reasoning and the mind (pp.11-33). London, UK: Psychology Press.

Huttenlocher, J., Vasilyeva, M ., N ewcombe, N ., \& Duffy, S. (2008). D eveloping symbolic capacity onestep atatime. C ognition, 106(1), 1-12. doi: 10.1016/j.cognition.2006.12.006 Hughes, M . (1986). Children and number: Difficulties in learning mathematics. Oxford, UK : B lackwell.

Joffe, H., \& Yardley, L. (2004). Content and thematic analysis. In D. Marks \& L. Yardley (Eds.), Research methods for clinical and health psychology (pp. 56-68). London, UK: SA GE.

Kamii, C. (1985). Young children reinvent arithmetic. Implications of Piaget's theory. N ew York, NY: Teachers College Press.

Kamii, C. (1986). Place value: An explanation of its difficulty and educational implications for the primary grades. J ournal of Research in Childhood Education, 1(2), 75-86.

Kamii, C. (2000). Young children reinvent arithmetic: Implications of Piaget's theory (2 ${ }^{\text {nd }}$ ed.). Early Childhood Education Series. New York, NY: Teachers College Press.

Kamii, C., \& Kato, Y. (2005). Fostering the development of logico-mathematical thinking in a card game at ages 5-6. Early Education and D evelopment, 16(3), 367-384.

K amii, C., Lewis, B. A., \& K irkland, L. D. (2001). M anipulatives: When are they useful? J ournal of M athematical Behavior, 20, 21-31.

K ato, Y., K amii, C., Ozaki, K., \& Nagahiro, M . (2002). Y oung children's representations of groups of objects: The relationship between abstraction and representation. J ourna for Research in Mathematics Education, 33(1), 30-45.

Klein, J. S., \& Bisanz, J. (2000). Preschoolers doing arithmetic: The concepts are willing but the working memory is weak. Canadian J ournal of Experimental Psychology, $54(2), 105$.

MacConnell, A., \& Daehler, M. W. (2004). The development of representational insight: Beyond the model/room paradigm. Cognitive Development, 19(3), 345-362. doi: 10.1016/j.cogdev.2004.03.002

M acCloskey, M . (1992). Cognitive mechanisms in numerical processing: Evidence from acquired dyscalculia. Cognition, 44, $105-107$.

M unn, P. (2008). Children's beliefs about counting. In I. Thompson (Ed.), Teaching and learning early number ( $2^{\text {nd }}$ ed.; pp. 9-20). Buckingham, UK: Open University Press. 
Patton, M . (2002). Qualitative research \& evaluation methods ( $3^{\text {rd }}$ ed.). Thousand Oaks, CA: SA GE.

Piaget, J. (1952). The child's conception of number. London, UK: Routledge.

Piaget, J. (1953). The origins of intelligence in children. New York, NY: B asic B ooks.

Piaget, J., \& Inhelder, B. (1971). M ental images and operations. M ental imagery in the child. New York, NY: B asic B ooks.

Piaget, J., \& Inhelder, B. (1983). Genesis de las estructuras logicas elementales. Clasificaciones y seriaciones [Origin of logics. Classification and seriation]. Buenos Aires, Argentina: Editorial Guadalupe.

Plainfield Board of Education. (2006). Mathematics curriculum guide. Kindergarten. Plainfield, NJ: Department of Curriculum and Instruction.

Rogoff, B. (1990). Apprenticeship in thinking. Cognitive development in social context. New York, NY: Oxford University Press.

Rogoff, B. (2003). The cultural nature of human development. N ew York, NY: Oxford University Press.

Sfard, A . (2000). On reform movement and the limits of mathematical discourse. Mathematical Thinking and Learning, 2(3), 157-189.

Siegler, R. S., \& Booth, J. L. (2004). Development of numerical estimation in young children. Child D evelopment, 75(2), 428-440.

Sinclair, A ., Siegrist, F., \& Sinclair, H. (1983). Young children's ideas about the written number system. In D. Rogers \& J. Sloboda (Eds.), The acquisition of symbolic systems (Vol. 22, pp. 535-542). New York, NY: Plenum.

Sophian, C. (2009). Numerical knowledge in early childhood. Encyclopedia on Early Childhood D evelopment. Retrieved from http://www.child-encyclopedia.com/documents/ SophianA N Gxp.pdf

Sun Lee, J., \& Ginsburg, H. P. (2007). Preschool teachers' beliefs about appropriate early literacy and mathematics education for low- and middle-socioeconomic status children. Early Education and Development, 18(1), 111.

Teubal, E., \& Dockrell, J. E. (2005). Children's developing numerical notations: The impact of input display, numerical size and operational complexity. Learning and Instruction, 15(3), 257-280. doi:10.1016/j.learninstruc.2005.04.006

Uttal, D. H., Scudder, K. V., \& DeL oache, J. S. (1997). M anipulatives as symbols: A new perspective on the use of concrete objects to teach mathematics. J ournal of Applied Developmental Psychology, 18(1), 37-54. doi 10.1016/S0193

Vygotsky, L. (1978). M ind in society. Cambridge, M A : Harvard University Press.

Van de Walle, J. (2001, October). D rill and practice. Paper presented at the National Conference of Teachers of M athematics Regional M eeting, New Jersey.

Williams, C., \& Kamii, C. (1986). How do children learn by handling objects? Young Children, 42(1), 23-46.

Zhou, X., \& Wang, B. (2004). Preschool children's representation and understanding of written number symbols. Early Child D evelopment and Care, 174(3), $253-266$. 


\title{
Voices From the Field: Full-day K indergarten Teams in Ontario Share Their Wisdom
}

\author{
M onica M cGlynn-Stewart and K imberly B ezaire
}

\begin{abstract}
M onica M cG lynn-Stewart, PhD, is a former elementary teacher, consultant, and principal. She now works as a professor in the School of Early Childhood, George Brown College, Toronto, Ontario, where she teaches courses in curriculum, early childhood program delivery models, and research methods. She is currently researching beginning elementary teachers' literacy practice and the teaching teams in the new full-day kindergarten program in Ontario. Email: mmcglynnstewart@ georgebrown.ca
\end{abstract}

Kimberly Bezaire, PhD, is a professor in the School of Early Childhood, George Brown College, Toronto, Ontario, teaching courses in play-based curriculum, child observation and documentation, and pedagogical leadership. She is a regular contributor to professional learning in the Early Y ears sector, consulting and collaborating with childcare, lab school, and elementary school professionals. K imberly's research background includes classroom-based research, and play-literacy in the early years.

Canadian educators and policy makers are in the midst of implementing an innovative approach to education for 4and 5-year olds. This study examined the perspectives of the teaching teams who are making this new full-day school-based model work: registered early childhood educators and Ontario certified teachers. These two groups have different professional backgrounds, status, salary, and professional development opportunities. Survey and interview results highlighted the complexity of the new teaching model and identified conditions that support interprofessional team building and effective team teaching in school settings. Themes arising from the data include the importance of relationship building, rethinking practice, sharing knowledge/specialization, and reestablishing roles. Implications and recommendations for teaching teams and system administrators are provided.

Understanding that the early childhood educator and kindergarten teacher have different but complementary skill sets is important. Give yourself time to figure out how all the pieces fit together. Building a team that is cohesive and effective takes time. You will both be used to working in a particular way and I think it is important to go slow and figure out how to make it work together. (registered early childhood educator, M arch 12, 2013)

In Ontario, educators and policy makers are in the midst of implementing an innovative approach to education for 4- and 5 -year-olds. The province is investing billions of dollars of public funds in the promotion and operation of universal full-day kindergarten (FDK). The success of this program relies heavily on the effectiveness of a new staffing model: teams made up of RECEs (early childhood educators registered with Ontario's College of Early Childhood Educators, Ontario) and OCTs (teachers certified by the Ontario College of Teachers). This study examined the successes and challenges of this new model as experienced by these innovative teaching teams. Team members who had been teaching in the new full-day kindergarten during the first three years of operation offered advice based on their experience in the new program. Their suggestions for creating equitable and effective teaching teams ranged from interpersonal team-building strategies to enhancing systemic program supports.

\section{Partnerships in C hild C are and Kindergarten}

F riendly (2008) notes that kindergarten programs and regulated child care are quite different in several respects, including the education, training, and approach of the educators who staff them. The education of early childhood educators focuses primarily on child devel opment, whereas the education of public school teachers is primarily focused on teaching methods (Friendly, 2008). However, early childhood education programs do have courses and meet vocational standards in play-based curriculum design and implementation, working with children with special needs, and working collaboratively with families and professionals from other disciplines (Ontario M inistry of Training, Colleges, and U niversities, 2012). In his report to the Premier of Ontario on full-day early learning, Pascal (2009) considered these differences to be a source of strength and suggested that interprofessional ism would provide an innovative foundation for the new integrated program. He recommended that the new program be staffed with a team of one teacher and two early childhood educators to "add to the strengths of the professional preparation and skill sets of both teachers and ECEs" (Pascal, 2009, p. 33). He cautioned, however, that there are challenges inherent in this team approach and argued that it is critical that both pre- and in-service learning for all team members focus on "how to engage in respectful, reciprocal mentoring, al ways with their learners in mind" (Pascal, 2009, p. 37). In FDK practice in O ntario, only one early childhood educator has been paired with each teacher. 
Different professionals from early childhood education and care services have successfully worked together in pilot projects in Ontario in the recent past. B oth B etter B eginnings, B etter Futures (BBBF) and Toronto First Duty (TFD) integrated early childhood services demonstration projects revealed the challenges and benefits of collaboration and partnerships. Findings from the BBBF project demonstrated the importance of a shared vision for collaboration among the professionals, the importance of clarifying partner roles, and the development of trust and positive working relationships (Corter \& Peters, 2011). The goal of the TFD project, which began in 2001, was to promote the heal thy development of children from birth through primary school while supporting parents in their work and their parenting roles (Corter \& Peters, 2011). Findings from this study highlighted the existence of struggles over "professional turf," the importance of strong leadership, and the need for time for staff team devel opment (Corter \& Peters, 2011).

In their recent report for UNESCO, Caring and Learning Together: A Cross-national Study of Integration of Early Childhood Care and Education Within Education, Kaga, B ennett, and M oss (2010) discuss the complexities inherent in integrating ECEC and education for young children within the education system. They looked at several countries who have completed this integration, focusing on Brazil, Jamaica, New Zealand, Slovenia, and Sweden. They note that successful integration "requires re-thinking as well as re-forming structures, such as funding, regulation and workforce" (Kaga, Bennett, \& Moss, 2010, p. 13). The potential benefits of integration include changed perceptions of ECEC among the workforce, parents, and the wider public (Kaga et al., 2010). Potential risks include the "schoolification" of ECEC and increased costs due to the creation of a better qualified and paid workforce, increased access, and the introduction of new curricula (Kaga et al., 2010).

Evaluation of the first two years of implementation of Ontario's full-day kindergarten identified that the new staffing model has successfully brought the two groups of professionals-RECEs and OTCS- together to provide an enriched play-based kindergarten program (Ontario Ministry of Education, 2013). Yet the study also indicated that the educator teams are "not fully leveraging the collective expertise of the two professions" (Ontario M inistry of Education, 2013, p. 13) and that the M inistry of Education needs to "foster continued growth in the educator teams" (p. 18).

Interprofessional team learning and practice

Little research has been done on the interprofessional relationship between teachers and ECEs working in school classrooms. The literature on interprofessional teams in other sectors provides a useful framework for considering the FDK teams. In the health care field, interprofessional practice has been defined as "two or more professions working together as a team with a common purpose, commitment and mutual respect" (Dunston et al., 2009, p. 6). The research on interprofessional teams in the health sector (Hall, 2005; Norsen, Opladen, \& Quinn, 1995; Sargeant, Loney, \& Murphy, 2008) highlights both the benefits and challenges of collaboration in terms of positive identity development, professional development, and outcomes for clients. An ongoing study of hospital play specialists in the U.K., many of whom have a background as early years educators, revealed that although they do not have a medical background, they are able to effectively advocate for children with the hospital medical team (Nuttall, 2013).

The Centre for the A dvancement of Inter-professional Education (2011) outlines key principles drawn from the literature, including keeping best practice central to all teaching and learning, acknowledging but setting aside differences in power and status, and utilizing distinctive contributions to learning and practice. The present study contributes to our understanding of the nature of the working relationship between teachers and ECEs in school kindergartens and the practices that support an effective collaborative working team.

\section{Full-day kindergarten in Ontario}

Integrating public education and child care in Canada is a recent development and is a "work in progress" (M uttart Foundation, 2012). Child care throughout the country is largely private, while kindergartens in public schools are publicly funded (Friendly, 2008). In their review of Canadian early learning and care, the Organisation for Economic Co-operation and Development (OECD; 2004) advised that a greater integration of kindergarten and child care would be advantageous to Canadians. Beginning in the 2010-2011 school year, the Ontario Ministry of Education (2011) began offering 4- and 5-year-old children full-day kindergarten. The program will be offered in all public schools by September 2014.

Each FDK classroom is staffed by a unique team of educators who come from dramatically different professional backgrounds: teachers and early childhood educators. Certified kindergarten teachers in Ontario (OTCs) have an undergraduate degree, typically in a discipline other than education, and a one-year (B Ed) or two-year (M T or M AT) preservice teaching degree specializing in teaching from kindergarten to grade six. They have the option of taking an additional qualification (AQ) course in kindergarten, but it is not mandatory. In publicly funded schools, they are represented by a province-wide union. Registered early childhood educators (RECEs) in O ntario typically have a two-year community college diploma specializing in child development, though a minority have an undergraduate degree in early childhood education. RECEs are not certified to teach in publicly funded schools. Many RECEs in FDK are unionized, 
but through a patchwork of different unions. U nlike the OCTs, they are not part of a single provincial union that can speak for them with a united voice. In addition, they receive a lower salary relative to teachers and have significantly lower social status than kindergarten teachers. Although the two professionals are meant to be a team, the kindergarten teachers in FDK are paid a much higher salary, have paid preparation time, and have more paid professional development time. The RECEs typically are not compensated for preparation or professional development time.

\section{The Study}

The purpose of this study was to explore the nature of the interprofessional teaching team experience from the perspectives of the two types of education professionals working in FDK classrooms. Specifically, our research question was this:

From the perspectives of teaching teams at the forefront of this new program, what supports the process of creating equitable and effective teaching partnerships in full-day kindergarten classrooms?

This study employed a qual itative approach (M erriam, 2009; Punch, 2009) al though some quantitative data was collected. The participants were FDK teams (Registered Early Childhood Educator/Ontario College of Teachers certified teacher) from Ontario, Canada. Data were collected through an anonymous online survey and in-person interviews. The survey included open-ended questions and was distributed through professional networks during the 2011-2012 and 2012-2013 academic years. The purpose of the survey was to gather information about team members' experiences, perceptions, and recommendations for program improvement. The hour-long semistructured interviews with self-selected FDK teams were conducted during the same time period in order to explore the emerging themes in more depth.

Total survey participation was 297 educators with a nearly even split between RECEs (46.5\%) and OCTs (53.5\%). All of the educators were part of a FDK teaching team in Ontario during the 2011-2012 and/or 2012-2013 school years. For the purposes of this article, we analyzed one of the open-ended questions on the survey which asked participants for suggestions that they would offer to new FDK teams. We analyzed the responses from RECEs (104 replies) and OCTs (126 replies) separately, and then compared and contrasted them.

\section{Findings}

There was a remarkable degree of agreement between the two groups of professionals regarding the advice they would give to new kindergarten teaching teams. The advice largely fell into two categories: interpersonal and structural. In terms of interpersonal relations, the educators talked about building relationships, communicating effectively, and negotiating roles and responsibilities.

Building relationships

By far the loudest call from both groups of professional educators was to focus on building the team relationship. As one OCT put it:

Being successful in this program is all about relationships. That doesn't mean you have to be 'best friends' or even friends outside of work, but it does mean that a mutual relationship built on trust and respect is built slowly from the beginning of the year. (OCT, M arch $12,2013)$

The importance of trust and respect in building a positive and effective working relationship was echoed by the majority of participants in the study. They reported that mutual trust and respect helped them feel valued in the team and increased their enjoyment of their jobs. The following two quotes are typical of the advice we heard on this topic:

Treat each other as equals and respect each other. (RECE, A ugust 1, 2012)

Build a strong partnership and respect one another. Have fun together! (OCT, M ay 28, 2012)

Team members gave specific advice about how to achieve a positive team relationship. Both ECEs and OCTs were clear that creating an effective team takes work. It involves considering each other as partners and deliberately recognizing each other's experience and expertise, as the following responses indicate:

See the team as a partnership. (RECE, M ay 6, 2012) 
Build your relationship deliberately. (OCT, A pril 30, 2012)

Remember that you both bring a lot to the table and that you can learn a lot from each other. (OCT, March 15, 2013)

A lthough the participants pointed out that teams do not need to be best friends (as an earlier quote mentions), nor do they have to be the same as each other, many reflected on the importance of building a personal as well as a professional relationship. The following quote exemplifies many of the comments we received on this topic:

Spend time getting to know each other before the year begins. For instance, my partner and I went out for tea and shared about our families, teaching philosophies, and experience. This way we got to know each other as human beings as well as teachers. (OCT, M arch $12,2013)$

Given that ECEs and OCTs needed to work closely with each other daily, it is not surprising that the issue of relationships was strongly represented in their comments. However, the new challenges that each set of educators faced made the issue of relationships more salient. M ost of the ECEs had experience working in teams in child care, but were new to working in the school system. M ost OCTs had experience teaching kindergarten in schools, but had not worked with a teaching partner. The new full-day, play-based kindergarten curriculum was new to both sets of professionals. In the face of so many novel elements, the study participants advocate making the most of the partnership to create an effective program.

Communicating effectively is key

One of the key ways to create and maintain a positive partnership is through effective communication, according to a great many of the participants. Nearly every survey response mentioned ongoing communication in some way. Many participants qualified the type of communication that was most beneficial. Having "open" communication was valued, but mentions of it were often accompanied by cautions about being caring and respectful at the same time, as in the following participant quotes:

Communicate ideas, opinions, and plans with care and respect for the person you are working with. (RECE, M ay 17, 2012)

Be open to sharing new ideas, challenging your partner, and listening to their viewpoint. (OCT, M arch 12, 2013)

Many participants noted that while open communication is necessary for an effective partnership, it can be difficult to discuss some topics, and some things may be better left unsaid. Both RECE and OCT participants shared this caution, as the following statements illustrate:

$H$ ave the hard conversations. It helps in the long run to express your feelings about things that are happening in the classroom. (RECE, March 16, 2013)

Communication is key. Always be open and honest with each other. Know when to speak up and when to keep it to yourself. (OCT, M arch 10, 2013)

It is easy to understand why communication between two educators collaboratively running a program is important. It is also important to understand why it may be difficult in the context of FDK. The two groups of educators have had different professional education and training, which in most cases utilized different pedagogies of education and practice teaching in different educational settings. Even if two team members had similar philosophies and approaches to educating young children, they likely had a different professional vocabulary to describe them. Furthermore, FDK takes place within school boards, the "home turf" of OCTs. Many RECEs are from outside the school system and are therefore "newcomers" who may not be as familiar with the procedures, routines, and terminology in that context. However, some RECEs have previously worked in the school system as educational assistants (EAs) to OCTs. In this role, asserting their professional knowledge and practices may not have been considered appropriate, particularly when their perspectives offered a differing viewpoint. In contrast, the new integrated team teaching model in FDK requires both the RECE and the OCT to communicate their distinct knowledge and perspectives to form an innovative, dynamic team. In practice, this becomes very difficult when all OCTs have paid preparation time daily and most RECEs do not. Therefore, there is not a built-in opportunity for the team to meet and discuss their work. The issue of preparation time will be addressed more fully in a later section. 
Negotiating roles and responsibilities

The issue of establishing roles and responsibilities within the program was evidently an important one for team members. Many participants wrote about the importance of clarity, but also of flexibility when deciding who would be responsible for different aspects of the program. Participants reinforced the point that responsibilities needed to be shared based on the individuals in the team and not on a predetermined formula. Indeed, being flexible, sharing responsibilities, and working from each other's strengths were three of the most often cited pieces of advice for prospective team members. A s one OCT put it:

Find each other's strengths and build on them. F or example, I can't sing but my partner sings beautifully. I have a strong interest in teaching literacy and my partner is strong in math instruction. (OCT, M arch 12, 2013)

$M$ any participants recommended meeting early in the year to discuss each other's strengths, goals, and expectations for their working relationship and then basing individual responsibilities on this. They noted that doing so would not only make for a happier and more harmonious team but would also benefit the children. The following quotes from participants represent these responses:

M eet as early as possible as a team and get to know each other's and your own goals for the coming year. F ind out what each other wants out of this experience and work together to ensure you are both happy - the kids know if you are not! (OCT, M arch 12, 2013)

Everyone has strengths and weaknesses. Figure out yours as individuals and as a team. U se this knowledge to your advantage for a stimulating program. (RECE, February 27, 2013)

Participants acknowledged that while conversations about roles and responsibilities are important, they can also be difficult, as this OCT participant expressed:

Talk to each other about expectations, even if it is awkward. Recognize each other's strengths and try to divide duties that way. The way we have always done it doesn't make it the best way. F ocus on the kids and building a program together. (OCT, M ay 7, 2013)

Again, it is not difficult to understand why establishing roles and responsibilities is important yet challenging. In the course of a busy day in kindergarten, there is no time to stop and discuss how each part of the program will be handled and by whom. As trailblazers in a new early learning delivery model, team members need to know who will facilitate which parts of the program. Yet FDK is a unique program and many aspects of it are left to the teaching team to figure out for themselves. While the FDK curriculum document is clear about some role differentiation between the two educators in the team (e.g., the OCT is responsible for completing report cards), many other responsibilities are left to the team members, principals, and boards to allocate. W hile teaching team members strongly voiced that they value the flexibility inherent in the partnership, they also called for more training and support to help them manage the process. This point will be discussed more fully in a later section.

\section{Implications}

The reflections and advice that the kindergarten teams shared have many implications at the classroom, school, school district, and education ministry levels. The teams were clear that the challenges they face are both interpersonal and structural, and that it will take time and continued support to effectively build on what they have started. In particular, they talked about holding on and letting go, structure and support, and recognition that the team is a work in progress.

Holding on and letting go

For both RECEs and OCTs, building a positive and collaborative working relationship appeared to involve a dance of old and new, a process of holding on and letting go. B oth groups commented on the importance of bringing their past skills, experiences, and interests to the partnership, while acknowledging that the new program requires them to leave behind some familiar practices. The following quotes from participants exemplify this sentiment:

Be prepared for a different environment than child care. Know the play-based curriculum! (RECE, M arch 18, 2013)

Think long and hard about whether you want to be put in a position of sharing these responsibilities. It is not at all like working with an EA [educational assistant] who supports your program. (OCT, M ay 10, 2013)

A Ithough both RECEs and OCTs appear to be dealing with the process of holding on to aspects of their past professional practice while 
figuring out the new model, the advice from OCTs was far more focused on letting go of control, while the advice from RECEs focused on holding on to their professional knowledge and experience. The following comments from OCTs sought to reassure prospective FDK OCTs that the program is different from a traditional kindergarten program in which the teacher needs to control everything alone. In FDK they have a partner who not only shares what were the typical responsibilities of a kindergarten teacher, but who brings new skills and experience that will enhance the program. OCT participants expressed it this way:

Let things go. D on't feel that you have to control everything. E mbrace the ECE and learn from her skills/experience. Have fun together! (OCT, M ay 28, 2012)

Teachers need to learn to let go. (OCT, M arch 13, 2013)

Be open to relinquishing some of your past roles and responsibilities. You are a team now and you need to give yourself permission to NOT do it all yourself! (OCT, March 15, 2013)

While OCTs advised prospective OCT team members to take a step back from the central role in the classroom, RECEs advised prospective RECE team members to assert themselves in their positions on the team. They advised "being confident," "speaking up," and claiming their role in the team, as the following participant quotes illustrate:

Be confident in your knowledge of early childhood education but understand that play-based learning does look different in the school boards. Trial and error goes a long way. (RECE, March 14, 2013)

Remember that you bring experience and expertise to your classroom. Speak up about your experiences and work as a team. Your knowledge of child development is an asset to the classroom. (RECE, M arch 2, 2013)

It's not just the teacher's job. It's your job, too! (RECE, January 23, 2013)

The difference in the nature of advice given by OCTS and RECEs may be due to the nature of the position they occupy in the team. OCTs, as kindergarten teachers, are well recognized for what they do in the program. RECEs as teaching team members in kindergarten school classrooms, however, are a new phenomenon. Many RECEs commented that they were regarded as teaching assistants (EAs) by administration, other staff, and parents, and not as full team members. They called for widespread education about their role, as the following participant comments illustrate:

Why do all school staff mistake ECEs as EAs? (RECE, M ay 7, 2013)

Make parents understand that they can speak to either member of the team. Make your school staff aware that you are a team. (OCT, May 9, 2013)

Educate families and administration regarding team teaching. This is not an EA role. (RECE, M ay 7, 2013)

Structure and support

A Ithough the OCTS and RECEs gave a great deal of advice about building and maintaining a positive working relationship from within the partnership, they al so had advice and suggestions for how other staff, administration, and the M inistry of Education could support the FDK teaching team. The success of the team was not seen as solely an interpersonal endeavour. The quotes in the previous section speak to the need for understanding and recognizing the nature of the teaching team by other groups, such as parents, staff, and administration. H owever, participants had advice about many other kinds of support that are needed from outside the team. Regarding the earliest stages of team creation, team members had suggestions about how to create teams that were more likely to be effective and harmonious. The following participant comments raise the issue of compatibility. To have an effective team, they emphasize that consideration has to be given to the individuals being paired:

The key to success would be both team members having the same philosophy and expectations regarding learning, behaviour, and classroom organization. This has been underestimated when hiring and creating teams, but it is the 'make or break' factor for harmony in the classroom and maximizing the learning experience for the kids. (OCT, M arch 19, 2013)

Once the team has jelled successfully, the principal needs to let them work together in subsequent years. It takes time to find the right 
person to work with. (OCT, M ay 12, 2013)

Team members in the study also specified particular types of training that they felt they needed to be successful. Training in child development, curriculum content, pedagogy, and school terminology were all identified by the participants:

Give ECEs more training in teaching practices and terms that are used within the school classroom. (RECE, M ay 17, 2012)

ECEs need some literacy and numeracy training. (RECE, M ay 18, 2012)

We need more on child development for OCTs and more curriculum exposure for ECEs. (OCT, M ay 28, 2012)

In addition, team members in the study noted that they needed training and support in how to work together:

We need more support in learning to work together (teachers especially). We need support in conflict resolution-how to deal with challenges. Administrators need this support, too. (OCT, May 14, 2013)

These positions were created and implemented quickly, and no follow-up had been given to help teams learn and work together. ... Further training needs to be given in all areas. What training has been given has always been 'share what you are already doing' and not focused on directing both teacher and RECE toward best practices. (OCT, M ay 7, 2013)

A major structural support that participants noted was lacking was a provision for daily planning time for the teams. OCTs have paid planning time as part of their collective agreement, but most RECEs do not. M any teams reported planning before or after school, which is unpaid time for RECEs. J oint planning time was seen as essential for collaborative learning and communication about the program and the children, as these participant quotes illustrate:

Allow ECEs and teachers planning time together. We need to work together and learn from each other. (OCT, A pril 20, 2012)

Advocate for shared prep time. It is vital to planning a curriculum jointly and communicating meaningfully about children's learning and other issues. (RECE, M ay 17, 2012)

A work in progress

The full-day kindergarten teaching team members' urgent call for increased outside support highlights the high expectations that have been put on team members to manage this new program and their roles within it largely on their own. Full-day kindergarten is an innovative new program with a new play-based curriculum, staffed by two groups of education professionals who have not worked with each other in this capacity before. The program demands that OCTs and RECEs quickly build a working relationship through learning from and with one another while together planning and implementing a new curriculum. The challenges they report facing are not surprising given the newness of the program and the relative lack of key systemic supports for team building, team communication, and team professional learning. Given the challenges they have faced over the first few years of this new program, it was all the more remarkable that the teams were able to share such wisdom and commitment with prospective FDK teams, as the following participant quotes illustrate:

It is about coming to a middle ground with both teaching styles and making it work with everyone. A little give and take goes a long way while maintaining open communication. Take it one step at a time. It can be overwhelming. . . It will likely take several attempts to find a way that works best for you and your team. Every team is going to be different. (RECE, March 14, 2013)

Understand that each of you has things to learn and remember that the children come first. (OCT, M arch 12, 2013)

\section{Discussion and Conclusion}

The advice given by members of FDK teaching teams in their first or second year of the new program echoes many of the findings and recommendations of recent research on ECEC and school integration, and interprofessional learning and practice. As the Better Beginnings, Better Futures (BBBF) study found (Corter \& Peters, 2011), the participants in this study emphasized the importance of clarifying roles and creating positive, trusting working relationships. They advocated deliberately building strong partnerships through recognizing each other's expertise in order to help manage the new el ements of the full-day, play-based, interprofessional teaching team 
program. They identified ongoing effective communication amid the challenges of different professional educations, vocabularies, and statuses as key.

FDK teams also called for strong leadership from administration to support the team, and time for paid staff development, as was recommended in the Toronto First Duty (TFD) study (Corter \& Peters, 2011). A dministrative leadership and support was requested by the FDK teams in the form of purposeful team creation for compatibility, recognition for the team and specifically for the role of the RECE, and education and training opportunities. Specifically, the FDK teams advocated training in child development for OCTs and in school curriculum and processes for RECEs.

Although the participants in this study had no formal training in interprofessional learning and practice, they clearly identified some of the key principals advocated by the Centre for the A dvancement of Inter-professional Education (2011). The FDK teaching teams' experience led them to advise future teams to set aside differences in power and status and to utilize their distinctive contributions to learning and practice. For both members of the team, this entailed holding on to some aspects of their previous knowledge and practice and letting go of others. The OCTs in the team advised letting go of control, while the RECEs advised holding on to their knowledge and skills and entering assertively into the partnership.

The teams went beyond interpersonal advice, however, and focused on necessary structural changes and supports, similar to the recommendations of Kaga, Bennett, and M oss (2010) in their international study of the integration of ECEC into the school system. While the new FDK program does contain innovative structural changes, a full day for 4- and 5-year-olds, a new curriculum and a team of one RECE and one OCT, the participants in this study agree with the recommendations of the UNESCO study (K aga et al., 2010) that more structural change and support is required in the form of paid preparation time and professional development for the team. The participants in the study addressed both the benefits and risks to integration that Kaga et al. (2010) identified in their study. Kaga et al. (2010) noted that a potential benefit of integration is the higher valuation of the ECE workforce. The RECEs in this study recognize that greater valuation of their skills and expertise is needed, but note that it has not been sufficiently realized, and they call for this increased valuation. They also acknowledge that a potential risk identified by Kaga et al. (2010) is also a risk in Ontario's FDK program: the "schoolification" of young children. In this study, the RECEs caution future RECEs in FDK teams to remember and speak up regarding their knowledge and experience of developmentally appropriate practice.

The FDK teams also called for structural support in the form of joint professional education and training. In fact, this education and training were part of the original program vision as set out by Pascal (2009) in his recommendations for the new FDK program. Pascal advocated interprofessional preservice as well as in-service education for RECEs and OCTs so that the two professionals would be able to experience reciprocal mentoring (Pascal, 2009). While there have been some joint in-service opportunities, as of yet there is no provision for interprofessional preservice education and training. The health care research literature al so emphasizes the importance of joint professional development at both the pre- and in-service levels (Hall, 2005; Norsen, Opladen, \& Quinn, 1995; Sargeant et al., 2008). Furthermore, the in-service opportunities that have been offered are insufficient and inequitable because OCTs have paid professional development time and RECEs typically do not. Opportunities for joint learning are largely left to the discretion of the principal. A recent evaluation of the FDK program found that where professional learning was available to support program implementation during the first two years, it was most often the OCTs who attended (Ontario Ministry of Education, 2013). However, FDK teams identified the efforts and advocacy of the teacher federations "to support the advancements of knowledge and day-to-day practice" within the first years of implementation (Ontario Ministry of Education, 2013, p. 15).

M oreover, the structure of the FDK team and the structure of the kindergartens' full day has not been implemented as was originally envisioned (Pascal, 2009). Pascal advocated for two RECEs, one starting early to staff the early morning before the start of the typical school day and staying until past midday, and the other to start before midday and stay until the late afternoon, after the end of the typical school day. One OCT would join the team for half the day. Kindergarten children would not need before and after school child care. Therefore, the children would experience a "seamless" day in one room from early morning until late afternoon, and the three educators would overlap at midday. What is happening instead in most schools is that one RECE and one OCT staff the traditional full school day, and other RECEs staff the before and after school programs, either in the same room or elsewhere. A significant result of this change to the original vision, apart from the loss of the seamless day for the children, is the loss of the second RECE. Two RECEs in the team could have supported each other in the transition to the school system and this innovative approach to kindergarten.

It is remarkable that in a program that was so rapidly launched, in just over a year from the tabling of Pascal's summer 2009 report to the beginning of FDK implementation in September 2010, the new FDK teams achieved this level of wisdom and insight into their interprofessional teamwork. These voices from the field remind us that this new program requires a great deal from the interprofessional 
educator teams in terms of professional innovation, flexibility, and collaboration. The Ontario government has invested heavily in this new program, both financially and politically. They have continued to roll out the implementation yearly, with full implementation across the province expected by September 2014. To further support a smooth implementation of the program and the ongoing work of the kindergarten teaching teams in FDK, key supports need to be reinforced, such as the coordination of equitable professional learning by colleges and universities, professional organizations, school boards, and the M inistry of Education; more common planning time for team members; and more clearly defined roles and responsibilities of team members, which would still allow for flexibility to draw on individual and professional strengths.

\section{Acknowledgments}

We would like to thank the FDK team members in O ntario for sharing their wisdom and expertise.

\section{References}

Centre for the A dvancement of Inter-professional Education. (2011). Principles of inter-professional education. Retrieved from: http://www.caipe.org.uk/about-us/principlesof-interprofessional-education/

Corter, C., \& Peters, R. (2011). Integrated early childhood services in Canada: Evidence from the Better Beginnings, Better F utures (BBBF) and Toronto First Duty (TF D projects. Retrieved from: http://www.eyeonkids.ca/docs/files/corter-peters article.pdf

Dunston, R., Lee, A drian, Lee, A lison, M atthews, L., Nisbet, G., Pockett, R., Thistlethwaite, J., \& W hite, J. (2009). Inter-professional health education in Australia: The way forward. Retrieved from: http://www.health.wa.gov.au/wactn/docs/wayforward.pdf

Friendly, M . (2008). B uilding a strong and equal partnership between childcare and early childhood education in Canada. International J ournal of Child Care and E ducation Policy, 2(1), 39-52.

Hall, P. (2005). Inter-professional teamwork: Professional cultures as barriers. J ournal of Inter-professional Care, Supplement 1, 188-196.

Kaga, Y., B ennett, J., \& M Oss, P. (2010). Caring and learning together: A cross-national study of integration of early childhood care and education within education. U NESC O: Paris, France. Retrieved from: http://unesdoc.unesco.org/images/0018/001878/187818e.pdf

M erriam, S. (2009). Qualitative research: A guide to design and implementation. San Francisco, CA : J ossey-Bass.

M uttart Foundation. (2012, October). Integrating childcare and early education: A central theme in early learning and care. M uttart Foundation: Edmonton, A B. Retrieved from: http://www.muttart.org/

Norsen, L., Opladen, J., \& Quinn, J. (1995). Practice model: Collaborative practice. Critical Care Nursing Clinics North America, 7, 43-52.

Nuttall, J. (2013). Inter-professional work with young children in hospital: The role of 'relational agency.' Early Years, 33(4), 413-425.

Organisation for Economic Co-operation and Development. (2004). Canada country note. Thematic review of early childhood education and care. Paris, France: A uthor.

Ontario M inistry of Education. (2011). Full-day kindergarten. Retrieved from: http://www.edu.gov.on.ca/kindergarten/whatwillmychildlearnanddo.html

Ontario M inistry of Education. (2013). A meta-perspective on the evaluation of full-day kindergarten during the first two years of implementation. Retrieved from: http://www. edu.gov.on.ca/kindergarten/FDK Report2013.pdf

Ontario M inistry of Training, Colleges, and Universities. (2012, December). Early childhood education program standard. Retrieved from: http://www.tcu.gov.on.ca/pepg/ audiences/colleges/progstan/humserv/eerchedu.pdf

Pascal, C. (2009). With our best future in mind: Integrating early learning in O ntario. Retrieved from: https://ozone.scholarsportal.info/bitstream/1873/15094/1/293046.pdf

Punch, K. (2009). Introduction to research methods in education. London, UK: SA GE.

Sargeant, J., Loney, E., \& M urphy, G. (2008). Effective inter-professional teams: "Contact is not enough" to build a team. J ournal of Continuing Education in the Health Professions, 28(4), 228-234. 


\title{
Using Play as a K ey to Unlocking the Silence for Children with Selective M utism
}

\author{
Poling B ork, Debra Harwood, and Sheila M . B ennett
}

\begin{abstract}
Poling B ork is a doctoral candi date in educational studies at B rock U niversity. Having devoted over six years to researching selective mutism (SM) to help her son overcome this "unfamiliar" anxiety disorder, Poling is dedicating her research to psychoeducational assessments and interventions for children with SM and other related anxiety disorders. With her undergraduate degree in computer science, Poling is currently investigating how to incorporate technology in the SM intervention program. Email: mentor@ brocku.ca
\end{abstract}

Dr. Debra Harwood is an associate professor in early childhood education at B rock U niversity. Her current research endeavours include an exploration of parents' and teachers' perceptions of early literacies, making learning visible in early years contexts, and student engagement and successes within A boriginal communities.

Dr. Sheila Bennett is a professor and current chair of the Department of Teacher Education in the Faculty of Education at B rock University. Co-author of Special Education in Ontario Schools, Dr. B ennett's current research interests include special education service delivery, inclusion, and policy.

Imagine being 4 and not being able to ask for a toy or snack when you attend your early years program. Selective mutism (SM) is the persistent failure to speak in specific social situations where speaking is expected. It results from intense anxiety and occurs in spite of a child's ability to speak in other situations, like the home environment. Children with SM can have lifelong issues with being able to engage with others, speak publicly, and succeed academically. In this article, the authors propose that play is a valuable and necessary medium to meet the needs of the child with SM, foster resiliency, and promote well-being. Additionally, play provides a much-needed context to lessen the anxieties associated with being seen or heard speaking. The educator's role is specifically assessed as an asset to meet the needs of children with SM in the early years classroom.

contacted J ohnny's parents to discuss their concerns.
Johnny is a quiet boy who is about to turn 5 . His mom wants J ohnny to have the opportunity to make friends and be prepared for his transition next year to kindergarten at the local elementary school, so Johnny is currently attending Westlake's full-day play-based child care program. His educator has often noticed that Johnny plays with and whispers to only one of his fellow playmates, Jacob, a neighbourhood friend who also joined the child care program. A few months have passed, and it has become apparent that J ohnny does not speak to anyone else in the program, including the educator. If J ohnny needs anything, he asks J acob to convey his needs (e.g., asking for a snack, a toy, or going to the washroom). During circle time, the educator can't get J ohnny to participate or speak one word. He often appears to be frozen on the spot when approached by anyone and he "refuses" to make a sound. F eeling frustrated, the educator asked a resource teacher to intervene, but J ohnny remained silent. Both professionals then

Children like Johnny (a pseudonym) have an anxiety disorder known as selective mutism (SM). SM is defined as the persistent failure to speak in specific social situations (such as child care programs and school) where speaking is expected, despite the child's ability to speak in other situations (A merican Psychiatric A ssociation, 2013). C hildren with SM have the ability and desire to talk, yet persistently fail to speak in social situations where speaking in front of others is expected. And, despite prevalence rates estimated as high as two percent (K umpulainen, Räsänen, Raaska, \& Somppi, 1998), many children with SM spend years without a diagnosis. Frontline educators often face the challenges of including a child with SM in classroom activities with limited resources, support, or knowledge. In most cases, parents are unaware that a problem exists. Often parents have been told by heal th care professionals that their child is simply shy and that he or she will "outgrow" the behaviour (Shipon-Blum, 2003, 2011). For many children like Johnny, SM is not discovered until the child's educator notices the child's consistent failure to speak and reports a concern (Sharp, Sherman, \& Gross, 2006). In this purely theoretical article, we posit that play is an invaluable medium to both meet the learning needs of the child with SM and provide a context to lessen the anxieties associated with being seen or heard speaking, thereby fostering more abilities for the child to engage in communicating. The educator's role as an informed and intentional co-player is specifically highlighted as an added resource needed to meet the needs of children with SM in the early years classroom. 


\section{Selective M utism - W hat I I It? What's It Like?}

Because they may speak in one context and not others, children with SM are often misunderstood. Historically, their "refusal" to speak was thought to be intentional and defiant (Kratochwill, 1981). Today, although awareness of SM continues to rise, the disorder is not recognized as a federal category of disability in the United States. Consequently, many children with SM are still not identified early and provided with needed support. The longer the mutism persists, the more entrenched the condition becomes (Shipon-Blum, 2011). SM persists into adulthood and can negatively impact a person's emotional, educational, occupational, and socialization experiences across the life span. Thus, finding ways to support children with SM is of paramount importance and needs to start with a child's first transition to any formal learning environment (Schwart, Freedy, \& Sheridan, 2006).

Many children with SM tend to blush, avoid eye contact, fidget, and exhibit social withdrawal when speech is expected, and/or they may appear to be frozen in a spot when spoken to directly. Diagnostic and Statistical M anual of M ental Disorders, Fifth Edition (DSM -V) defines SM as consistent failure to speak in specific social situations in which speech is expected (e.g., at school), despite speaking in other situations. DSM - V also states that:

- The disturbance interferes with educational or occupational achievement or with social communication.

- The duration of the disturbance is at least one month (not limited to the first month of school).

- The failure to speak is not due to a lack of knowledge of, or comfort with, the spoken language required in a social situation.

- The disturbance is not better explained by a communication disorder (e.g., childhood onset fluency disorder) and does not occur exclusively during the course of autism spectrum disorder, schizophrenia, or another psychotic disorder. (A merican Psychiatric Association, 2013, p. 195).

A formal learning context can be intimidating for many young children because it often represents their first transition from home life to a more formalized environment. This feeling of intimidation may explain the early age of onset of SM, which typically occurs between the ages of 3 and 5 (Garcia, Freeman, Francis, Miller, \& Leonard, 2004). The environment, expectations, and individuals can all be vastly different within an early learning environment compared to a child's experience at home. For a child, the idea that "I need to ask for play dough, request a snack, or sing the morning welcome song" can be daunting and anxiety provoking. A nd, since SM appears most predominantly within, and appears to be triggered by, the learning environment, researchers (Cline \& Baldwin, 2004) suggest that strategies and interventions need to take place within the classroom context. Unfortunately, many children with SM might experience delays of up to four years in having these interventions and support plans operational ized (Sharp et al., 2006). Thus, it is not surprisingly that $63 \%$ of children with SM are also described as withdrawn (Kumpulainen et al., 1998).

Despite a lack of noticeable differences in arithmetic and overall academic performance, older school-age children with SM tend to have lower reading test scores (Cunningham, McHolm, Boyle, \& Patel, 2004). However, because young children need ample opportunities to practice with oral communication and receptive and expressive language (M orrow, 2012; M orrow \& Dougherty, 2011), it is not surprising that children with SM often suffer from speech and language delays as well.

Children with SM also tend to experience difficulties in social skill development resulting from this lack of practice with social engagement in comparison to their peers (Cunningham et al., 2004). Additionally, it is estimated that only $30 \%$ to $40 \%$ of children older than 12 who are diagnosed and treated properly will speak to a wide circle of schoolmates throughout their schooling experiences (Bergman, Piacentini, \& McCracken, 2002). Therefore, finding ways to accommodate and support young children's needs within an early years environment is extremely important and sets the foundation for lifelong learning. U nfortunately, educators are rarely provided with proper information, and additional supports for children with SM vary. These inconsistencies and lack of knowledge may result in educators unintentionally reinforcing the child's mutism behaviour through actions such as making eye contact when speaking to them, asking direct questions, attempting to persuade the child to talk, bribery, or accepting the child's silence (0 mdal, 2008). So how can an educator meet the needs of a child with SM in a classroom or program?

\section{Using Play as a Key to Well-B eing}

Children's play seems to be an obvious place to start in considering three important factors: (1) play "is important in a child's experience"; (2) play "provides a useful window for assessing development"; and (3) play "is an important domain for intervention" (Lifter, M ason, $\&$ Barton, 2011, p. 282). Play is multifunctional and serves many intellectual and social-emotional purposes for the developing child (Saracho \& Spodek, 2003). 
Adapting Lifter and Bloom's (1998) definition of play, we too propose that "play is the expression of intentional states-the representations in consciousness constructed from what children know about and are learning from ongoing events-and consists of spontaneous, naturally occurring activities with objects that engage attention and interest." (p. 164)

However, because Lifter and Bloom restricted their framework to object play, a significant area of research and theoretical exploration, we offer that play with others (i.e., the social aspect of play) is also significant for children with SM in that social play affords a major context for social-emotional development (Fromberg \& B ergen, 2006; R ubin, Fein, \& Vandenberg, 1983) for the child with intense fears of being seen or heard speaking. As Samuelsson and Carlsson (2008) state, "in play, children communicate and interpret continuously in the negotiation with peers and role play" (p. 627), thus the social aspect of play is significant for children with SM. Additionally, play has long been held as one of the important contributors to fostering resiliency in vulnerable children (Berger $\&$ Lahad, 2010; Fearn \& Howard, 2012; Mortimer, 2004; Nowakowski et al., 2011). And children with SM are vulnerable to a variety of social-emotional and communicative delays the longer the mutism persists (O mdal, 2007).

\section{Play as a M edium for L earning}

Various conceptualizations of play have resulted in distinct definitions of what constitutes play. Relational play, pretend play, symbolic play, object play, and rough-and-tumble play are just a few examples of these varied conceptualizations and meanings (Lifter et al., 2011). Several researchers informed Mayfield's (2001) compiled list of constructs that defines children's play as voluntary, nonliteral, active, and meaningful. Mayfield adds that play is "child-directed, intrinsically motivating, flexible, fun, often spontaneous, and free from external rules" (p. 257). Learning, on the other hand, is often associated with adult-initiated activities within an educational context. Often play and learning are separated by time and structures within classrooms (e.g., circle time as instructional time versus free play; literacy centre versus outdoor playground; Samuelsson \& Carlsson, 2008). Like Samuelsson and Carlsson, here we wish to highlight and examine the symbiotic and mutually interdependent constructs of play and learning to address how the two are related-a topic that remains largely undiscussed. Certainly, from a child's perspective, play and learning are not always mutually exclusive practices (Samuelsson \& Carlsson, 2008). A nd perhaps the historical paradox between play and learning within early years education is no longer pertinent and one can examine the commonalities shared by play and learning to counter the enigma of pitting one against the other. Play and learning share several theoretical concepts, such as creativity (M iller, Cable, \& Goodliff, 2010; Russ, 2003), divergent thinking (Russ \& Schafer, 2006), and mindfulness (Langer, 1993).

Creativity is significant in both play and learning because both cognitive and affective processes are implicated (Russ, 2003). Here, we emphasize the significance of the creative process (versus the creative product) as a legitimate outcome of children's play, particularly pretend play (Russ \& Dillon, 2011; Torrance, 1962). In pretence, children's creativity is cultivated because pretend play involves make believe, the imagination, fantasy, innovative problem solving, and assigning literal meaning to the nonliteral (Singer \& Singer, 1990). In pretend play, children can create a magical castle with an alligator-filled moat and a pet dragon from an empty cardboard box. In pretend play, children negotiate complex roles through action and language. They also sustain the theme of the play by utilizing a complex system of problem solving and divergent and creative thinking. Divergent thinking has long been recognized within learning as a highorder skill (Bloom, 1956). In play, divergent thinking is naturally involved as children generate multiple ideas and solutions and make literal and remote associations with play mates and playthings (Russ \& Dillon, 2011, p. 330). Play (like storytelling and play acting) is the "universal medium" through which children express themselves (Paley, 1990, p. 10). And, as Nicolopoulou (2005) emphasizes, "both play and storytelling should be viewed as complementary expressions of children's symbolic imagination that draw from and reflect back upon the inter-related domains of emotional, intellectual, and social life" (p. 496).

M indfulness is described as "a state of mind that results from drawing novel distinctions, examining information from new perspectives, and being sensitive to context" (Langer, 1993, p. 44). In the learning process, mindfulness means remaining open to possibilities, being creative in exploring alternative perspectives, and being able to recognize the diversity of possible answers and explanations. An observation of a selectively mute preschooler playing with a train track illustrates this mindfulness concept in action. As the 4-year-old child trials countless track and train configurations to achieve the goal of transporting her passengers between town and the station, one can see the endless possibilities and responses to meet the needs of her goal. This is mindfulness.

In sum, when play is construed as a reflection of a "child's construction of knowledge about objects, people, and events" (Lifter et al., 2011, p. 282) the value of play within early years settings cannot be overestimated. For the child, play is voluntary, self-initiated, engaging, pleasurable, and self-motivating (Rubin et al., 1983). Play is a medium of creativity, expression, communication, and thinking that the child is well versed with and immersed in within daily life. A s Paley (1990) highlights, "there is a tendency to look upon the noisy repetitious fantasies of children as non-educational, but helicopters and kittens and superhero capes and Barbie dolls are storytelling 
aids and conversational tools" (p. 39) as well as mediums of children's meaning making. Perhaps by examining play and learning as complementary constructs, new avenues can be explored that challenge the more "verbocentric" (Fueyo, 1991) and traditional program practices of early years education (Harwood \& B ork, 2011). For the child with SM , play provides a mode of communication that she or he is al ready familiar with and comforted by-making it an obvious and necessary avenue for the child's success.

\section{Play as a M edium for Intervention and Accommodation}

Play provides a mirror of the child's level of devel opment (Russ, 2003). M oreover, play offers a context for practicing skills and fuelling developmental change. Thus, play serves as an important conduit for intervention strategies that are both developmentally appropriate and contextually rel evant for the child with SM (Lifter et al., 2011). A dditionally, play offers a suitable al ternative to standardized forms of assessing children's learning that are often required of an early years educator ( $L$ inder $\&$ Linas, 2009). The role that play can have in addressing the needs of a child with SM in an early years program is apparent.

Selective mutism can severely limit a child's ability to engage in some of the more formalized traditional program practices, such as circle time, the morning greeting song, calendar time, question and answer story recall, and many others. Formal practices that rely on direct eye contact, overt verbal communication, and whole-group formats present a particular challenge for the child with a debilitating fear of being seen or heard speaking. Often children with SM are unable to communicate or raise their hands to participate in these everyday classroom routines, and many of the children may also be socially withdrawn (K umpulainen et al., 1998). Hence, it is important that educators plan play activities and tasks that do not rely solely on direct involvement of speech (e.g., whole-class dramatizations of the morning welcome song). Educators must include the child in varied ways to avoid reinforcing the child's exclusion (Bork \& Harwood, 2010). Table 1 (B ork, 2010) highlights a few play activities that are age appropriate and important to consider including within an early years program, since the onset of SM coincides with entry into a formal learning environment.

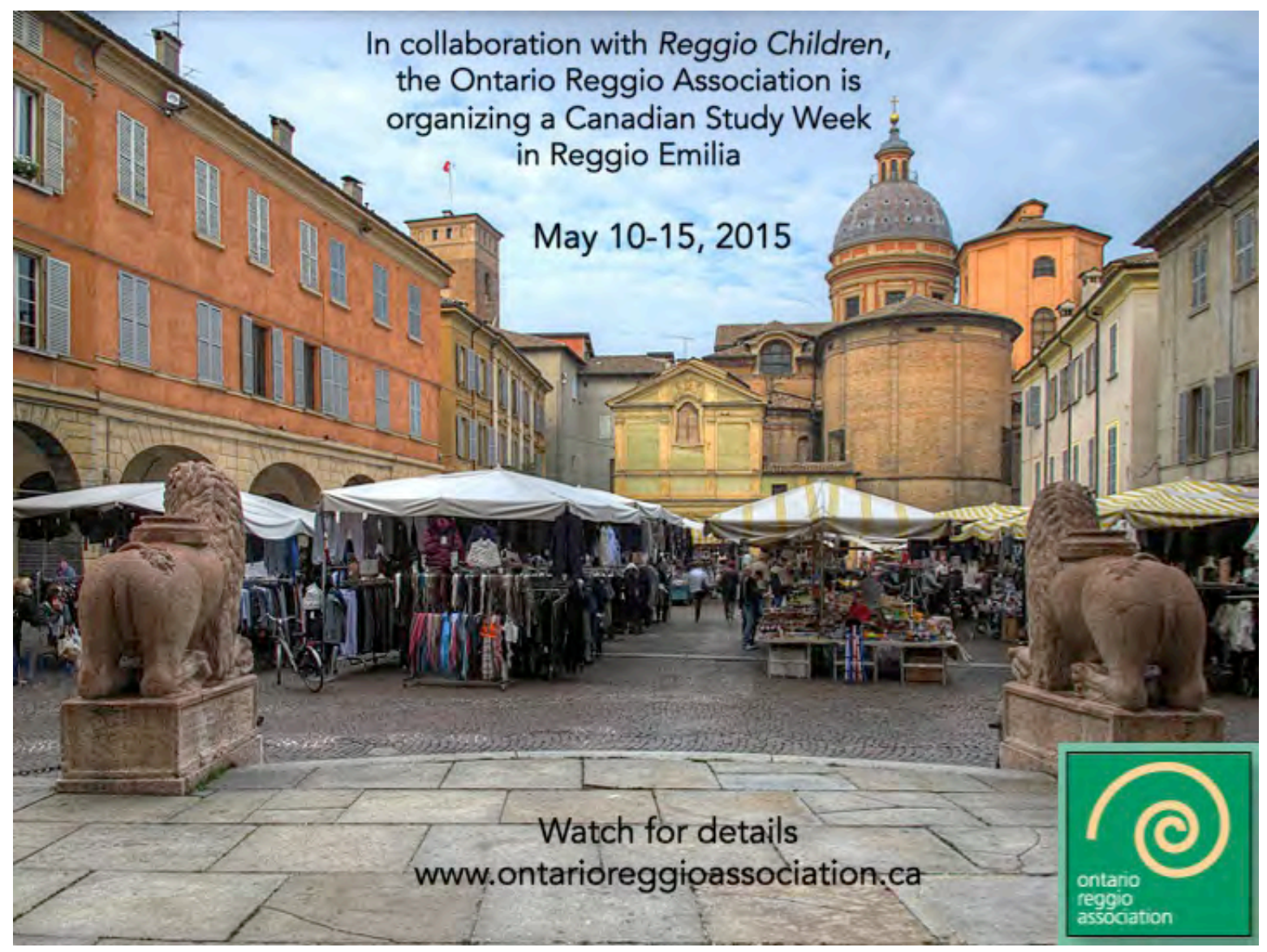


Table 1. Some learning activities that involve play to help engage children with selective mutism (adapted from Bork, 2010).

\begin{tabular}{|c|c|c|}
\hline $\begin{array}{c}\text { SM } \\
\text { Severity }\end{array}$ & $\begin{array}{c}\text { Type of } \\
\text { E ngagement }\end{array}$ & Rationale/Benefit \\
\hline $\begin{array}{l}\text { For children } \\
\text { who are } \\
\text { severely } \\
\text { mute } \\
\text { (unable } \\
\text { to make a }\end{array}$ & $\begin{array}{l}\text { 1. Play that } \\
\text { involves } \\
\text { puppets }\end{array}$ & $\begin{array}{l}\text { Children have vivid imaginations. Some children with SM } \\
\text { may lose themselves during play and believe that the puppets } \\
\text { are speaking, not themselves! Pair children who are extremely } \\
\text { anxious with a partner in case they fail to make a sound and are } \\
\text { put on the spot. The gentlest way to carry this out is to involve } \\
\text { the child as a silent character and gradually move on. }\end{array}$ \\
\hline $\begin{array}{l}\text { sound or eye } \\
\text { contact) }\end{array}$ & $\begin{array}{l}\text { 2. Sign language } \\
\text { and/or symbolic } \\
\text { language }\end{array}$ & $\begin{array}{l}\text { Teach everyone in the classroom some basic sign language and } \\
\text { use it daily. Encourage students to use sign language to ask to go } \\
\text { to the washroom. Signs such as "right" or "wrong," "good" or } \\
\text { "bad" can also be very helpful. A n important note: Do not make } \\
\text { it obvious that sign language or other activities are specifically } \\
\text { implemented for the child with SM. Incorporate sign language } \\
\text { in some of the program's routines, such as the "good morning" } \\
\text { greeting song. If sign language is not an option, then any symbol } \\
\text { system can be used for communication. Giving each child a } \\
\text { set of simple shapes in red, green, and yellow can help them } \\
\text { communicate when concepts are too challenging (red), are easy } \\
\text { to understand (green), or the child needs more time to fully } \\
\text { understand (yellow). }\end{array}$ \\
\hline & $\begin{array}{l}\text { 3. Imitate animal } \\
\text { sounds }\end{array}$ & $\begin{array}{l}\text { Although children with SM are unable to speak, many of them } \\
\text { will make funny sounds and laugh out loud. If the child is unable } \\
\text { to repeat words, try to induce play and have the children imitate } \\
\text { animal sounds (bark, roar, etc.). Try using M aurice Sendak's } \\
\text { classic Where the Wild Things Are as a starting point. }\end{array}$ \\
\hline $\begin{array}{l}\text {... to those } \\
\text { who are } \\
\text { mute but } \\
\text { somewhat } \\
\text { relaxed and } \\
\text { are ready } \\
\text { to risk } \\
\text { speaking }\end{array}$ & $\begin{array}{l}\text { 4. Turn off the } \\
\text { lights }\end{array}$ & $\begin{array}{l}\text { Children with SM are afraid of being heard or seen speaking } \\
\text { (McHolm, Cunningham, \& Vanier, 2005). Turning off the light } \\
\text { in a bright room (in a safe place and ensuring that every child is } \\
\text { al right with this) and teaching them new words can be fun. For } \\
\text { instance, inside a dark room, the educator (who turns her back } \\
\text { to her students) yells, "L et's bring some light to this room" and } \\
\text { spells L-I-G-H-T. Once the students repeat the spelling, a tiny } \\
\text { little light illuminates. Then the teacher can move onto other } \\
\text { words, such as candle, lamp, sun, star, etc. }\end{array}$ \\
\hline
\end{tabular}




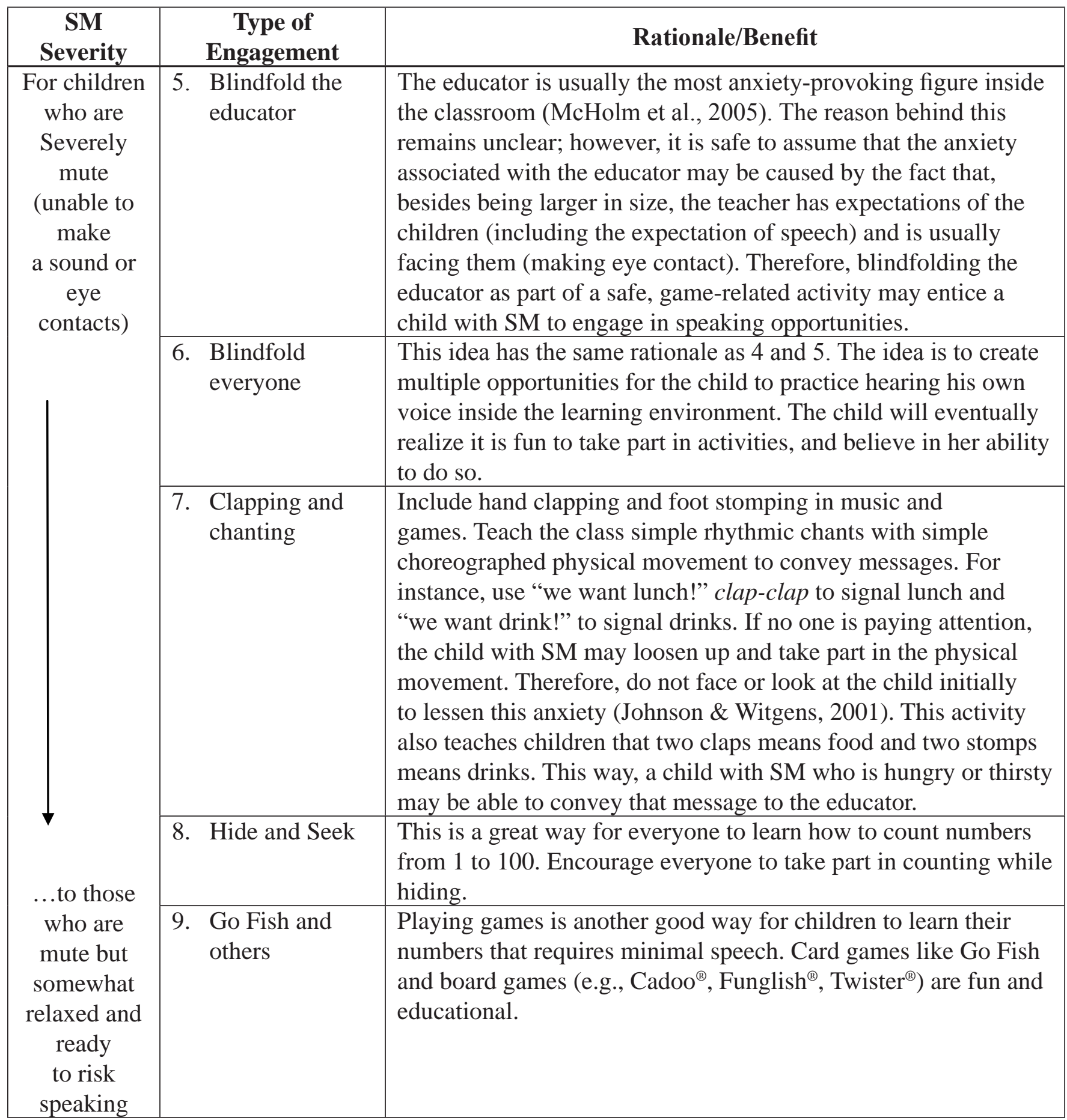

It is important to note that the suggested list of play activities is not exhaustive, and by no means do the authors intend to imply that by simply including play, the selective mutism will be alleviated. Rather, we posit that play offers an accessible, equitable, universal medium that values the SM child's way of knowing and being in the world, empowering that child to feel comfortable and included in all program activities. The intentional educator also has a significant role in ensuring that the child's strengths, interests, and abilities are reflected in the microcosm of classroom life. 


\section{The E ducator as C o-Player}

Informed, intentional, authentic educators can help create an inclusive environment, one that fosters well-being and resiliency for a child with SM. The educator as co-player is a keen observer and documents children's interests, learning approaches, and rhythms to inform both their own teaching practices and the educational experiences that are made available in the classroom context (J ones, 1999). Educators' interactions with children as a co-player demonstrate a greater impact on children's oral language devel opment than either more directed approaches or noninvolvement in children's play (Enz \& Christie, 1993). By engaging the child with SM as a co-player in authentic ways, the educator can lessen the anxiety inherent in their role as the teacher and promote greater agency for the child to find suitable mediums for more expressive communication.

In addition to the educator as co-player, other varied approaches can be used by educators to create opportunities for young children with SM to participate and succeed within situations that do not produce anxiety. Strategies such as getting to know the child in different contexts (e.g., at home), collaborating with other professionals, and incorporating play can all contribute to reducing anxiety and encouraging speaking in the classroom environment.

\section{Understanding the C hild with Selective M utism}

It is imperative that educators know that speaking is not a choice for children with SM. M ost children with SM want to speak, but are unable to do so. A s such, children with SM will go to extremes to avoid verbal communication. Younger children often have accidents inside the early years program because they are unable to ask to go to the washroom. A s they get older, they learn to avoid drinking water unless there are other outlets for them to communicate. Over time, these children become very adept at avoidance strategies and thus often suffer from a wide variety of social developmental issues, such as low self-esteem and substance abuse, and hel plessly "allow" their mutism behaviour to persist into adulthood (Remschmidt, Poller, Herpertz-Dahlmann, Henninghausen, \& Gutenbrunner, 2001). Educators hold an important and unique position to identify these children, and they play a pivotal role in facilitating the much-needed timely intervention.

As with all children, building rapport with a child with SM is important. To connect with a child with SM, educators need to gain the child's trust. Simple approaches, such as avoiding direct eye contact and letting the child know there is no initial expectation for speech, can greatly reduce the child's anxiety. The educator can also make home visits to establish rapport with the child, discover the child's interests and strengths, and "prepare the environment and curriculum to reflect these needs" (Allen, Paasche, Langford, \& Nolan, 2011, p. 64). In addition, children should be encouraged to visit their new program with their parents and pay conversational visits prior to officially starting in the new educational environment.

\section{C reate an Inclusive C lassroom to $\mathrm{M}$ ake the $\mathrm{C}$ hild Feel L ess Anxious}

By definition, children with SM "shut down" when there is an expectation for speech. Therefore, any attempt to force or trick them to talk may strengthen their refusal to speak and deepen the child's social exclusion. The following general guidelines are helpful in creating a program that does not provoke anxiety for a child with SM :

- M ost children with SM do not wish to be noticed. Avoid putting the child on the spot or making the child the centre of attention.

- Do not insist on making eye contact initially, and avoid speaking to the child face to face.

- Do not pressure or bribe a child to speak. Give the child time to conquer fears slowly.

- A ssist children to convey their needs by providing them with a variety of alternative means (e.g., simple written notes, pictures, communicative devices like a Go Talk Now $\odot$ application).

- Help children feel more at ease inside the classroom by pairing them with someone they are comfortable with.

- Avoid asking questions that the child is unable to respond to through alternative means.

- Assess the child through a process of observation and documentation versus direct tools that rely on speaking (e.g., direct questioning, call and response techniques).

- Include playful activities that involve minimal speech so the child will be more likely to join in.

- Act as a co-player alongside the child, authentically engaging in the child's play and encouraging the child to take the lead and 
direct the play.

- If the child has a sibling attending the same centre, provide plenty of opportunities for the child to practice audible speech inside the program with the sibling present.

- Invite immediate family members into the program regularly to converse with the child within the early learning environment.

- When the child speaks for the first time, do not show extreme excitement. It is best to pretend that nothing unusual has happened and carry on the conversation to ensure the child feels there is no turning back.

- It may take several years for a child to overcome SM, so be patient and communicate with the child's next educator.

Note that the important goal is to reduce anxiety while creating a setting that fosters communication through both direct and indirect speech. To accomplish this goal, consider combining strategies such as reorganizing the room's physical layout, incorporating play into all learning activities, collaborating with other personnel, and using assistive technologies (e.g., iPads, Go Talk Now $\odot$, audio/video recorders). It is important to remember that each child with SM is unique, with anxieties and level of mutism that may be distinctly different from other children with SM. Thus, each plan and strategy will need to be tailored to the specifics of that child's comfort level. Strategies and goals for fostering communication and reducing anxieties will need to consider children's existing patterns of speaking according to the location (where the child feels most comfortable), people (who the child speaks with or avoids speaking to), and activities; aim for a balance of activities that require speaking and those that do not, and plan activities of interest to the child ( $\mathrm{M} \mathrm{cH} \mathrm{olm}$ et al., 2005).

\section{Conclusion}

Children with SM predominately fail to speak inside the early years setting al though they are fully capable of speaking in other contexts, such as the home environment. Thus, educators are on the front line and need to collaborate with parents and experts to provide an inclusive classroom that accommodates and maximizes the children's social, educational, and emotional experiences. Throughout this article we proposed that play offers an accessible and invaluable medium to meet the needs of the child with SM. The view of the playing-learning child (Samuelsson \& Carlsson, 2008) can help fuel a dialogue within education and impel research to examine play as a context for addressing the needs of children with SM within early learning settings. The educator's role as an informed and intentional co-player was also specifically highlighted as an added resource to meet the needs of children with SM in the early years classroom. We contend that through an inclusive play-based philosophy and an early identification system, children with SM will be able to express their thoughts and ideas and participate as full members of the early learning environment. By providing the child with plenty of "speaking" outlets through play to build up confidence, and allowing the child the freedom to choose in what context and through which outlet to speak, the fear and anxiety associated with participation will be minimized.

\section{References}

Allen, K .E., Paasche, C.L., Langford, R., \& N olan, K. (2011). Inclusion in early childhood programs: Children with exceptionalities (5 ${ }^{\text {th }}$ ed.). Toronto, ON: Thomson N elson.

A merican Psychiatric A ssociation. (2013). Diagnostic and statistical manual of mental disorders (5 $5^{\text {th }}$ ed.). Washington, DC: A merican Psychiatric A ssociation.

Berger, R., \& Lahad, M . (2010). A safe place: Ways in which nature, play and creativity can help children cope with stress and crisis- Establishing the kindergarten as a safe haven where children can develop resiliency. Early Child D evelopment \& Care, 180(7), 889-900. doi: 10.1080/03004430802525013

Bergman, R.L., Piacentini, J., \& M cCracken, J.T. (2002). Prevalence and description of selective mutism in a school-based sample. J ournal of the American Academy of Child $\&$ Adolescent Psychiatry, 41(8), 938.

Bloom, B.S. (1956). Taxonomy of educational objectives: The classification of educational goals (1 ${ }^{\text {st }}$ ed.). New York, NY: Longmans.

Bork, P.M . (2010). O vercoming selective mutism: Play now... talk later! Paper presented at the Designing for Children International Conference, M umbai, India.

Bork, P.M., \& Harwood, D. (2010). Transient $\neq$ persistent: Determining the best approach to selective mutism intervention. International J ournal of Interdisciplinary Social Sciences, 5(3), 237-247.

Cline, T., \& Baldwin, S. (2004). Selective mutism in children $\left(2^{\text {nd }}\right.$ ed.). London, UK: W hurr.

Cunningham, C.E., McHolm, A., Boyle, M.H., \& Patel, S. (2004). Behavioral and emotional adjustment, family functioning, academic performance, and social relationships in children with selective mutism. J ournal of Child Psychology \& Psychiatry, 45(8), 1363-1372.

Enz, B., \& Christie, J.F. (1993). Teacher play interaction styles and their impact on children's oral language and literacy play. Paper presented at the annual meeting of the National Reading Conference, Charleston, SC. (ERIC Document Reproduction Service No. ED366015). 
Fearn, M., \& Howard, J. (2012). Play as a resource for children facing adversity: An exploration of indicative case studies. Children \& Society, 26(6), 456-468. doi: 10.1111/j.1099-0860.2011.00357.x

Fromberg, D.P., \& Bergen, D. (2006). Play from birth to 12. New York, NY: Routledge.

Fueyo, J.A . (1991). Reading "literate sensibilities": Resisting a verbocentric writing classroom. Language Arts, 68(8), 641-648.

Garcia, A.M., Freeman, J.B., Francis, G., Miller, L., \& Leonard, H. (2004). Selective mutism. In T.H. Ollendick \& J.S. March (Eds.), Phobic and anxiety disorders in children and adolescents: A clinician's guide to effective psychosocial and pharmacological interventions (pp. 433-456). New York, NY: Oxford University Press.

Harwood, D., \& Bork, P.M . (2011). M eeting educators where they are: Professional development to address selective mutism. Canadian J ournal of Education, 34(3), 136-152.

Johnson, M ., \& Witgens, A . (2001). The selective resource manual. M ilton K eynes, UK : Speechmark.

Jones, E. (1999). A n emergent curriculum expert offers this afterthought. Editorial. Young Children, 54(4),16.

Kratochwill, T.R. (1981). Selective mutism: Implications for research and treatment. Hillsdale, NJ : L awrence Erlbaum.

K umpulainen, K., Räsänen, R., Raaska, H., \& Somppi, V. (1998). Selective mutism among second-graders in elementary school. E uropean 」 ournal of Child and Adolescent, $7(1), 24-29$.

Langer, E.J. (1993). A mindful education. Educational Psychologist, 28(1), 43.

Lifter, K., \& Bloom, L. (1998). Intentionality and the role of play in the transition to language. In A.M. Wetherby, S.F. Warren \& J. Reichle (Eds.), Transitions in prelinguistic communication: Preintentional to intentional and presymbolic to symbolic (pp. 161-198). Baltimore, MD: Brookes.

Lifter, K., Mason, E.J., \& Barton, E.E. (2011). Children's play: Where we have been and where we could go. Journal of Early Intervention, 33(4), 281-297. doi: $10.1177 / 1053815111429465$

Linder, T., \& Linas, K. (2009). A functional, holistic approach to developmental assessment through play. Zero to Three, 30(1), 28-33.

Mayfield, M.I. (2001). Early childhood education and care in Canada. Toronto, ON: Pearson.

McHolm, A., Cunningham, C.E., \& Vanier, M.K. (2005). H elping your child with selective mutism. Oakland, CA : N ew Harbinger.

M iller, L., Cable, C., \& Goodliff, G. (2010). Supporting children's learning in the early years. N ew York, NY: Routledge.

M orrow, L.M . (2012). Literacy development in the early years: Helping children read and write ( $7^{\text {th }}$ ed.). B oston: Pearson.

Morrow, L.M., \& Dougherty, S. (2011). Early literacy development: Merging perspectives that influence practice. J ournal of Reading Education, 36(3), 5-11.

Mortimer, H. (2004). Hearing children's voices in the early years. Support for Learning, 19(4), 169-174. doi: 10.1111/j.0268-2141.2004.00343.x

Nicolopoulou, A. (2005). Play and narrative in the process of development: Commonalities, differences, and interrelations. Cognitive D evelopment, 20(4), 495-502.

Nowakowski, M .E., Tasker, S.L., Cunningham, C.E., M cH olm, A .E., Edison, S., Pierre, J.S., \& Schmidt, L.A. (2011). J oint attention in parent-child dyads involving children with selective mutism: A comparison between anxious and typically developing children. Child Psychiatry \& Human D evelopment, 42(1), 78-92. doi: 10.1007 s10578-010-0208-Z

Omdal, H. (2007). Can adults who have recovered from selective mutism in childhood and adolescence tell us anything about the nature of the condition and/or recovery from it? European J ournal of Special Needs Education, 22(3), 237-253.

Omdal, H. (2008). Including children with selective mutism in mainstream schools and kindergartens: Problems and possibilities. International J ournal of Inclusive E ducation, 12(3), 301-315.

Paley, V.G. (1990). The boy who would be a helicopter: The uses of storytelling in the classroom. Cambridge, M A : Harvard University Press.

Remschmidt, H., Poller, M., Herpertz-Dahlmann, B., Henninghausen, K., \& Gutenbrunner, C. (2001). A follow-up study of 45 patients with elective mutism. European Archives of Psychiatry and Clinical Neuroscience, 251(6), 284-296.

Rubin, K., Fein, G., \& Vandenberg, B. (1983). Play. In E.M. Hetherington (Ed.), Handbook of child psychology: Socialization, personality, social development (Vol. 4, pp. 694-759). New York, NY: John Wiley.

Russ, S.W. (2003). Play and creativity: Developmental issues. Scandinavian J ournal of Educational Research, 47(3), 291.

Russ, S.W., \& Dillon, J.A . (2011). Changes in children's pretend play over two decades. Creativity Research J ournal, 23(4), 330-338. doi: 10.1080/10400419.2011.621824

Russ, S.W., \& Schafer, E.D. (2006). A ffect in fantasy play, emotion in memories and divergent thinking. Creativity Research J ournal, 18, $347-354$.

Samuelsson, I.P., \& Carlsson, M .A. (2008). The playing learning child: Towards a pedagogy of early childhood. Scandinavian J ournal of Educational Research, 52(6), 623-641. doi: 10.1080/00313830802497265 
Saracho, O.N., \& Spodek, B. (2003). Contemporary perspectives on play in early childhood education. Greenwich, CN: Information A ge.

Schwartz, R.H., Freedy, A.S., \& Sheridan, M J. (2006). Selective mutism: A re primary care physicians missing the silence? Clinical Pediatrics, 45(1), 43-48.

Sharp, W.G., Sherman, C., \& Gross, A.M . (2006). Selective mutism and anxiety: A review of the current conceptualization of the disorder. J ournal of Anxiety Disorders, 21, $568-579$.

Shipon-Blum, E. (2003). The ideal classroom setting for the selectively mute child: Handbook and guide. Philadel phia, PA: Selective M utism A nxiety Research and Treatment Centre.

Shipon-Blum, E. (2011). Assessment and treatment of selective mutism: Beyond the basics. Paper presented at the Selective M utism Conference, Cherry Hill, NJ .

Singer, D.G., \& Singer, J.L. (1990). The house of make-believe: Children's play and the developing imagination. Cambridge, M A : Harvard U niversity Press.

Torrance, E.P. (1962). Creative thinking of children. J ournal of Teacher Education, 13(4), 448-460. 


\title{
21 $1^{\text {st }}$-Century Vision Using a 20 ${ }^{\text {th }}$-C entury C urriculum: Examining British Columbia's K indergarten C urriculum Package
}

\author{
L aura Teichert
}

\begin{abstract}
L aura Teichert is a PhD student at the U niversity of B ritish Columbia in the Department of Language and Literacy Education. Previously, she worked as an early literacy specialist in Ontario and completed earlier degrees at Western U niversity (L ondon, $\mathrm{ON}$ ) and Deakin University (A ustralia). E mail: teichert.la@gmail.com
\end{abstract}

This article provides a critical analysis of British Columbia's early learning curricula concerning 21st-century education and the role of digital technology in the early years. The data sources were the Premier's Technology Council: A Vision for 21stCentury Education (Premier's Technology Council, 2010), BC's Education Plan (B ritish Columbia M inistry of Education, 2011), and the Kindergarten Curriculum Package (B ritish Columbia Ministry of Education, September 2010). Rapid advances in technology call for a review of traditional curriculum standards and active movement toward a realization of 21stcentury education beyond mere vision. As children navigate an increasingly digital world, one with blurred lines between content and advertising, critical thinking and critical analysis skills are essential in order for children to effectively manage the vast amounts of information available to them. Educators and policy makers, through curricula developed reflecting digital media use, can play an important role in educating young, technologically engaged students.

In an increasingly digital and technological world, itis perhaps to be expected that many young children are using digital technologies and new media from an early age (Plowman, M cPake, \& Stephen, 2008). For example, approximately $70 \%$ of American children aged 4 to 6 years have used a computer, spending an average of one hour per day using the computer, with approximately $56 \%$ of these children having used one independently (Hisrich \& Blanchard, 2009). It is thought that children develop their understanding of the role of media and technology in society through observation as technology is used in socially and culturally relevant practices (Marsh et al., 2005) by older siblings, parents, caregivers, and so forth. As such, "preschoolers are there, inextricably intertwined within the interaction of people, language and digital media" (Hisrich \& Blanchard, 2009, p. 242).

In Canada, data from the 2009-2010 school year indicate that more than 71,000 students were using the LearnNowBC online system and that one out of every three students takes at least one online course before graduating from secondary school (Premier's Technology Council, 2010). During the 2011-2012 academic year, the courses with the highest enrollment were at the senior secondary level; however, courses from kindergarten to grade 12 are available to BC students through distributed learning schools (British Columbia M inistry of Education, Business, Technology, and O nline Service, 2012). Distributed learning schools offer courses for any school-aged student or nongraduated adult in BC in accordance with BC M inistry of Education quality standards. Tutorials and early learning supports are also available on the LearnNowBC website (http://www.learnnowbc.ca), including information for parents, students, and teachers about online learning.

Created in 2001, BC's Premier's Technology Council (2010) has noted a need to emphasize technology and e-learning in addressing potential future shortages in work force skills. Yet, early childhood educators and primary teachers, although technologically savvy in their personal practices, appear not to embrace digital tools in classrooms. A deficit model of digital engagement suggests that media make children "passive learners" and take away from more worthwhile activities, such as outdoor play (R azfar \& Yang, 2010). Wolfe and Flewitt (2010) found that their participant early childhood educators were concerned that a technology-dominated childhood was toxic because of increased inactivity and "an inability to critically evaluate competing sources of information" (p. 391). Further, they were concerned that technology was damaging to "family time" in that communication among family members suffered as children were allowed to absorb themselves in digital worlds. Other reasons for the lack of digital uptake by educators comes from a perceived lack of experience and expertise and limited curriculum instruction supports (Murphy \& Beggs, 2003; Plowman \& Stephen, 2005; RobertsHolmes, 2013; Wolfe \& Flewitt, 2010).

Educators also believe that children spend enough time engaging with digital screens, yet not all children have the same level of access to new technologies and digital media. Children enter schools with varying levels of technology experience. For example, Dodge, H usain, and Duke (2011) found that 16\% of their kindergarten to grade 2 participants were unable to successfully connect to the Internet, $16 \%$ of participants needed assistance opening a website, and 54\% needed the researcher to open the site entirely and did not understand the "back" button. Schools can play a role in addressing equity issues by providing opportunities for children to learn and engage with 
digital media. The National A ssociation for the Education of Young Children (NAEYC) has acknowledged that early childhood care settings could narrow the gap between children from homes with less access and those with more access through "skillful teaching and complementary resources" (2012, p. 4) and access for exploration of digital tools, such as digital cameras or audio and video recorders.

Lankshear and Knobel (2004) describe the "world of texts" (p. 5) as significantly changed, becoming multimodal and incorporating print, images, and sound, yet print is the major focus of instruction in many kindergarten and primary classrooms. Schools maintain differences between old and new technologies while children move seamlessly between technologies and do not distinguish between them (Davidson, 2009).

The purpose of this paper is to present a critical analysis of B ritish Columbia's early learning curricula concerning $21^{\text {st }}$-century education. The data sources were the Premier's Technology Council: A Vision for 21 $1^{\text {st }}$ Century Education (Premier's Technology Council, 2010), BC's Education Plan (British Columbia M inistry of Education, 2011) and the Kindergarten Curriculum Package (British Columbia M inistry of Education, September 2010). The paper critically examines the discourse in the Premier's Technology Council's vision and BC's Education Plan as well as the current educational review underway in British Columbia, and compares and contrasts these visions. The paper then examines the Kindergarten Curriculum Package, the prescribed document for BC teachers to use in classrooms,

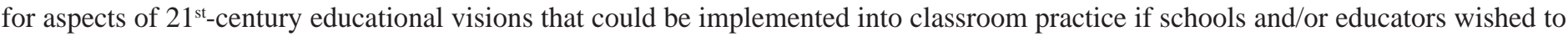

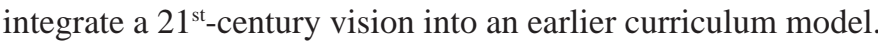

\section{Theoretical Background}

Conceptions of early literacy development have experienced a significant shift in the first decade of the millennium. Print-based literacy is no longer seen as the exclusive medium toward children's literacy development; rather, it is recognized that a more "robust semiotic field that includes a variety of electronic media" (Razfar \& Yang, 2010, p. 122) has proliferated into the daily lives of adults and children. Both adults and children are "expected to fluently interact in an increasingly diverse world using multiple mediational tools and modalities" (p. 122). Yet, literacy within preschools and schools remains entrenched in a print-based literacy model despite educational theorists and researchers arguing that literacy needs to be redefined to reflect new literacies. Street (1984) distinguishes between "autonomous models" and "ideological models" of literacy. A utonomous models of literacy adhere to a belief that literacy development occurs individually within the learner's head, while ideological models recognize the social and cultural aspects of literacy development, which are unique within differing communities. In the $21^{\text {st }}$ century, an ideological model of literacy would recognize and value the digital literacy practices used in modern society. Redefining literacy to an ideological model perspective would allow schools to respond to new literacies and not risk using a curricul um that bears little connection to children's current or future lives (B urnett, 2009; Gee, 2004; Goodwyn, 2000; Pahl \& Rowsell, 2005). One rationale for the lack of recognition of new literacies is that some educators are not ready to recognize the implications technology holds for literacy because they may not problematize the socially and culturally embedded practices relating to print literacy (Reinking, Labbo, \& M cK enna, 2000). Rather, educators may focus on the ways in which technology can be used to teach about print, such as mastery of the al phabetic principle.

A lthough M arsh and Singleton (2009) argue that communication has always involved many and varied modes, such as the symbol and drawing depictions found in caves of prehistoric peoples, they argue that "letters, words and symbols will continue to be an integral part of many texts" (p. 1). Reading and writing will remain integral to human life; however, the world has changed. People now use electronic devices for their reading and writing activities. These devices have developed to such sophisticated levels that searching the World Wide Web is easily done from a cellular phone and communication en masse is completed instantly through social media sites such as Twitter and Facebook. And, while technology and literacy continue to intertwine in the real world, most curricula and educational systems remain focused on developing and testing print-based literacy skills through standardized attainment tests which prioritize print literacy skills (Burnett, 2009).

Like the term literacy, digital literacy has a wide-ranging definition (Burnett, 2009). Marsh's (2004) techno-literacy refers to literacy practices and events conducted through new technologies, along with old technologies that are embedded in new technologies through updated tooling, such as cellular phones. Digital literacy may be narrowed in definition to focus on digitally based text production (Burnett, 2009). This paper follows Marsh (2004) and Burnett (2009) to define digital literacy as practices and events conducted through digitally based text production, such as a redramatization of a favourite television or movie sequence or creation of a story through photovoice software.

A lso relevant to this paper is a focus on varied and situated social practices informing and guiding digital text production, following a sociocultural model. Learning, from a sociocultural viewpoint, is fundamentally social and is mediated by signs, symbols, and cultural 
artifacts used over generations (Razfar \& Yang, 2010). Within this perspective, literacy learning cannot be "abstracted from cultural practices in which it is nested" (Razfar \& Gutierrez, 2003, p. 34), and it must be recognized that each generation transforms the symbols, signs, and tools of the earlier generations to better suit its purposes (Razfar \& Yang, 2010). In a digital age, children engage in meaning making by using and experiencing the digital tools of the relevant adults in their lives. A dults scaffold children into technoliteracy practices by demonstrating uses of a variety of devices (Plowman, Stevenson, Stephen, \& McPake, 2012; Shifflet, Toledo, \& M attoon, 2012). Children can then "pretend their way into literacies by 'playing at' using computers, iPads, or cellphones as they try on technologically savvy user identities" (Wohlwend, 2010, p. 145). Like traditional literacy practices, digital texts operate within social and cultural traditions and may not be isolated once inside a classroom, whether physically available or not. For example, Wohlwend (2009) describes a kindergarten boy cutting and pasting paper to create his ow n iPod. His iPod included headphones and an "LCD screen display" (p. 126) so that he could read and view "Thomas and Friends" (p. 126) with his classroom peers.

Burnett (2009) argues that studies examining technology use in the classroom focus on print-based notions of literacy and narrowly review technology's use and appropriateness in the classroom. She writes:

Some studies seem to neglect aspects of technology use because they are preoccupied by print-based literacy outcomes or teaching approaches.... It may be that when assumptions relating to print literacy drive the focus and methodology of studies, research inevitably reinforces rather than challenges existing models of literacy. (p. 31)

In a similar vein to Burnett (2009), Marsh (2004) argues that a focus on literacy as a "paper-based activity" (p. 52) is no longer appropriate given the range of digital tools children access daily in their lives, such as televisions, computers, and smartphones. A focus on literacy as "relating to print-based texts" (Marsh, 2004, p. 52) further marginalizes some children's vast skill set that is brought with them upon entry to the classroom. Suggested reasons for a lack of attention to children's burgeoning digital literacy skills may stem from educators' ow n lack of knowledge and understanding of digital device uses or a negative viewpoint toward technology and digital media use in childhood by educators (Marsh, 2004; Wolfe \& Flewitt, 2010).

Despite concerns over children's digital uses, children are still engaging in techno-literacy practices in their homes (e.g., using iPads to draw or search engines such as Google for information retrieval). Thus researchers have begun to examine the digital activities of children in their homes and classrooms. In examining primary- and secondary-aged children's home- and school-based computer activity through questionnaires, M urphy and Beggs (2003) found that, at home, children had choice surrounding computer activities which left ample time for exploration and incidental learning. In contrast, school-based activities were teacher controlled, and limited time was designated for use. In her survey of Internet use among grade 1 and 2 students, J ohnson (2010) found that children enjoying Internet use in the home had an inverse effect on those children enjoying Internet use in the classroom. Students who used the Internet more in their homes used the Internet less in school, which J ohnson suggests may be due to restrictions and limitations placed on Internet use in the classroom by the teacher. Johnson explains that, in the home, children using the Internet enjoyed fewer restrictions and controls. Wolfe and Flewitt (2010) documented how 3- and 4-year-old children used traditional and new technologies in their home and preschool to develop literacy knowledge and skills. In one particular subset of participants, the researchers found that the three-and-a-half-year-old twin female participants had a strong interest in computers and were provided opportunities, with their mother's encouragement, to engage with the technology. They observed the girls developing ability to read and respond to graphic images on the computer screen, even when audio functions were muted. A lthough computer use was not encouraged in their preschool, computers were accessible, and toward the end of the study the girls were observed learning how to log in to the computer, a procedure that "tested their abilities to match upper and lower case letters in their names with the symbols on the keyboard" (p. 395). Wolfe and Flewitt conclude that some young children are capable of "navigating around screens, connecting and taking meanings from a myriad of interrelated images (still and moving), words and sounds" (p. 397), while others may not have similar access to computers and Internet. Therefore, they argue, schools and educators need to provide children with opportunities to become proficient and literate in the digital world. Given the influx of digital tools and media within society which are consistently being accessed by younger and younger children, it is necessary for schools and school boards to begin reflecting these practices through classroom activity and curriculum. I next examine British Columbia's vision of

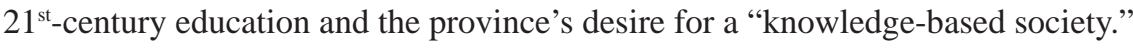

\section{$21^{\text {st }}$-C entury E ducation in British Columbia}

In A ugust 2001, then British Columbia Premier Gordon Campbell announced the formation of the Premier's Technology Council (PTC), which included 23 members from the private sector and academia, and gave them the responsibility of reporting to the Premier on all technology issues concerning B ritish Columbia and its citizens. Currently, the PTC has urged government to work toward the creation of a knowledge-based society in British Columbia, arguing that a knowledge-based society improves the lives of British 
Columbians through improved health and education services and the creation of more jobs, which could generate economic growth and improved government efficiency. To accomplish these outcomes, three key areas were recommended to act as pillars in development: infrastructure, government services, and a knowledge-based economy. As a government service, BC's education system underwent review. The PTC suggests including smooth delivery of services across government organizations and elementary, secondary, and

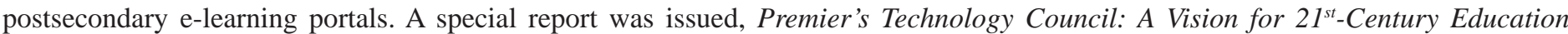
(2010), envisioning how an education system responsible for creating citizens of a knowledge-based society could operate and function.

Separately from the Premier's Technology Council, beginning in 2010, the Ministry of Education, in conjunction with stakeholders throughout $B C$, began a review of the education system with a goal of transformation to better meet the needs of learners (BC $M$ inistry of Education, 2012). BC's E ducation Plan (2011) was established to outline and guide the M inistry of Education's directions and actions as the education system transformed. N ovember 2011 saw the formation of the C urricul um and A ssessment Framework A dvisory Group. The role of this group was to make recommendations to the M inistry of Education on curriculum and assessment directions. To date, the $B C$ M inistry of E ducation has stated that it is

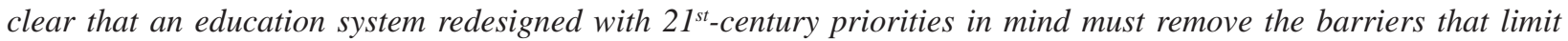
teachers' ability to innovate and personalize learning based on students' needs and the community context. ... . However, to truly transform education, the $\mathrm{BC}$ education system must empower innovation throughout the province. $(2012$, p. 2)

With a desire for BC to situate itself as a knowledge-based society, both the PTC and BC's E ducation Plan (BC E d) envision an education system operating on the notion of "personalized learning," which would give students a larger responsibility in creating an individual and personalized curriculum so as to "explore an educational path that is best suited to their interests, their capabilities, and their chosen future" (Premier's Technology Council, 2010, p. 2). Learning would emphasize skill over content, with project-based learning being central and technology being used to assess student progress continually, rather than at the conclusion of units. The use of technology in the classroom would provide a "better link between what kids learn at school and what they experience and learn in their everyday lives" (BC's E ducation Plan, 2011, p. 2) and would also provide parents a better opportunity to be involved in planning their child's education.

It is worth noting that BC Ed, although promoting greater student self-assessment, will continue to monitor student progress through "rigorous province-wide assessments" (BC's E ducation Plan, 2011, p. 4). The rationale for these assessments is that "effective classroom assessment" (p. 4) is seen as necessary for student success, and will be "even more vital in a more personalized learning environment" (p. 4). However, province-wide standardized examinations seem to counter $21^{\text {st }}$-century learning notions of personalized learning. BC Ed argues that technology will provide greater access to "richer information, and more consistency across the province on student progress" (p. 4), yet it does not indicate how these tests will be constructed given that students will be responsible for creating an individual and personal ized curriculum. Current assessment prioritizes print-based literacy skills and requires all students to be assessed with the same test during a predetermined examination period.

\section{M ethods}

Discourse on $21^{\text {st }}$-century learning has gained traction in the education community through the creation of documents and websites, yet schools and teachers are still bound to learning outcomes contained in earlier curricula. The aim of this paper is to present a

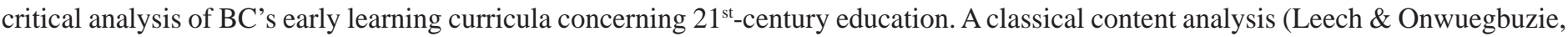
2008) of BC government documents was undertaken. Specifically, Premier's Technology Council: A Vision for $21^{\text {st- }}$ Century Education (Premier's Technology Council, 2010) and BC's E ducation Plan (BC Ed; B ritish Columbia M inistry of Education, 2011) were analyzed.

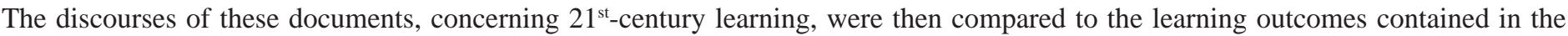
K indergarten Curriculum Package (B ritish Columbia M inistry of Education, 2010). The aim of this analysis was to juxtapose the vision of the Premier's Technology Council (PTC) and the reality of the current curriculum that guides teachers' practice in BC in the early years of schooling.

The Kindergarten Curriculum Package was analyzed for words and/or phrases consistent with the PTC's vision and BC Ed as needs associated with a knowledge-based society. For example, the needs for "technology literacy," "communications and media literacy," and "collaboration and teamwork" were noted within each document as core skills and needs for citizens to successfully function in a knowledge-based society. 


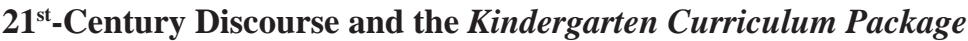

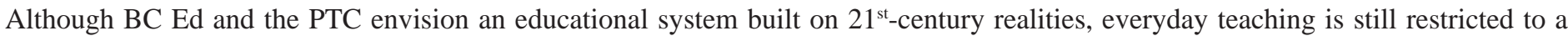
structured curriculum guided by prescribed learning outcomes, which reflects a traditional orientation. Content in the Kindergarten Curriculum Package focuses on prescribed learning outcomes that children are expected to meet within a school year. Content is categorized into domains of English/French language arts, social studies, mathematics, science, physical education, arts education (dance, drama, music, and visual arts), health and career education, and daily physical activity. Regardless of the document's prescriptive nature, it provides this caveat for schools:

Schools are responsible for ensuring that all Prescribed Learning 0 utcomes for each required area of study are met; however, schools have flexibility in determining how delivery of the curriculum can best take place. (p. 5, emphasis added)

Although the current curriculum provides little flexibility as to what may be taught, there is space for schools and/or educators who so

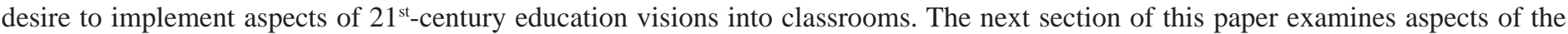
Kindergarten Curriculum Package which could align with the PTC's and BC Ed's discourses.

The two kindergarten domains most suited to $21^{\text {st }}$-century education discourse are English language arts and art education, specifically, the visual arts domain. Although examples of "suggested achievement indicators" remain entrenched in print-based literacy, there is space for children's digital understandings and knowledge to become apparent to teachers. As Dyson (2003) shows in The Brothers and Sisters Learn To Write: Popular Literacies in Childhood and School Cultures, children bring popular literacies from outside school into classroom practice. Dyson showed how her participants were able to mediate school-based literacy practices with knowledge gained through popular music, sports culture, and video games. J ust as R ita, Dyson's participant teacher, provided space and opportunity for her students to engage in writing activities based on popular media culture, BC kindergarten teachers may allow a space for their students to utilize knowledge and skills learned from the digital devices they use outside the classroom.

U nder "Iearning reading (and viewing) and extended thinking," prescribed learning outcome B2 states: "respond to literature through a variety of activities (e.g., role playing, art, music, choral reading, talking)" (p. 13) and describes a suggested achievement indicator of "connect information and events in texts to self, personal experiences, and to other texts including media texts (e.g., television shows and movies)" (p. 13). Although not expressly indicating digital texts, the use of "media" allows teachers to make assessments based on students' articulations and connections to texts such as video games, websites, or smartphone applications.

A Iso suggested as an indicator is "create a representation (e.g., draw a picture, dramatize feelings, create a new page for a story" (p. 13). This description is quite open ended and allows for teachers to recognize a variety of ways that something may be represented, including digital creations. Following a $21^{\text {st }}$-century education vision, allowing students the opportunity to create as they so desire aligns with the vision of greater flexibility and student choice. Granted, choosing to create a representation is unequal to designing and articulating one's own educational path; however, it is this type of open-ended indicator that would allow for student design.

A nother suggested achievement indicator for B2 states: "make connections between literary experiences and imaginative play (e.g., puppets, housekeeping centre, dress up centre)" (p. 13). Wohlwend (2009) describes two first-grade boys in a print-centric classroom engaging in a paper-based invented game based on their favourite video game, Digimon Rumble A rena. On a single sheet of paper, the boys created a "screen view," including a "life bar" to gauge the health of each of their characters. The boys took turns attacking one another until completion of the game. A close observer of these young boys engaged in peer play in their classroom environment might see these boys as responding to the "literature" of their favourite videogame and producing a paper-based version of the game. The complex understanding needed to create their own game might indicate a strong comprehension that could be applied to other texts read and used in their classroom.

Prescribed learning outcome B 7, under "learning reading (and viewing) and extended thinking," requires students to "demonstrate understanding of concepts about print and concepts about books" (p. 15) and suggests achievement indicators such as the following: "demonstrate understanding that letters represent sounds that written words convey meaning (e.g., read short labels, familiar signs)" (p. 15) and "use sounding out to demonstrate that the sequence of letters in a written word represents the sequence of sounds (i.e., phonemes) in a spoken word (i.e., alphabetic principle)" (p. 15). Northrop and Killeen (2013) provide a framework for teachers to "teach letter-name phonics with iPad integration" (p. 533), using "abc PocketPhonics (Apps in my Pocket Ltd, \$2.99; Lite version is free)" (p. 533). They lay out a lesson plan which seamlessly integrates non-iPad use instruction with iPad-use instruction and argue that 
this process will highlight the learning children will be undertaking, and not have them simply "pushing buttons and going through the motions" (p. 536). While helpful to less "technology savvy" teachers, some researchers (Marsh \& Singleton, 2009; Reinking, Labbo, \& M cK enna, 2000) may argue that this type of lesson uses technology to improve print literacy skills.

A nother feature of the English language arts domain is "learning writing (and representing) and extended thinking." Prescribed learning outcome C1 states: "create simple messages using a combination of pictures, symbols, letters, and words to convey meaning" ( $p$. 16) and suggests that a student achieving this standard will "write and represent using a variety of tools and media (e.g., crayons, paper, computer, chalkboard, coloured markers, cardboard)" (p. 16, emphasis added). The suggested achievement indicator "write and represent for a variety of purposes and in different forms" (p. 16) could allow for individual student-teacher discussion or larger classroom discussions about different types of writing and the different ways people write, extending beyond grocery lists to include online and/or smartphone-based texts. For example, teachers might ask students to reflect on ways that parents or significant adults in their lives use their smartphones to write and record information.

The arts education domain, specifically the area of visual arts, contains aspects that connect with $21^{\text {st }}$-century visions of education. Prescribed learning outcomeA 3, "experiment with a variety of materials, technologies, and processes to make images" (p. 31), suggests that achievement may be indicated by students "us[ing] technologies, such as computers, paint brushes, scissors, and cameras to create a variety of images" (p. 31, emphasis added). A s well, B2, "identify and apply a variety of materials, technologies, and processes to create images" (p. 32), suggests that students could name and use technologies such as computers and cameras to fulfill this prescribed learning outcome. For example, children could use digital cameras to photograph themselves creating particular facial expressions and label these images using appropriate vocabulary, which would al so target learning outcome A 7, "experiment with language and demonstrate enhanced vocabulary usage [such as] begin to use descriptive words to describe own feelings and the feelings of others" (p. 11).

Under the learning area "drama," specifically "presenting and performing," prescribed learning outcome D2 asks students to "respond to a drama presentation" (p. 25) and suggests that this activity may be completed by a student using "stories, pictures, or movement to communicate personal thoughts, images, and feelings experienced in response to drama" (p. 25). Although not specifically referencing digital texts or media, a response using digital tools is foreseeable, such as the reenactment of the Digimon Rumble A rena vignette (Burnett, 2009) or students using digital storytelling software to articulate their responses. Software such as iM ovie or Photostory allows users to create stories using still photographs, video, audio, and printed text. Hill (2010) describes a year $1 / 2$ classroom in A ustralia using Photostory during a fairy tale unit. Digital media lessons were incorporated into a mix of traditional print-based methods, such as reading fairy tales, with new media, such as watching Hoodwinked (Edwards, 2005), an animated movie that tells the Little Red Riding Hood story from multiple perspectives. Using an interactive white board, the teacher scaffolded the children's learning through brainstorming, mapping, and communication using audio, visual, and kinesthetic means. She deconstructed fairy tale features, such as good versus evil and heroes/heroines. Eventually the children created their own fairy tales, first in print and later adapted to Photostory. Not only did children fulfill print-based learning outcomes, they learned to communicate meaning through pictures and were learning about "the choices authors and film directors make about what to include and leave out, how to create visual and sound effects to create meaning" (p. 330).

Finally, under the domain "social studies- economy and technology," students are required to "identify examples of technologies used in their lives" (D3, p. 51). D3 suggests that students "use pictures and discussion to identify examples of technologies they use at school and at home (e.g., pencil, photocopier, computer, telephone, television, refrigerator, bicycle, assertive technologies for people with special needs)" (p. 51) to achieve this standard. This prescribed learning outcome presents students with the opportunity to articulate knowledge and understanding of the $21^{\text {st }}$-century core needs of technological literacy and communication and media literacy, as outlined by the PTC (2010). A s well, conversations about home and classroom technologies could spark a discussion of similarities and differences between home and school environments. They would also al low teachers an opportunity to discover some of the devices and tools students are using in their homes. Students could be asked to take pictures of different technologies used in their homes and bring the images to class for discussion. Students could explain why each image was selected and what it represents to them.

To summarize, in this researcher's view, although not explicitly suggested, there are aspects of the Kindergarten Curriculum Package that incorporate aspects of $21^{\text {st }}$-century learning. More specifically, the domains of language arts and arts education present opportunities for educators to provide digital media and technology for children's uses that would allow children to show their learning and growth in accordance with prescribed learning outcomes. Yet it is noteworthy that the domains of science and social studies, areas one might expect new technologies and digital media to be referenced in, present no meaningful opportunities for teachers to incorporate $21^{\text {st. }}$ century education ideals as expressed by either the PTC or BC M inistry of Education documents. 


\section{Conclusion}

BC is experiencing "an exciting time of change for education" (B ritish Columbia M inistry of Education, 2011, p. 2). These proposed changes will significantly alter the education system as society has come to know it and will present many challenges. Undergoing educational and curricular change is not an easy feat. $M$ any stakeholders hold differing beliefs and positions about what should be taught and how. While many schools and teachers are ready and willing to embrace techno-literacies, many others believe that digital practices are devel opmentally inappropriate for young children. Dissenters argue that digital media create passive learners and that early education should focus instead on providing children with "real" materials, such as plants, animals, books, and traditional play centres, to explore meaning. There are also concerns about screen effects on devel oping brains and increased inactivity leading to obesity and other health issues (A merican A cademy of Pediatrics, 2011; National A ssociation for the Education of Young Children, 2012). But there are also concerns about schools continuing to ignore the increased use of digital media by their students and using outdated curricula irrel evant to students' out-of-school lives (B urnett, 2009). The Premier's Technology Council and BC's E ducation Plan are supporting visions of how the $B C$ education system can build a knowledge-based society by advocating that students engage with digital knowledge during school hours. However, with standardized tests that continue to privilege print literacy skills, those skills will continue to drive large portions of the curriculum. And although we have moved from using digital technology in schools to measure print literacy skills, schools need to address "literacy of technology A N D literacy through technology" (Razfar \& Yang, 2010, p. 123) and provide spaces for children to become aware of the "multiple functions of language and literacy content, as well as how the medium/technology shapes it" (Razfar \& Yang, 2010, p. 123).

Although BC's M inistry of Education has developed an action plan, the BC Education Plan, in an effort to foster and encourage $21^{\text {st }}$ century education, there is still a long road ahead before the transformational education system envisioned by the Premier's Technology Council comes to fruition. Until that time, creative teachers will continue to find spaces for $21^{\text {st }}$-century education practices in $20^{\text {th }}$ century curricula models.

\section{R eferences}

A merican A cademy of Pediatrics. (2011). Policy statement: M edia use by children younger than 2 years. P ediatrics, 128(5), 1-7. Retrieved from: http://pediatrics.aappublications. org/content/early/2011/10/12/peds.2011-1753

B ritish Columbia M inistry of Education. (2010, September). Kindergarten curriculum package. Victoria, BC: A uthor.

British Columbia M inistry of Education. (2011). BC's education plan. Victoria, BC: A uthor. Retrieved from: http://www.bcedplan.ca/assets/pdf/bc_edu_plan.pdf

B ritish Columbia M inistry of Education. (2012). Enabling innovation: Transforming curriculum and assessment. Victoria, BC: A uthor. Retrieved from: http://www.bced.gov. bc.ca/irp/docs/ca transformation.pdf

B ritish Columbia M inistry of Education, Business, Technology, and Online Service. (2012). LNBC monthly statistical report and financial statements fiscal year April 2011M arch 2012. Retrieved from: http://docs.openinfo.gov.bc.ca/d43466113a_response_package_edu-2013-00058.pdf

B urnett, C. (2009). Research into literacy and technology in primary classrooms: A n exploration of understandings generated by recent studies. J ournal of Research in Reading, 32(1), 22-37. doi: 10.1111/j.1467-9817.2008.01379.x

Davidson, C. (2009). Y oung children's engagement with digital texts and literacies in the home: Pressing matters for the teaching of English in the early years of schooling. English Teaching: Practice and Critique, 8(3), 36-54.

Dodge, A., Husain, N., \& Duke, N. (2011). Connected kids? K-2 children's use and understanding of the internet. Language Arts, 89(2), 86-98.

Dyson, A. (2003). The brothers and sisters learn to write: Popular literacies in childhood and school cultures. N ew York, NY: Teachers College Press.

Gee, J. (2004). Situated language and learning: A critique of traditional schooling. London, UK: Routledge.

Goodwyn, A . (Ed.) (2000). English in the digital age: Information and communications technology and the teaching of English. London, UK: Cassell.

Hill, S. (2010). The millennium generation: Teacher-researchers exploring new forms of literacy. Journal of Early Childhood Literacy, 10(3), 314-340. doi: $10.1177 / 1468798410372820$

Hisrich, K ., \& Blanchard, J. (2009). Digital media and emergent literacy. Computers in the Schools, 26, 240-255. doi:10.1080/07380560903360160

Johnson, G. (2010). Young children's internet use at home and school: Patterns and profiles. J ournal of Early Childhood Research, 8(3), 282-293. doi: 10.1177/1476718X10379783

Lankshear, C., \& Knobel, M. (2004). Text-related roles of the digitally 'at home.' Paper presented at the American Education Research Association Annual Meeting, April 15, 
2004. Retrieved from: http://everydayliteracies.net/files/roles.html

Leech, N., \& Onwuegbuzie, A. (2008). Qualitative data analysis: A compendium of techniques and a framework for selection for school psychology research and beyond. School Psychology Quarterly, 23(4), 587-604. doi:10.1037/1045-3830.23.4.587

Marsh, J. (2004). The techno-literacy practices of young children. J ournal of Early Childhood Research, 2(1), 51-66. doi: 10.1177/1476718X0421003

Marsh, J., Brooks, G., Hughes, J., Ritchie, L., Roberts, S., \& Wright, K. (2005). Digital beginnings: Young children's use of popular culture, media, and new technologies. Sheffield, UK: Literacy Research Centre, University of Sheffield.

Marsh, J., \& Singleton, C. (2009). Editorial: Literacy and technology: Questions of relationship. Journal of Research in Reading, 32(1), 1-5. doi:10.1111/j.14679817.2008.01377.x

M urphy, C., \& B eggs, J. (2003). Primary pupils' and teachers' use of computers at home and school. British J ournal of Educational Technology, 34, 79-83. doi:10.1111/14678535.d01-9

National A ssociation for the Education of Young Children. (2012). Technology and interactive media as tools in early childhood programs serving children from birth through age 8. A joint position statement of the National A ssociation for the Education of Young Children and the Fred Rogers Center for Early Learning and Children's M edia at Saint Vincent College. Washington, DC: A uthor.

Northrop, L., \& Killeen, E. (2013). A framework for using iPads to build early literacy skills. The Reading Teacher, 66(7), 531-537. doi:10.1002/TRTR.1155

Pahl, K., \& Rowsell, J. (2005). Literacy and education: Understanding the new literacy studies in the classroom. London, UK: Paul Chapman.

Plowman, L., M cPake, J., \& Stephen, C. (2008). Just picking it up? Young children learning with technology at home. Cambridge J ournal of Education, 38(3), 303-319. doi:10.1080/03057640802287564

Plowman, L., \& Stephen, C. (2005). Children, play, and computers in preschool education. British J ournal of Educational Technology, 36(2), $145-157$.

Plowman, L., Stevenson, O., Stephen, C., \& M cPake, J. (2012). Preschool children's learning with technology at home. Computers \& Education, 59(1), 30-37. doi:10.1016/j. compedu.2011.11.014

Premier's Technology Council. (2010, December). Premier's technology council: A vision for 21 1 st-century education. Vancouver, BC: A uthor. Retrieved from: http://www.gov. bc.ca/premier/attachments/PTC_vision for_education.pdf

Razfar, A., \& Gutierrez, K. (2003). Reconceptualizing early childhood literacy: The sociocultural influence. In N. Hall, J. Larson, \& J. Marsh (Eds.), Handbook of early childhood literacy (pp. 34-47). London, UK: SAGE.

Razfar, A ., \& Yang, E. (2010). Digital, hybrid and multilingual literacies in early childhood. Language Arts, 88(2), 114-124.

Reinking, D., Labbo, L.D., \& M cK enna, M . (2000). From assimilation to accommodation: A developmental framework for integrating digital technologies into literacy research and instruction. J ournal of Research in Reading, 23(2), 110-122.

Roberts-Holmes, G. (2013). Playful and creative ICT pedagogical framing: A nursery school case study. Early Child D evelopment and Care, 184(1), 1-14. doi:10.1080/0300 4430.2013 .772991

Shifflet, R., Toledo, C., \& Mattoon, C. (2012). Touch tablet surprises: A preschool teacher’s story. Young Children, 67(3), 36-41.

Street, B. (1984). Literacy in theory and practice. Cambridge, UK: Press Syndicate of the U niversity of Cambridge.

Wohlwend, K. (2009). Early adopters: Playing new literacies and pretending new technologies in print-centric classrooms. J ournal of Early Childhood Literacy, 9(2), 117-140. doi:10.1177/1468798409105583

Wohlwend, K. (2010). A is for avatar: Young children in literacy 2.0 worlds and literacy 1.0 schools. Language Arts, 88(2), 144-152.

Wolfe, S., \& Flewitt, R. (2010). New technologies, new multimodal literacy practices, and young children's metacognitive development. Cambridge J ournal of Education, 40(4), 387-399. doi:10.1080/0305764X.2010.526589 


\title{
Are We Ready? Early Childhood E ducator Students and Perceived Preparedness for School-Based Special E ducation
}

\author{
K imberly M aich and Carmen $\mathrm{H}$ all
}

\begin{abstract}
K imberly Maich, PhD, OCT, is an assistant professor in the department of teacher education at Brock University in Niagara, Ontario. Her background has been primarily as a resource teacher in the K-12 school system from coast to coast in Canada, and her research is focused on students with autism spectrum disorders and other exceptionalities, their peers, and their teachers. She is completing a graduate degree in applied behaviour analysis at B rock U niversity. Email: kmaich@ brocku.ca

Carmen Hall, MC, C CC, BCBA, is a professor and the coordinator of the autism and behaviour science program at Fanshawe College in London, Ontario. She comes to postsecondary education from a clinical background, focusing her teaching on applied behaviour analysis and her research on peer-mediated social skills instruction for children with autism spectrum disorders. She is a PhD student in clinical psychology at Saybrook U niversity in San Francisco. Email: cl hall@ fanshawec.ca
\end{abstract}

This paper describes a small-scale, single-region research project to investigate early childhood educator (ECE) students' understanding of special education in the kindergarten context thathas been in placein O ntario schools since2010. Theperceived preparedness of five ECE students on placement in kindergarten classrooms was evaluated through pre- and poststudy questionnaires and through interviews with five Ontario-certified teachers teaching early learners and experienced with mentoring ECE students. Results demonstrated that ECE students' selfratings of combined knowledge, exposure, and experience with school-based special education did not significantly change, and these student rankings fell in the very low to moderate ratings overall (i.e., scores of 1 to 2 on a 5-point scale). Comments from the Ontario-certified teachers emerged in three main themes, including (1) strong foundations (i.e., skills and knowledge); (2) education for all (e.g., students who may not yet be formally identified); and, (3) universal frameworks (i.e., for all students with diverse needs). Suggestions for ECE preparedness and ECE curriculum changes are included.
In 2010, Ontario began to implement a new province-wide, government-sponsored initiative for all early learners-including children with special needs - which continues to be piloted in school boards until its full implementation, namely, full-day kindergarten (FDK ; O ntario M inistry of Education, 2010b; O ntario $M$ inistry of Education, 2013). K indergarten itself, of course, is not a new concept in the sphere of publicly funded, institutionally based education. With the advent of Friedrich Froebel's first usage of the term kindergarten in the 1800s (Allen, 1986), it was conceptualized for supporting the growth and development of young children. By the mid-1800s, its outgrowths were already established in the well-populated region of what is now known as southern Ontario (Nixon, 1994). By September 2014, FDK for young children aged 4 and 5 was fully implemented across the province (Ontario M inistry of Education, 2013).

One of the new initiatives to support this unique project is the on-site collaboration among educators with varied roles, designed to share educational responsibilities (Legislative Assembly of Ontario, 2010) and meet the needs of all the young learners in a play-based early learning classroom environment (Ontario

Ministry of Education, 2010a). More specifically, this initiative is supported by professional collaboration between early childhood educators registered with the College of Early Childhood Educators (2012) as registered ECES (RECES) and teachers registered with the Ontario College of Teachers (n.d.) as Ontario-certified teachers (OCTs) working as a teaching team to support the learning and development of junior and senior kindergarten students (Lewington, 2010). This collaborative strategy was envisioned in this local context by Charles Pascal (2009), who imagined the possibility and potential of Ontario's FDK - With our Best Future in M ind-as follows: "A blend of K indergarten teachers and ECEs would work best [and] educator teams have been found to add to the strengths of the professional preparation and skill sets of both teachers and ECEs" (p. 33). It is important to recognize that this initiative supports all learners in the publicly funded FDK program, and that these youngest learners are a diverse group in many ways, including students with special educational needs. In other words, educators need to support all students- and future educators need to learn to support all students-from the perspective of universal design, rather than as a strict dichotomy of "typical" students and those with "special needs." Instead of circumventing the development of specialized knowledge, however, a framework of universal design for learning $(U D L)$ assures the proactive devel opment of educational strategies for all learners with diverse needs, creating "a foundation for likely success from which [educators] can later address the particular needs of individual students" (Stockall, Dennis, \& M iller, 2012, p. 10).

Future educator team members, teacher candidates, and ECE students - the latter being the focus of this project- engage in multiple, sustained engagements as practicum experiences in the school system as part of devel oping such a foundation. Such experiences undergo 
not only academic supervision, but onsite professional mentoring in order to "connect effective strategies to a teacher's actual interactions with young children" (Chu, 2012, p. 19). David Kolb's holistic experiential learning theory (1984) emphasizes the role of experience in learning. In the context of experiential learning theory, learning is characterized as a continuous process where concepts and ideas are "derived from and continuously modified [and] formed and re-formed through experience" (p. 28). Throughout this everyday process, self-directed learners open themselves objectively to new experiences, and thus experience tension, conflict, and resolution as they reflect and integrate these new experiences as learning. This process applies not only to new information but to the cyclical adaptation of the whole person throughout life in all settings, or the "integrated functioning of the total organism-thinking, feeling, perceiving, and behaving" (p. 31). The environment is an essential component in the back-and-forth transactional nature of learning, which is not only intrapersonal but also active and objective, or socially based. These transactions between the subjective and the objective devel op knowledge; Kolb writes that "learning is the process whereby knowledge is created through the transformation of experience" (p. 38).

With today's emphasis in Ontario on inclusive school and class environments (Bennett \& Dworet, 2013), all educators- both OCTs and RECEs- will encounter children with exceptionalities and will need to respond to such needs with knowledgeable navigation of school-based special education programs and services as a team of what the Ontario Ministry of Education (2010a) refers to as "key educators of children who have special education needs" (p. 29). In the 2010/2011 school year, for example, 15.56\% of all students in the entire school-based population in Ontario were receiving special educational services, for a total of 319, 214 students. Eighty-three percent of these students were taught in inclusive classroom environments, and only $60 \%$ were formally identified with exceptionalities through the Identification, Placement, and Review Committee (IPRC; Bennett, 2012). In the kindergarten context, it is likely that the kindergarten teaching teams will also encounter such students every year in each kindergarten classroom as part of their responsibility in supporting inclusive classrooms (Pascal, 2009); however, these students may not yet be either clinically diagnosed or identified as exceptional in the school system. Since the seminal Special Education Transformation (Bennett \& Wynne, 2006) report emphasized "improved learning for all students receiving special education programs and services" (p.25) through the coordination of "all ministry initiatives related to improving student achievement (e.g., Student Success, L iteracy and N umeracy Secretariat) to include students who have special education needs" (p.25), it seems reasonable that this edict would apply to all of our classroom-based educators in the FDK initiative, as well. A fter all,

early intervention is multidisciplinary. This is an important difference from school age supports for children with disabilities and/or special educational needs. In schools, while there may be itinerant supports such as child and youth workers, social workers, speech and language pathologists, and psychologists, the primary service providers are teachers. (Underwood, 2012, p. 127)

These changes mean that RECEs will be adjusting to a novel role in a new environment, supporting all students in kindergarten with diverse skills and abilities (Bennett, 2009; Stockall, Dennis, \& M iller, 2012). This role includes exposure and support in the area of school-based special education services, for needs that may be undetected prior to school entry (Canning \& Lyon, 1989). For example, a 2012 report on the implementation of FDK noted that $43 \%$ of 107 students referenced as having special educational needs in this extensive study were reported as "not specified" with a special needs identifier (Vanderlee, Youmans, Peters, \& Eastabrook, 2012). It is not apparent, however, whether community-college-based ECE experiences address this shift. In the context of this project, the involved postsecondary institution offered a semester-long course focused on inclusion, but this course was limited to early childhood programs, excluding any mention of school-based special education in its stated outcomes. Perhaps, though, ECE students are developing more knowledge, being exposed to, and/or are experiencing school-based special education within the context of an in-school practicum placement and daily, in-depth mentoring (Doan, 2012), in this case from experienced classroom-based OCTs. Therefore, the purposes of this project are to (1) delineate the current role of ECE students from one community college postsecondary setting in school-based special education from multiple perspectives; (2) explore the preparedness of ECE students for involvement in school-based special education from multiple perspectives; and, (3) provide curriculum recommendations for an ECE community college postsecondary setting.

\section{M ethodology}

The information below outlines a small-scale, single-region research project designed as a first investigation into the above purposes of this study. Participants in the study were comprised of two groups: ECE students and Ontario-certified teachers, referred to throughout as OCTs or simply "teachers." Various methodologies and instruments were utilized in a mixed methodology approach to attain the unique perspectives of involved participants and to enhance findings with both quantitative and qualitative views. 


\section{Participants and setting}

ECE students. The student participants in this research included five female ECE students enrolled in their final term of studies in one community-college-based postsecondary ECE program in southwestern Ontario- a two-year diploma program. During this term, ECE students were completing their final program placements with early and/or primary-aged learners in various levels and programs from junior kindergarten (J K) to grade 1. All participants in this project had a placement role in a kindergarten setting. During the fall term of 2011, this research project was presented and explained from an exploratory, emergent standpoint by the authors prior to the placement experience, and interested ECE student volunteers accompanied the researchers to an adjacent classroom to complete preplacement questionnaires. Following approval from both postsecondary research ethics boards and the involved school board's research and assessment services, ECE students completed pre- and postplacement questionnaires. Preplacement questionnaires were typically completed on-site, but postplacement follow-up questionnaires were completed through electronic and/or mail-out options. Over two academic terms from fall 2011 to spring 2012, 13 students participated, but only a total of five ECE students completed both pre- and postplacement questionnaires. A lthough all ECE student participants were given follow-up reminders and the incentive of a textbook gift related to school-based special education, this lower completion rate for postplacement surveys was likely influenced by the following factors: student placements were the final program requirement and students did not return to campus; students had a decreased level of contact with researchers; and the necessarily web-based and/or mail-out postplacement options tend to produce lower response rates (Kaplowitz, Hadlock, \& Levine, 2004; Sax \& Bryant, 2003). Only one of these five participants was in a classroom placement simultaneously with an OCT participant.

Ontario-certified teachers. Five classroom-based teacher participants employed in one public school board in southwestern Ontario al so volunteered for this project on-site at their local schools. They offered their involvement following a letter of invitation distributed electronically from school board personnel to school administrators and then to school staff, according to the initiative of the involved parties. All five participants were OCTs with responsibility for early and/or primary-aged learners in various levels and programs from JK to grade 1, including Ontario's new full-day learning program, and various combined grades (e.g., SK/grade 1). These five OCT participants ranged in their experiences mentoring ECE students, from three who had one-time, recent, or current experiences with ECE students, to two who have had numerous experiences with supporting ECE students in school-based placements. Lily is an early years teacher with less than 10 years of experience in school settings and a long history experience in the child care setting, Rose is a JK/SK teacher with close to 15 years of experience, Violet and Daisy are FDK teachers, and Iris teaches a combined SK/grade 1 class.

Materials and procedure

The materials for this study consisted of a student pre-post questionnaire completed by the ECE students and a teacher interview guide completed with OCTs in a semi-structured interview.

Q uestionnaire. Five ECE student participants completed both pre- and postplacement 37-item questionnai res in either paper or el ectronic versions. Due to a lack of existing, replicated tools specific to Ontario's bachelor of education curriculum or the inclusion of special education in the Ontario College of Teachers Act (Service Ontario e-Laws, 1996) prior to its planned amendments in 2015, an authordesigned questionnaire was created from the eight areas of school-based special education in Ontario schools (e.g., learning disabilities), as outlined in a bachelor of education special education syllabus from one mid-sized Ontario university. Each question was overlaid with a five-point rating scale ranging from very low or none to very high self-reported ratings of knowledge, exposure, and experience in these areas related to school-based special education. For each question, participants were asked:

On a scale of 1-5 with 5 being the M OST comfortable and 1 being the LEAST comfortable, how comfortable do you currently feel about your current level of knowledge (e.g. understanding the topic), exposure (e.g. having observed) and intervention (e.g. having done) experiences related to school-based special education?

The following are sample questions from these pre- and postplacement questionnaires, which were identical for both pre and post measure: "M y knowledge about "Individual Education Plans"; "M y exposure to differentiated instruction"; "M y experiences with children with a behaviour exceptionality." Completed questionnaires were converted to electronic files, and visual results were constructed using Excel.

Semi-structured interview. Five OCTs participated in on-site, pre- and/or post-ECE-student-placement semi-structured interviews using a prepared yet flexible interview guide consisting of 14 items and additional prompts for verbal interviews. While potential participants were invited to complete both pre- and postplacement interviews, one-time interviews are typically carried out on a onceonly basis (DiCicco-Bloom \& C rabtree, 2006). Five participants chose to take part in preplacement interviews, and two participants al so completed postplacement interviews, for a total of seven OCT interviews over the course of this study. Interviews were audiotaped with a digital recorder as well as a backup cassette tape recorder, transferred to a computer-based file, transcribed, and explored for emergent 
themes and common perceptions in both within-case and between-case perspectives: both within questions and across topics (F rels \& Onwuegbuzie, 2013). Conversations ranged from 12 to 52 minutes, with the longer lengths being shared interviews with on-site teaching partners, at the request of involved participants. The interview guide was related to recommendations for knowledge around schoolbased special education, likely exposure and interventions during practicum placements, and knowledge of local and provincial policies, practices, and documents. Questions included, for example, What types of knowledge do you feel ECE students should have related to special education before they are placed in —or are employed in - the school system? For each interview question, responses from each participant were delineated and summarized, and responses from all participants were grouped together into a detailed, comprehensive overview. From these detailed overview statements, summary statements were developed, with stronger commonalities indicated by the number of teacher participants who provided responses which could be grouped together. F rom these summary statements, overall points of view and themes were constructed related to the purpose of this study.

\section{Results and Discussion}

The following results and related discussion are presented from the vantage points of the ECE students and OCT participants, providing both a quantitative and a qualitative view.

\section{A student view}

ECE students' self-ratings were converted into a comprehensive document summarizing their pre and post responses. For this authordesigned scale (see Table 1), a summed score of 41 self-rated items was calculated to create a summed score for preplacement measures $(M=81)$ and postplacement measures $(M=96)$. 
Table 1. Replicated ECE student pre- and postplacement questionnaires.

\begin{tabular}{|c|c|}
\hline Topic Area & Related Q uestions \\
\hline \multirow{17}{*}{ (1) Introduction to Special Education } & (1.1) M y knowledge of Bill 82. \\
\hline & (1.2) M y knowledge of "R egulation 181/98." \\
\hline & (1.3) M y knowledge of the "in-school model." \\
\hline & (1.4) My exposure to the "in-school model." \\
\hline & (1.5) My knowledge of assessment in special education. \\
\hline & (1.6) M y exposure to assessment in special education. \\
\hline & (1.7) M y experience with assessment in special education. \\
\hline & $\begin{array}{l}\text { (1.8) My knowledge of the "Identification, Placement and Review } \\
\text { Committee" process. }\end{array}$ \\
\hline & $\begin{array}{l}\text { (1.9) My exposure to the "Identification, Placement and Review } \\
\text { Committee" process. }\end{array}$ \\
\hline & $\begin{array}{l}\text { (1.10) My experience with the "Identification, Placement and Review } \\
\text { Committee" process. }\end{array}$ \\
\hline & (1.11) M y knowledge about "Individual Education Plans." \\
\hline & (1.12) M y exposure to "Individual Education Plans." \\
\hline & (1.13) M y experiences with "Individual Education Plans." \\
\hline & (1.14) My knowledge of the document "Education for All." \\
\hline & (1.15) My knowledge about "Differentiated Instruction." \\
\hline & (1.16) M y exposure to "Differentiated Instruction." \\
\hline & (1.17) M y experiences with "Differentiated Instruction." \\
\hline \multirow{6}{*}{$\begin{array}{l}\text { (2) Intellectual Exceptionalities: M ild } \\
\text { Intellectual Disability \& Developmental } \\
\text { Disability }\end{array}$} & (2.1) M y knowledge about children with a "M ild Intellectual Disability." \\
\hline & (2.2) M y exposure to children with a "M ild Intellectual Disability." \\
\hline & (2.3) M y experiences with children with a "M ild Intellectual Disability." \\
\hline & (2.4) My knowledge about children with a "Developmental Disability." \\
\hline & (2.5) My exposure to children with a "Developmental Disability." \\
\hline & (2.6) M y experiences with children with a "D evelopmental Disability." \\
\hline \multirow{3}{*}{$\begin{array}{l}\text { (3) Communication Exceptionality: A utism } \\
\text { Spectrum Disorders }\end{array}$} & (3.1) M y knowledge about children with "A utism Spectrum Disorder." \\
\hline & (3.2) M y exposure to children with "A utism Spectrum Disorder." \\
\hline & (3.3) M y experiences with children with "A utism Spectrum Disorder." \\
\hline \multirow[t]{3}{*}{ (4) Intellectual Exceptionality: Gifted } & (4.1) My knowledge about children who are "Gifted." \\
\hline & (4.2) My exposure to children who are "Gifted." \\
\hline & (4.3) My experiences with children who are "Gifted." \\
\hline \multirow{3}{*}{$\begin{array}{l}\text { (5) Communication Exceptionality: Learning } \\
\text { Disability }\end{array}$} & (5.1) My knowledge about children with a "Learning Disability." \\
\hline & (5.2) My exposure to children with a "Learning Disability." \\
\hline & (5.3) My experiences with children with a "Learning Disability." \\
\hline \multirow[t]{3}{*}{ (6) Behaviour Exceptionality (Special Need) } & (6.1) M y knowledge about children with a "B ehaviour Exceptionality." \\
\hline & (6.2) M y exposure to children with a "B ehaviour Exceptionality." \\
\hline & (6.3) M y experiences with children with a "B ehaviour Exceptionality." \\
\hline \multirow{6}{*}{$\begin{array}{l}\text { (7) Physical Exceptionalities (Special Need) } \\
\& \text { M ultiple Exceptionalities (M ore Than } \\
\text { One) }\end{array}$} & (7.1) M y knowledge about children with a "Physical Exceptionality." \\
\hline & (7.2) M y exposure to children with a "Physical Exceptionality." \\
\hline & (7.3) M y experiences with children with a "Physical Exceptionality." \\
\hline & (7.4) My knowledge about children with "Multiple Exceptionalities." \\
\hline & (7.5) My exposure to children with "Multiple Exceptionalities." \\
\hline & (7.6) M y experiences with children with "M ultiple Exceptionalities." \\
\hline
\end{tabular}

Using a graphical display of pre- and postplacement summed total of ECE students' self-ratings of combined knowledge, exposure, and experience with school-based special education, Figure 1 (below) provides an overview for all five participants. Overall, no ECE student 
participants had individual average scores in the very high or high range; rather, even in postinterview self-ratings, they fall equally between either very low to none (rating of 1 ) and low (rating of 2), or between low and moderate (rating of 3). Only one of the five participants' self-ratings, overall, falls between moderate and high (rating of 4). Although most ECE students rated themselves slightly higher in postplacement ratings, it seems clear that these ECE students see themselves as having "less" rather than "more" overall when it comes to school-based special education, even following a sustained, full-time on-site experience. In fact, one ECE student rated herself with lower scores following the practicum placement than before.

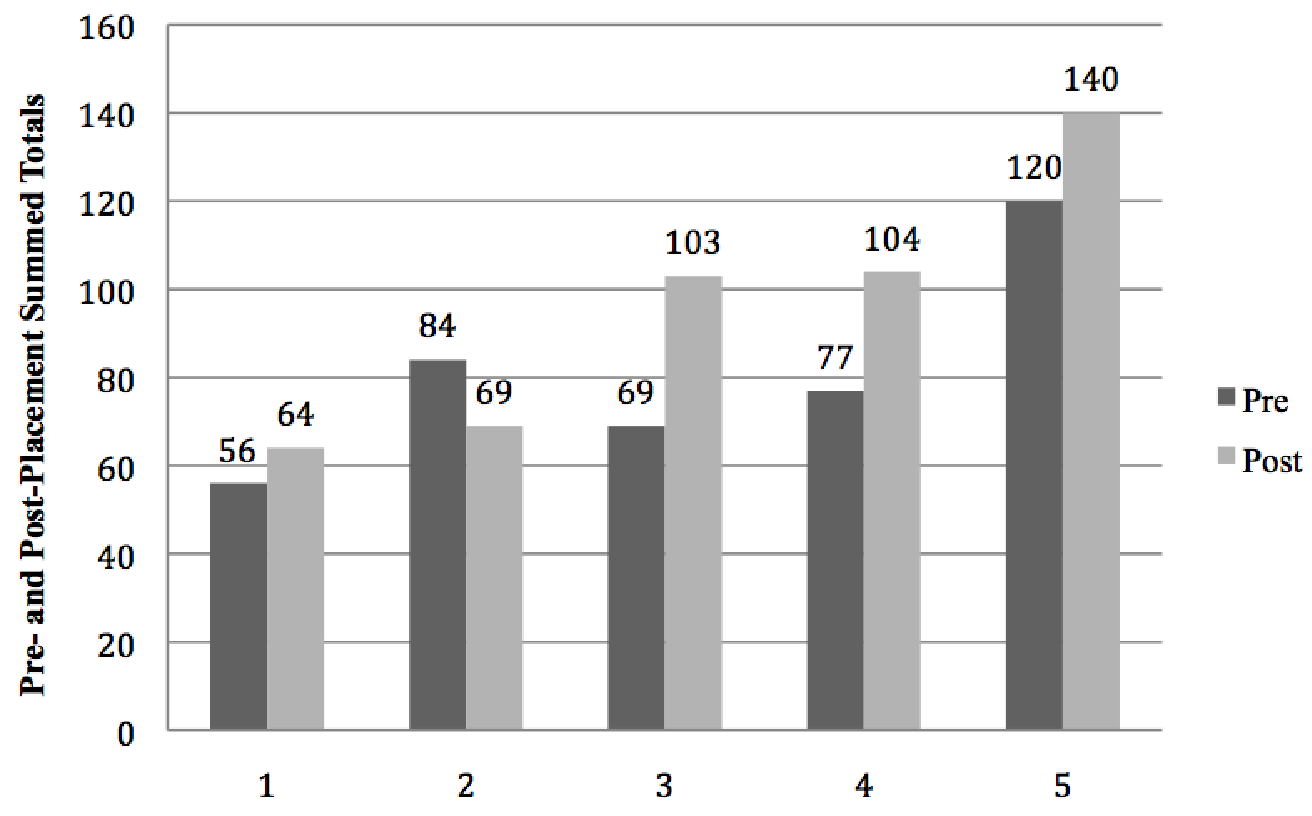

ECE Student Participants

\section{Figure 1. Pre- and postplacement summed total of ECE students' self-ratings of combined knowledge, exposure, and experience with school-based special education.}

It is clear that the ECEs in their final field placements are undergoing environmental, socially based objective experiences; however, it is unclear whether there is sufficient opportunity for personal and/or socially mediated reflection —using Piagetian language - to assimilate and/or accommodate schemas about special education into cognitive growth within this time frame of the final practicum experience (Kolb, 1984).

One anomaly existed in the direction of self-ratings (refer again to Figure 1, above). O ne ECE student rated herself with lower scores following the practicum placement than at her preplacement scores. Perhaps this student's outcomes suggest a learning style which is different from the remainder of the group. Like K olb suggests, she may "apprehend and transform [her] experiences differently" (K ovac, 2008, p. 148). Perhaps her learning happens through concrete experience rather than reflective thought, or she is an accommodator who prefers "concrete experience and active experimentation" (Kovac, p. 147). Perhaps this student is moving toward a conscious, metacognitive, attentive experience of the learning process ( $\mathrm{Kolb} \& \mathrm{Kolb}, 2009$ ) while moving away from a probable lack of awareness when "what we don't know we don't know" (p. 628). These processes describe the first stage of learning in everyday events and significant activities from an unconscious incompetence to a conscious incompetence or "a sense of our own ignorance and limitations" (р. 628).

\section{A teacher view}

A somewhat dynamic, universal flow emerged out of the contemplations and conversations of teacher participants in the kindergarten field when it comes to the special-education-related knowledge needs of ECE students: we are different, but we are the same. This dominant representation unifies the following emergent themes: (1) that a strong foundation of professional knowledge and practical skills is necessary to support students with special needs; (2) that education, care, and support must be in place for all students, including those with special needs; and, (3) that universal frameworks are needed to support all students proactively, not "just" those with special 
needs. These three themes are discussed below.

Strong foundations. As a group, the teacher participants expressed a significant list of new learning related to professional knowledge and practical skills that ECEs working in inclusive early years placements should have prior to entering the school setting (i.e., in their preparation programs). $M$ any of these areas of need are easily grouped and categorized (see Table 2 bel ow for a comprehensive list).

Table 2. A reas of knowledge for E CE students prior to entering school-based employment.

\begin{tabular}{|l|c|}
\hline \multicolumn{1}{|c|}{ Suggested Areas of Knowledge } & Number of OCT Participants \\
\hline $\begin{array}{l}\text { Individual education plans (e.g., accommodating, modifying, } \\
\text { differentiating, universal design for living [UDL ]) }\end{array}$ & 5 \\
\hline $\begin{array}{l}\text { A utism spectrum disorder (e.g., Treatment and Education of A utistic } \\
\text { and Related Communication Handicapped Children [TEA CCH], Picture } \\
\text { Exchange Communication System [PECS]) }\end{array}$ & 4 \\
\hline $\begin{array}{l}\text { Behaviour (e.g., choosing battles, ADHD, data collection, identifying } \\
\text { needs, observation) }\end{array}$ & 3 \\
\hline $\begin{array}{l}\text { General knowledge (e.g., special needs, setting up the environment, main } \\
\text { areas of disability, red flags) }\end{array}$ & 3 \\
\hline Identification, Placement, and Review Committees (IPRCs) & 2 \\
\hline
\end{tabular}

The three most common areas expressed as knowledge needs for new ECE graduates entering school-based employment focused on knowledge of (a) individual education plans (IEPs), which are legislated documents that outline school-based special education services geared to the needs of individual students, (b) autism spectrum disorders (A SD), and (c) behavioural concerns.

For example, one teacher participant stated: "Special education [and] special needs students are on the rise in general. A nd I think most of them are being mainstreamed, so I think any general knowledge of special education and what IEP stands for, and those sorts of things are always going to be beneficial to these students" [Daisy]. Lily expressed a need for knowledge around behaviour-behaviour that is beyond what is commonly considered to be typical classroom management issues:

I don't think [the ECE students] realize the extent of the behaviours that they will work with when they' re in the school system; the range as well as the intensity of some of these kids. They work in day care with kids that are a lot younger and it's calmer, and yes, you have temper tantrums in child care and there are issues in child care too, but when you get into the school system you could have a kid that's bigger than you are sitting beside you, that's having a full-fledged whatever, meltdown, temper tantrum, whatever it is, right? I don't know how to prepare them more for that, but just to be aware of it when they think, Oh, I want to work for the board. They pay lots of money; it's a great job. Be prepared for what you're getting into here first. (emphasis added)

Interventions that ECE students and/or future ECEs might implement include behaviour support for all students (e.g., understanding the functions of behaviour), supporting transition to school, proximity, cueing, redirection, providing individual, small group, and centre-based support, hands-on support, using visuals for communication, using a visual calendar, a first/then board, and social scripts. H owever, the teacher participants emphasized that the implementation of supports and interventions might look different between child care and school contexts:

I think the hard part that we have found with [ECE students] is for them to differentiate the difference between day care and school. It's very different and sometimes it's hard for them to see that. I think in day cares, they are a lot more hands on; they want to be more buddy-buddy with them, and where here they have to take on a little bit more of an authoritative role, and I think that's hard for them sometimes to make that distinction. Sometimes I think they think we're a little bit tough because if somebody's having difficulty we'll let them sit and kind of just think about it for a bit before we come back to them, and they're always there trying to make it into a positive situation. But sometimes they just need that time. So it's just very different philosophies trying to merge into one. And I think that is sometimes hard on their aspect and our aspect trying to make two worlds collide in a positive light. [Rose]. 
M ost of these recommendations would be described as hard competencies, sometimes known as cognitive, functional, or technical skills; in other words, "what people should know and are able to do to complete the work successfully" (Kovac, 2008, p. 144).

E ducation for all. All teachers shared that, in careers within the school system, ECE students and/or RECEs will most definitely have exposure to special educational needs, though this exposure will vary in place and time. It is significant to note that the majority of these interviewees also emphasized that we might not know these students have special needs at the time: their special needs may just be "blossoming" just as their overall development is doing. Students in the kindergarten system who may eventually be identified with an exceptionality may not yet be diagnosed or may not yet be identified, but we provide education, care, and support for the characteristics observed. Interestingly, this perspective aligns with the approach provided to school-aged special education in toto for some Canadian jurisdictions, like N ew B runswick, with the longest history of a fully inclusive model. For example, in a study of programs and policies related to services for students with emotional/behavioural disorders, the researchers reported that "there are no categories that are used for criteria to either determine eligibility, funding, or service provision" (D woret \& M aich, 2007, p. 36). These children might be facing multiple potential barriers or red flags, such as emergent issues, behavioural problems, peer difficulties, lack of clinical support, and/or lack of diagnoses; in addition, these children might not be identified, and they might not have an IEP, but they are still present in the classroom every day being supported by educators. This is not a new situation, however. The first province-wide study of young children with special needs in Nova Scotia (Canning \& Lyon, 1989) noted an increase in identification past the preschool level. Teacher participant R ose explained that observing and responding to perhaps more subtle needs, in order to support all students regardl ess of any "label," takes time, experience, and exposure. She shared that:

We have 3-year-olds to 6 -year-olds, students that might later on be diagnosed with a [learning disability] but might be having certain areas of difficulty even at [the] JK/SK level. With experience comes that awareness. I can usually pick [them] out when they come in: this is what their needs are right now, and usually down the road, a diagnosis is made. But it just comes from experience and exposure and learning what the characteristics are.

Universal framework. One message that was clear in the conversations and contemplations of these teachers is that special needs are not the only diversity in the classroom setting. A lthough ECE students as a group were exposed to what were presented as diagnosticspecific behaviours, related, at times, to students with diagnoses in place (e.g., ASD, oppositional defiance disorder, developmental delay), OCT participants suggested that it is necessary to develop a range of proactive and reactive strategies related to both general classroom management, social skills (e.g., K elso's Choice), and the management of oppositional behaviours (i.e., watching for cues that behaviours are escalating) - in other words, a universal design approach that focuses on the proactive development of a teaching and learning environment to support a range of present and potential needs (Ontario M inistry of E ducation, 2011). Two teacher participants shared that special needs are only part of the diversity in classrooms and issues. Violet explained a little further regarding the exposure of ECE students to the classroom environment:

We sort of felt like our students were here to, yes, get experience with special needs kids, but the overriding goals of students is to get experience programming for kids at large, so the special needs of all. They can be part of the process of helping little J ohnny who's got ASD, but no more with him than they are with Suzy who has emotional problems because she's lost a parent.

In other words, student experiences should not focus more on special needs than on other concerns, such as those related to emotional issues (i.e., feelings), management (e.g., playground), transitions (e.g., parental separation), academics (i.e., programming), English as a subsequent language, and speech and language concerns, for example. Violet further reflected on the reaction of her ECE student to such diversity: "On more than one occasion she expressed a disbelief at the behaviours [be]cause - it's so diverse - there [are] so many different needs. This is a very, very, very diverse group. Very. I think it's just the sign of the times." Violet further described her views:

We're working with what we have and we want to make our program meet the needs of the child. So, what different strategies we can use to make everyone successful. And it might have to vary: it can't be just one thing across the board because they're all coming in at different levels.

It is clear that the teacher participants in this study recognize the diversity in students with special needs as important in their classrooms and, subsequently, in their professional development and related skills development; however, they value and respect all diversity in their classroom settings and want to approach it in a proactive manner. While most teachers-including the group in this study - no doubt utilize a strategic combination of approaches, a clear sense of first utilizing a proactive, universal approach emerged from this study as a recommendation for educators entering the field. Inspired by architectural design, a framework of universal design for 
learning (UDL) fulfills the understanding that essential strategies that may be recommended for one student (e.g., a student with special needs) may be beneficial for many other learners, thus allowing for multiple means of engagement, expression, and representation. The core concepts of UDL are simplicity, safety, classroom design, universality and equity, and flexibility and inclusion (Ontario Ministry of Education, 2011).

Overall, the teachers in this study are firmly grounded in a complex understanding of inclusion for all students. DeLuca (2013) provides a relevant theoretical foundation for examining inclusion specific to Canadian schools, moving away from a deficit or "psycho-medical response" (p. 309) to a sociological one, through four perspectives in a framework that includes special education as a contributing discipline. These four conceptions and treatments of diversity are normative (assimilation focused), integrative (where difference are recognized, but a dominant versus minority duality exists), dialogical, and transgressive. As a group, these educators from one school board in southern Ontario are likely hovering between two of these perspectives. First, a dialogical conception is evident in which cultural complexities are respected, diversity is invited, "differences are recognized and accepted by institutions with provisions for equitable access to education leading to the same educational standards" (p. 332), and interactions "bring forward knowledge as rooted in the lived, cultural experiences of diverse students" (p. 333). Second, a transgressive conception is apparent that includes an "ideal istic benchmark" (p. 336) where "student diversity is used as a vehicle for the generation of new knowledge and learning experiences" ( $p$. 334) and issues such as a social justice, power, inequity, discrimination, stereotypy are recognized, yet individuality is empowered and celebrated as foundational to knowledge.

\section{Conclusions and Next Steps}

The purposes of this project were to delineate the current role of ECE students from one community college postsecondary setting in school-based special education from multiple perspectives, to explore the preparedness of ECE students for involvement in schoolbased special education from multiple perspectives, and to provide recommendations for curriculum for an ECE community college postsecondary setting. The below conclusions and related next steps, however, must be taken in the context of this small-scale, singleinstitution study. The questionnaire utilized to gather data was author-prepared, and further work needs to be done to assess its validity and reliability, which low response rates inhibited. These low response rates also precluded statistical analysis. However, unique conclusions and next steps for future recommendation can be made without an intention for extensive generalization of findings.

\section{The current role of ECE students}

From these results, it can be presumed that ECE students in this study are not significantly expanding their knowledge, exposure, and experience levels related to school-based special education during their practicum placement-at least in their own estimation. However, it is clear from the reflections of the mentoring educators that the ECE students are interacting with children with identified exceptionalities in the kindergarten classrooms and also children who may later be identified and children with challenges and needs of a diverse nature that may or may not be related to an exceptionality.

The preparedness of ECE students

Further, ECE students as a whole, in this study, did not see themselves as high in knowledge, exposure, and/or experience with schoolbased special education, even following full-time sustained placements in a kindergarten setting with a mentoring classroom relationship, including the requisite modelling, observation, discussion, feedback, and gradual rel ease of responsibility (D oan, 2013). Exposure and/or experience will come with time and future employment in the field if it is indeed true that "everything begins and ends in the continuous flux and flow of experience" (Kolb \& Kolb, 2009, p. 300). However, it would be a positive outcome for students to envision themselves as at least highly knowledgeable in school-based special education as a foundation for entering the field as professionals (Kovac, 2008).

\section{Recommendations for ECE programming}

Given the inclusive perspective of the teacher participants in this study, a positive recommendation for college-level preparation for ECE students entering kindergarten settings would be to develop strategies for students not only with special educational needs, but with a range of other needs related to diversity in the whole child and all of its related challenges. As stated above, a universal design approach that focuses on the proactive development of a teaching and learning environment to support a range of present and potential needs would be ideal (Ontario Ministry of Education, 2011); however, it is important not to dismiss the potentially significant outcome of a diagnosis or an identification. As one teacher participant suggested, these conclusions mean that we must make such experiences part of school-based placements and/or adapt the college classroom curriculum. A s recommended for OCTs, RECEs working together in FDK teaching teams should have a similar foundation of basic knowledge in school-based special education. Special Education Transformation emphasizes that all newly certified teachers should complete "a minimum of a half-course on special education before [being issued] an Ontario teaching certificate" (Bennett \& Wynne, 2006, p. 12). Our ECE students perhaps should emerge with the same 
foundation, covering topics such as IEPs, IPRCs, ASD, behaviour, and general knowledge about special education (e.g., red flags). In their research in N ova Scotia, Canning and Lyon (1989) similarly concluded that programs for early childhood educators "should prepare for work with young children with special needs, most of whom will be in regular programs. All trainees preparing to work with young children should be educated in both [typical and atypical] development and in methods of designing and implementing programs for all children" (p. 378). At the same time, a documented barrier for effective service provision for children with exceptionalities is the very heterogeneity found within any given diagnosis, identification, or "label," rendering potential matches between such labels and their interventions more complex than simple. In other words, it is important to retain a focus on inclusion, but also to include a deliberate focus on school-based special education topics, with a special emphasis on future identification. These areas of emphasis should come not only from a postsecondary classroom emphasis, but also from professional and collegial mentoring.

K ohut's self-psychology model emphasizes the importance of developing a robust, resilient self (K ohut \& Wolf, 1978), necessitating "different kinds of experiences throughout their lifetime" (Grady \& Cantor, 2012, p. 402). Grady and Cantor apply this idea to the professional development of social workers; perhaps it can also be applied to the development of others in the helping professions, such as ECE students. Positive, meaningful experiences called selfobjects help to develop stable, strong, resilient people-including professionals - who are "vibrant, productive, and [feel] confident" (p. 407). The context for much of this learning and self-development is through the critically important supervisory relationship, but also through peer-to-peer relationships. Colleges and hosting schools could continue to maintain and improve supervisory mentoring at the college and school levels which focuses on moving students through cycles of experience, reflection, conceptualization, and experimentation, ensuring that "crucial links between the different moment in the process are made" (de Jong, 2006, p. 253). However, a helpful addition could be adding a time, place, and /or method for reflective practice, and devel op a purposeful peer-to-peer learning community throughout their practicum placement(s) as a "conversational space" (Baker et al, 2005, p. 411). Both colleges and hosting schools can fulfill learning through "conversational learning, a process whereby learners construct new meaning and transform their collective experiences into knowledge through their conversations" (p. 411). For the purposes of this paper, this would be for the development of critical knowledge around school-based special education; however, it appears that such practices can potentially be of widespread benefit.

Over a lifetime - throughout the inevitable career-long development of knowledge, exposure, and experiences with school-based special education-a goal for any professional would be to reach a place where "our mastery of facts and decision-making in certain areas will become so automatic that we work mainly through intuition and past experience, a state of mind described as 'unconscious competence'" (L auner, 2010, p. 628). For ECE students just entering a professional role supporting all children in Ontario's kindergarten classrooms and just concluding a program of professional preparation, an appropriate goal would be comparable to that of inclusion and universal design - to support all students in the classroom, including careful preparedness in knowledge, exposure, and experience for co-teaching children with special needs in a school environment.

\section{References}

Allen, A.T. (1986). Gardens of children, gardens of god: Kindergartens and day-care centers in nineteenth-century Germany. J ournal of Social History, 19(3), 433.

Baker, A.C., Jensen, P.J., \& Kolb, D.A. (2005). Conversation as experiential learning. M anagement Learning, 36(4), 411-427. doi: 10.1177/1350507605058130

Bennett, B. (2012, November). Current trends and issues in special education. Presentation to the Regional Special Education Committee, Grand B end, Ontario.

Bennett, S., \& Dworet, D. (2013). Special education in Ontario schools. St. David's, ON: Highland Press.

Bennett, S., \& Wynne, K. (2006). Special education transformation. Toronto, ON: Queen's Printer. Retrieved from: http://www.edu.gov.on.ca/eng/document/reports/speced/ transformation/

B ennett, S. (2009). Including students with exceptionalities. Literacy and Numeracy Secretariat: What works? Research into Practice M onograph Series, 16. Retrieved from: http://www.edu.gov.on.ca/eng/literacynumeracy/inspire/research/whatWorks.html

B rewer, C., Gasko, J.W., \& M iller, D. (2011). Have we been here before? Lessons learned from a microhistory of the policy development of universal kindergarten. Educational Policy, 25(1), 9-35. doi:10.1177/0895904810386603

Bryant, D.M., \& Clifford, R.M. (1992). 150 years of kindergarten: How far have we come? Early Childhood Research Quarterly, 7, 147-154

Canning, P.M ., \& Lyon, M.E. (1989). Young children with special needs: Prevalence and implications in Nova Scotia. Canadian J ournal of Education, 14(3), 368-380. doi: $10.2307 / 1495365$

Chu, M. (2012). Observe, reflect, and apply: Ways to successfully mentor early childhood educators. Dimensions of Early Childhood, 40(3), 20-28. 
Chung, S., \& Wash, D.J. (2000). U npacking child-centeredness: A history of meanings. J ournal of Curriculum Studies, 32(2), 215-234.

College of Early Childhood Educators. (2012). Public register. Retrieved from: http://collegeofece.on.ca/en/M embers/Pages/Public-Register.aspx

de Jong, W. (2006). From 'doing' to 'knowing what you are doing': Kolb's learning theory in teaching documentary practice. J ournal of M edia Practice, 7(2), 151-158. doi: $101386 / \mathrm{jmpr} / 7.2 .151 / 3$

DeL uca, C. (2013). Toward an interdisciplinary framework for educational inclusivity. Canadian J ournal of Education, 36(1), 305-348.

DiCicco-Bloom, B., \& Crabtree, B. (2006). The qualitative research interview. M edical Education, 40(4), 314-321.

Doan, L.K. (2013). M entoring: A strategy to support novice early childhood educators. Canadian Children, 38(2), 21-24

Durlak, J.A . (2009). How to select, calculate, and interpret effect size. J ournal of Pediatric Psychology, 34(9), 917-928.

Dworet, D., \& M aich, K. (2007). Canadian school programs for students with emotional/behavioural disorders: A n updated look. Behavioural Disorders, 1(33), 33-42.

Frels, R.K., \& Onwuegbuzie, A.J. (2013). A dministering quantitative instruments with qualitative interviews: A mixed research approach. J ournal of C ounseling \& D evelopment, 91(2), 184-194. doi:10.1002/j.1556-6676.2013.00085.x

Grady, M.D., \& Cantor, M. (2012). Strengthening the professional selves of social workers through the lens of self psychology. Smith College Studies in Social Work, 82 , 401-417. doi: 10.1080/00377317.2012.717027

Kaplowitz, M.D., Hadlock, T.D., \& Levine, R. (2004). A comparison of web and mail survey response rates. Public O pinion Q uarterly, 68(1), 94-101. doi: 10.1093/poq/nfh006

Kohut, H., \& Wolf, E.S. (1978). The disorders of the self and their treatment: A n outline. International J ournal of Psychoanalysis, 59, 413-425.

Kolb, A.Y., \& K olb, D.A . (2009). The learning way: M eta-cognitive aspects of experiential learning. Simulation \& Gaming, 40(3), $297-327$.

Kolb, D.A. (1984). Experiential learning: Experience as the source of learning and development. Englewood Cliffs, NJ: Prentice-Hall. Retrieved from: http:// learningfromexperience.com/research_library/the-process-of-experiential-learning/

Kovac, D. (2008). Competence model in education and training process. Tourism and Hospitality Management, 14(1), 141-152.

Launer, J. (2010). Unconscious incompetence. Postgraduate M edical J ournal, 86(1020), 628. doi: 10.1136/pgmj.2010.108423

Legislative A ssembly of Ontario. (2010). Bill 242: An Act to amend the Education Act and certain other Acts in relation to early childhood educators, junior kindergarten and kindergarten, extended day programs and certain other matters. Retrieved from: http://www.ontla.on.ca/web/bills/bills_detail.do?locale=en\&Intranet=\&BillID=2269

Lewington, J. (2010, September). All-day kindergarten comes to Ontario. Professionally Speaking. Retrieved from: http://professionallyspeaking.oct.ca/september_2010/ features/kindergarten.aspx

Nixon, G. (1994). The first years of kindergarten in Canada. Canadian Children, 19(2), 6-9.

Ontario College of Teachers. (n.d.). Requirements. Retrieved from: http://www.oct.ca/ /link.aspx?_id=25CD74DDD6A14F3BA968490666FB1733\&_z=z

Ontario M inistry of Education. (2013). Full day kindergarten: A question and answer guide for parents. Retrieved from: http://www.edu.gov.on.ca/eng/multi/english/ FDK FactSheetEN.pdf

Ontario M inistry of Education (2011). Learning for all [draft]. Retrieved from: http://www.edu.gov.on.ca/eng/general/elemsec/speced/learning.html

Ontario M inistry of Education. (2010a). The full-day early learning-kindergarten program. Draft Version. Retrieved from: http://www.edu.gov.on.ca/eng/curriculum/ elementary/kindergarten_english june3.pdf

Ontario M inistry of Education. (2010b). Full day kindergarten schools. Retrieved from: http://www.edu.gov.on.ca/kindergarten/fulldaykindergartenschools2.asp

Pascal, C. (2009). With our best future in mind. Toronto, ON: Queen's Printer. Retrieved from: http://www.ontario.ca/education-and-training/early-learning-report

Service Ontario. (1996). Ontario College of Teachers Act, 1996. Retrieved from: http://www.e-laws.gov.on.ca/html/regs/english/elaws_regs_020347_e.htm

Smith, J.G. (2011). A bstracting the concrete, concretizing the abstract: R eframing diversity education through experiential learning theory. J ournal of Diversity M anagement $6(4), 1-8$.

Sax, L.J., Gilmartin, S.K., \& Bryant, A.N. (2003). A ssessing response rates and nonresponse bias in web and paper surveys. Research in Higher Education, 44(4), 409-432.

Stockall, N.S., Dennis, L., \& M iller, M . (2012). Right from the start. Teaching Exceptional Children, 45(1), 10-17.

Underwood, K. (2012). M apping the early intervention system in Ontario, Canada. International J ournal of Special Education, 27(2), 126-135.

Vanderlee, M ., Youmans, S., Peters, R., \& Eastabrook, J. (2012). Final report: Evaluation of the implementation of the Ontario full-day early learning-kindergarten program. Retrieved from: http://www.edu.gov.on.ca/kindergarten/FDELK_ReportFall2012.pdf 


\title{
Beyond Red Week: Working with Inquiry in E arly Years Settings
}

\author{
Kim A tkinson
}

Kim Atkinson is an early childhood educator and a pedagogical facilitator with the University of Victoria's U nit for Early Years Research and Development. She also co-coordinates, with Danielle Davis, the Images of Learning Project- an exhibit, blog, and series of presentations that highlights the work of ECEs and the competencies of children (www.imagesoflearningproject.com). Email: klatkins@uvic.ca

Drawing on the experience of the author and her colleagues, this article explores moving from a theme-based curriculum in early years settings to an inquiry-based approach. New possibilities for doing curriculum are described as educators challenge themselves to engage in processes of critical reflection, enact democratic principles, and adopt an inquiry as a focal point for discussion among children, colleagues, and families. The article shares examples of educators reimagining curriculum as they embrace both the flow and uncertainty of an inquiry.
It is 1995 and I am working with a group of 4-year-olds in a preschool. I have cut a large circle out of red construction paper and printed the word RED in the centre. At group time, I explain that this week is Red Week and we will be collecting red items to post on the red circle, doing red art projects, and wearing red clothing. Next week will be Yellow Week.

In thinking back, I wonder why I chose to engage with themes based on colour. I don't think I found the colour red particularly interesting, nor, I suspect, did the children. Did I think children did not know about red? Did I think they should know about red? Can one really know red by wearing red clothes?

\section{Shifting to an Inquiry-based A pproach}

I was not alone in my thematic approach to creating curriculum. It was standard practice in early childhood education at that time to plan and implement a weekly or monthly topic and introduce art, stories, and materials accordingly. Fortunately, in the ensuing years, many early childhood educators and teachers have begun to shift their practice, moving from preplanned activities toward an inquirybased curriculum. With the introduction of early years education frameworks in B ritish Columbia (Government of B ritish Columbia, 2008), Saskatchewan (Government of Saskatchewan, 2008), Ontario (Ontario M inistry of Children and Y outh Services, 2006) and N ew Brunswick (Government of New Brunswick, 2008), and with the influence of the philosophy and pedagogical documentation practices of early childhood programs in Reggio Emilia, Italy, Sweden, New Zealand, Australia, and elsewhere, early years professionals have begun reflecting on their image of the child, their image of the educator, and the values they hold about knowledge and education.

In these curriculum frameworks and philosophies, children are viewed as competent, as constructing knowledge and theories as they investigate their world (G overnment of B ritish Columbia, 2008; Government of N ew B runswick, 2008; L angford, 2010). This image of the child moves away from viewing children through a "future citizens" lens where childhood is understood as preparation for the future. Instead, children are considered citizens who are "full of potential; as persons with complex identities, grounded in their individual strengths and capacities, and their unique social, linguistic, and cultural heritage" (Government of British Columbia, 2008, p. 4).

\section{Critical Reflection and Democratic Principles}

This image of the child invites educators to critically reflect on the beliefs and assumptions we hold about children, and to consider how these beliefs play out in our daily practice. If we believe that children are capable and competent, do our environments and programs reflect that belief? Do we, as the New Brunswick framework proposes, "acknowledge children as curious and communicative individuals in their own right: young citizens actively constructing, co-constructing and reconstructing their understanding of the world within various communities of learning" (Government of N ew Brunswick, 2008, p. 8)?

Through processes of critical reflection, educators have begun to shift to new understandings of practice. We are becoming observers and researchers of children and their theories, paying close attention to what children know. We recognize that knowledge is not something to be transmitted from teacher to child, with the teacher determining the content of that knowledge. R ather, knowledge is co-constructed between and among children and adults. Langford (2010), in her analysis of the Canadian provincial early education framew orks, summarizes this image of the educator: "This educator is an observer, documenter, listener, researcher, creator of stimulating 
environments, co-constructor of knowledge, negotiator, supporter of children's participation in decision-making, facilitator of small group learning, supporter of social relationships, partner with parents, and supporter of diversity" (p. 17).

Through this image of the early childhood educator, democratic principles are brought to early childhood practice in which listening and reciprocity between children and adults structures the process of learning and being together. The N ew B runswick framew ork terms this living democratically, stating: "We value the everyday enactment of democracy that gives children a voice in matters that concern them and provides opportunities to participate in making and questioning collective decisions" (Government of New B runswick, 2008, p. 7). The Saskatchewan framework suggests an "expanded role" for educators in which educators "respect children as competent learners who are able to participate in decisions that affect their learning opportunities. Children share in decisions about routines and schedules to accommodate their ideas and needs" (Government of Saskatchewan, 2008, p. 17).

\section{Reimagining C urriculum}

But where do these shifts in understanding leave us? What does curriculum look like if our role is reimagined as co-constructor of knowledge, if we invite democracy? W here do we go when the themes that used to structure our days and weeks are taken away? W hat do we do instead?

In my roles as pedagogical facilitator in the Investigating Quality (IQ) Project at the U niversity of Victoria (Pacini-K etchabaw, N xumalo, Kocher, Elliot, \& Sanchez, forthcoming) and as co-coordinator of the Images of Learning Project (http://imagesoflearningproject.com/ info/), I work with early childhood educators to support new thinking about practice by sharing new perspectives and ideas. We discuss moving away from preplanned activities toward an inquiry-based practice. As we begin to reflect on our practice, educators often tell me they would like to embrace these ideas. Y et, many questions arise: How do we choose an inquiry? How does one start? Won't some children be left out if they are not interested? How do I know when to end the inquiry? What does one actually do in an inquiry? To engage with some of these questions, I provide some insights by presenting a moment in my own practice.

It is Valentine's Day and the children are making and giving cards to one another. Alice makes a card for William. Handing it to him, she looks him straight in the eye and says, "I love you." This bold declaration surprises me and makes me curious about what children think about love, so at group time the next day I ask, "What is love?" This is the dialogue that ensued:

A rlo: Love means you fall in love and you are going to marry.

B riar: It means you want to be nice and help your little brother.

Alice: It means you love them.

Ronan: When someone dies you love them. It means you miss them. You have to find a new family if they die.

Briar and Alice: No! No!

Alice: Every single person will die.

William: He said then you get another family. But that's wrong.

A rlo: Wrong!

A rlo: If someone dies you turn into a skeleton, then a ghost, then a spirit.

Alice: Spirit means you're dead.

A rlo: It means that you're a ghost that sneaks into people, that's evil.

A misha: Love means if you die you put something over the hole so you know where they are buried.

Ronan: A tombstone.

Once again I am utterly surprised - a conversation about love has turned into a discussion about death! It seems clear to me that children want to talk about death and that perhaps we adults are reluctant to broach the subject. I am al so intrigued by Ronan's assertion that you have to find a new family if your family dies. I revisit the conversation in subsequent group times, and the theme of what to do if one's parents die continues. The children discuss whether parents can die when they still have children to care for, and if they did die would you have to marry a new family? They agree that people die because they are old, and decide their parents are only a "tiny bit old." I video-record these dial ogues, transcribe them, and share them with parents, who then tell their stories: two preschool-age sisters drawing a grave with chalk on the basement floor claiming it is the grave of their great-grandmother, despite the fact that the woman is very much alive; a boy wondering if his mother needs a new father now that her own father has died.

This inquiry into death arose from questions I had when I observed a girl giving a boy a card. It went in an entirely different direction than I had intended, but was far more interesting as a result. I had not previously considered death as a topic to pursue in my work with young children, but once the children brought it up, I was intrigued and wanted to find out more. I was interested in the children's 
thoughts and theories, and I wanted to be led by them to discuss death in the ways they wanted to discuss it, following threads they began. I pursued the inquiry during our group time by listening and asking questions about the ideas that emerged. Together we explored causes of death, the importance of graves as markers of remembrance, and the possible ways a child would find someone to care for them if their parents died. The discussions spanned a few weeks, and when I sensed that the children's interest had waned, that the topic was no longer of such urgent importance to them, the inquiry ended.

Unlike Red Week, this inquiry on death had no clear outline of how it would proceed. There were long gaps between discussions. I needed time to think, to discuss my thoughts with families, and to reflect with colleagues. In this way, an inquiry is an organic process: it moves forward and backward in ways not necessarily dictated by the calendar. It emerges from our questions, curiosities, and new thinking. A nn Pelo (2006) puts the idea of a culture of inquiry beautifully: "Like life, it unfolds moment by moment, one step at a time, with surprises and detours and new questions to take up" (p. 50).

I initially had questions about children's conceptualization of love, which quickly shifted into a question about conceptualizations of death. While these questions emerged as I listened to children's dialogue, it was my own curiosity that spurred the inquiry. I wanted to investigate and provoke both my own and the children's thinking by pursuing this inquiry. So while the topic originated with the children, it was my decision to delve into it more deeply.

\section{A F ramework to Think With}

Thus an inquiry is generated with educators. It may emerge from observation of theories the children are working with, or it may emerge from questions the educators are working with, or it may be a combination of both. I am reminded of some questions that an educator at a preschool I worked with posed: "W hy do I do what I do as an educator? A re there other ways of being that I can explore as an educator?" She stayed with these questions for a year, challenging herself to reconsider her role. By continually returning to the questions, she shifted how she responded to children's encounters with materials, with mess, and with "chaos." She altered the schedule and rules as she listened to the children's ideas, and she invited parents to create provocations that would extend the children's thinking.

A $n$ inquiry becomes a framework to think with (V. Pacini-K etchabaw, personal communication, October 2012, original emphasis), to struggle with, and to bring some focus to our pedagogies. A n inquiry should provoke us to challenge ourselves to see and do differently without having clear answers. It becomes a focal point for discussion among colleagues, parents, and children.

A $n$ inquiry can emerge from something that challenges us, or from conversations or events that leave us uncertain and not knowing how to respond. The following was one of those moments for a group of educators:

A group of 3-year-olds sit at a table eating lunch. O ne boy begins a loud high-pitched rhythmic chant, "Yah, yah, yah, yah!" The other children at the table quickly pick up the idea and join in, and the room becomes filled with sound. Over the next few days this scenario is repeated at group time, snack time, as the children get ready to go outside. The educators are uncomfortable with the noise, but the children appear to love it. The educators are curious about why this sound making fascinates the children, and they ask themselves questions: What is our relationship with sound? Our perceptions of a good/bad binary of sound? Or the sound/noise binary?

Artists work with sound and "soundscapes," creating acoustic environments that listeners experience as surrounding them in space. What is the soundscape of a children's environment? Do we attend to soundscapes?

What does listening do? In ECE, we often relate listening to behaviour. How can we complexify listening? How can we listen to the classroom, the children, the educators?

What experiments could we consider to explore sound? Can we collect sounds on a tape recorder? Ask families to collect sounds with children? What sounds would children want to collect?

As the educators thought with these questions, they experienced a heightened awareness of sounds around them. They attended to the different sounds children noticed, or did not notice, and to the sounds the adults noticed or did not notice. They observed the unexpected ways children experimented with making sound and paid attention to their ow $n$ responses to the different sounds in the environment.

A $n$ inquiry can weave in and through the daily life of a program as ideas and questions arise. Experiments with sound did not happen every day or every week, but flowed with the interests of those involved. Sometimes there were large group experiments and at times 
only one or two children investigated an idea. Different educators and children had different interests within the inquiry. But thinking together enriched all of the various interests.

\section{Pedagogical Narration as a Tool for Reflection}

Integral to the process of thinking together with an inquiry is pedagogical narration or pedagogical documentation. Understanding the BC Early Learning F ramework: From Theory to Practice defines pedagogical narration as

the process of observing, recording, and, individually and collectively, interpreting a series of related ordinary moments in your practice. The process should be ongoing, cyclical and based on the art of critical reflection on the part of a community of learners. Importantly, it 'is contextual and involves children in a process of co-construction with teachers' (Dahlberg, M oss, \& Pence, 2007). (Government of B ritish Columbia, 2009, p. 13).

Within an inquiry, educators make notes, take photos, or video children in ordinary moments of investigation and theory making. Educators revisit pedagogical narrations to reflect on the theories the children may be working with and collaborate with one another, with families, and with children to invite multiple perspectives. Through critical reflection, educators can begin to see different possibilities and thus plan for further investigations or provocations.

In the example below, A nne is intrigued as she observes a boy making a ramp. The process of documenting her observations leads to further investigation and a deeper understanding of the complexity of a seemingly simple moment.

Anne is an educator in a family drop-in program. She observes a boy using a long plank to make a ramp that he then rolls cars down. Anne is fascinated and takes dozens of photos as the boy adjusts the angle and slope of the ramp to ensure that the car will end up in a precise spot. The boy and the ramp stay in Anne's mind, and she pores over her photos, curious as to the boy's intention and wondering why it holds such fascination for her. She begins researching ramp construction, reading about engineering, physics, gravity, and Newton's laws of motion. She takes photos of bridges, sloped roads, and on-ramps and discusses her pedagogical narration with engineers, friends, and colleagues, all of whom share different perspectives. Anne makes this observation: "The more I reflected and researched on my own, and the more people's perspectives and reflections I invited and subsequently pondered, the more knowledge I gained, which sent me delving into even more research to only spiral into even more thoughts and questions."

\section{Inviting M ultiple Disciplines}

Thinking with an inquiry often takes our practice in unexpected directions, and we are led toward disciplines outside the "typical" realm of early childhood. A nne's research into motion, gravity, physics, and construction enabled her to think differently about an ordinary moment of block play. A s A nne learned about the complexity of the engineering involved in building a ramp, she was able to more fully see the complexity of the boy's ramp making, to more deeply appreciate the theoretical knowledge he was thinking with.

Inviting knowledges from many disciplines creates openings for new perspectives. By looking into the worlds of art, philosophy, engineering, dance, music, Indigenous knowledges, architecture, history, or biology, among others, we can begin to see ideas, ways of being, and encounters differently. Allowing these other disciplines to "blur the edges" of our field of knowledge allows us to see children's theories, their meaning making, their play, and their relationships with materials in ways that unsettle our taken-for-granted thinking. As one educator put it: "As educators, what we think and expect can narrow our perceptions. We see what we expect to see and assign our own meaning."

In the following example, Lindsay draws on relational materialist theories (Clark, 2011) to inspire new ways of thinking about children, art, and art materials.

Lindsay became intrigued with the agency of materials, how materials invite particular responses. She read articles by artists and philosophers who challenged the idea that objects can be neutral subjects that humans act upon. She began to see materials differently, as having a presence, and to recognize that "materials, ideas, and the environment continually come together, connect, and break apart" (Clark, 2011, p. 3). She began to experiment with materials in her centre, putting clay on the floor, arranging blocks under tables, stacking two tables and putting paint jars and brushes on the very top, turning the easel upside down, all the while observing, questioning, and reflecting. She documented many moments of children's encounters with materials and posted these in her centre, inviting dialogue and multiple perspectives. Her inquiry into materials and materiality led her to think deeply about the "truths" we hold 
about children, and how challenging these truths can lead us into new ways of being as an educator and transform practice.

\section{Finding J oy in Uncertainty}

Red Week did not challenge me to see or think differently. I did not reflect on what the children understood about red, or how they might investigate red. Red Week progressed al ong a predictable trajectory with each group of children, year after year. Inquiries, on the other hand, involve unpredictability and invite uncertainty. They flow with the group that undertakes them and take many unanticipated twists and turns along the way.

The challenge and the wonder of an inquiry is that there is no prescriptive manual. Finding joy with, and becoming comfortable within, the uncertainty of the flow of an inquiry is to take a risk. It means putting trust in yourself and the children - trusting that together you can create, investigate, challenge, and surprise one another. It means embracing an openness to listening deeply to children, to colleagues, and to families, knowing that all are partners in a collaborative process.

\section{References}

Clark, V. (2011). A rt making as a political and ethical practice. Canadian Children, 37(1), 21-26.

Dahlberg, G., M oss, P., \& Pence, A. (2007). B eyond quality in early childhood education: Languages of evaluation (2 ${ }^{\text {nd }}$ ed.). London, UK: Falmer Press.

Government of British Columbia. (2008). British Columbia early learning framework. Victoria, BC: M inistry of Health and M inistry of Children and Family Development.

Government of British Columbia. (2009). Understanding the British Columbia early learning framework: From theory to practice. Victoria, BC: Ministry of Health and M inistry of Children and Family Development.

Government of New B runswick. (2008). Early learning and child care curriculum. Fredericton, NB: Department of Social Development.

Government of Ontario. (2006). Early learning for every child today. Toronto, ON: B est Start Panel on an Early Learning Program.

Government of Quebec. (2007). M eeting early childhood needs: Quebec's educational program for childcare services. Québec City, QC: M inistry of Family and Children.

Government of Saskatchewan. (2008). Play and exploration: Early learning program guide. Regina, SK: M inistry of Education.

Langford, R. (2010). Innovations in provincial early learning curriculum frameworks. Ryerson University Occasional Paper \#24. Retrieved from: http://www.childcarecanada. org/

Pacini-K etchabaw, V., N xumalo, F., Kocher, L. Elliot, E., \& Sanchez, A. (forthcoming). J ourneys: Complexifying early childhood practices through pedagogical narration. Toronto, ON: University of Toronto Press.

Pelo, A . (2006). Growing a culture of inquiry: Observation as professional development. Exchange, Nov/D ec, 50-53. 


\title{
Seeking the Otherwise: Attending to the Complexities of Listening
}

\author{
Vanessa Clark and Deanna Elliott
}

\begin{abstract}
Vanessa Clark is a PhD student and a sessional instructor of early childhood studies in the School of Child and Youth Care at the University of Victoria. She worked as an atelierista with a SSHRC-funded project entitled "Encounters with Materials in Early Childhood Education." Her research and presentations focus on colonialism and art pedagogies in early childhood spaces. Email: vanessa.vondruska@gmail.com
\end{abstract}

Deanna E lliott is a lead infant/toddler educator at U niversity of Victoria Child Care Services and the mother of two young children. She is a participant in the same SSHRC-funded project referenced above. Her presentations at various practitioner and academic conferences focus on her interests in ordinary spaces, materials, project work, and collaborations. Email: dinnieelliott@ yahoo.ca

This article presents our attempt to move beyond both developmental and Reggio Emilia guidelines for listening. We situate our efforts within our wounded colonial context- what is now called Victoria, British Columbia. Our effort is to begin to consider listening within unequal spaces of power, and to wonder what ethics such arrangements might require. In our engagements with clay and stones with the children, we noticed the sound the stones and clay made. In this article, we work with several stories of our investigations into sound, which have helped us to think about the complexities of listening in childcare spaces.

I ask Sam, "Do you think the sound is a colour?" He says, "yes" and moves to select the white charcoal. He draws first on the dark paper and then switches to the graphite on the white paper. I ask, "Are both the sound?" He replies, "no" and points to the white charcoal.

Within devel opmental frameworks, children are typically expected to learn to sit and listen during circle time and during "teachable" moments. Children need to demonstrate listening, while educators might instruct and encourage children in the appropriate way to listen. Listening is shown by certain body postures, such as sitting upright and looking forward, by certain facial expressions, such as eye contact and appropriate emotional expressions, through the medium of language, using age-appropriate words to communicate, and by self-regulation, such as taking turns talking (Garforth, 2009; Mosley \& MyiLibrary, 2005; Yifat \& Zadunaisky-Ehrlich, 2008; Zaghlawan \& Ostrosky, 2011). The environment is generally understood as passive within these listening contexts, and the child and educator act ( $\mathrm{M}$ acNaughton, 2003). A developmental understanding of listening might help us see that Sam has good listening skills. Our focus would be on the humans talking in English. We might assume that an educator is asking the questions and a child is responding. Sam replies appropriately to the questions he is asked, he does not get distracted by the materials he is playing with, and he waits his turn to respond.

The pedagogical project of Reggio E milia in I taly has generated important new directions for listening through Rinaldi's (2001) pedagogy of listening. R inaldi presents guidel ines for educators to listen to children in which she suggests several meanings of listening. Listening is a difficult task that involves many aspects, such as suspending judgment, recognizing, and remaining open to difference, change, and uncertainty. A search for meaning is a central component of listening. Listening also means being influenced by children through the many languages in the arts that they speak. Within these listening contexts, Reggio Emilia has also presented the understanding of the environment as a "third teacher" (G andini, 1998, p. 177). The pedagogy of listening might hel p us focus on the meanings Sam is making. We might listen deeply to Sam's voice, and really hear what he is saying with our whole bodies. He is telling us that sound can be a colour- perhaps making visible what he is learning about sounds. We would be challenged to listen to the languages of Sam's drawing, to also explore the meanings he is communicating to us. The white charcoal, graphite, and paper are also teachers to us.

We attempt to move bey ond R eggio E milia's guidel ines for listening because we are interested in expanding beyond human conversations. We attempt to pay attention to the complex, political spaces of listening relationalities among educators, children, and more-thanhuman others. We question the assumption that we can "do" listening, as though it is a demonstrable skill. Rather, we pay attention to the spaces of listening, and to how and why listening takes shape. We also move beyond Reggio E milia's human-centred approach to listening, which also means thinking beyond children's hundred languages. We wonder where the spaces of listening with children to more-than-human others might take us. Our challenges of listening have provoked us to question whether we need a common language to talk. We therefore also focus on moments where we might not understand what we hear, and we are curious about the ways in which listening fails. Who and what are privileged through listening, and who and what become blocked out? Our questions and curiosities have provoked us to engage with the more difficult conversations we encounter. Our hope is that our struggles with listening point to an ethics in practice. 


\section{The Context of Our Work}

Our work is located on unceded Coast and Straits Salish territories. Specifically, we work in the territory of the Lekwungen (Esquimalt and Songhees Nations). Through colonization, this territory has also become known as Victoria, British Columbia. We find this location meaningful for listening to more-than-human others because we are continually grappling with what it means to live ethically in these "wounded places" (Rose, 2004) where our worlds are made up of many more-than-human others that do not belong to us (Taylor \& Guigni, 2012). Our worlds are continually in contact with difference- with Indigenous bodies, land, and dignity (Hill, 2008; Watts, 2013).

Together with the children, we have been engaging with grey clay for six months, beginning in a "forest studio" and then moving inside our childcare centre's atrium. Vanessa Clark acted as an atelierista during the project and Deanna Elliott acted as an infant/toddler educator. Each week we would meet, moving between outside and inside, and participate with clay. Sometimes we would set out the clay in a large lump and the children would grab pieces of it as needed. Sometimes we would place balls, slabs, and chunks of clay out on the ground. Sometimes the children would help us set out the clay and tell us where to put it. Each time we worked with the clay, a different element would also be there. When we met outside, the forest presented us the challenges of working with stones, sticks, dirt, trees, a cigarette wrapper, bits of glass, fallen tree needles, and so on. Inside our atrium, we engaged a low table, walls, branches, stones, hair and bits of dirt from the floor, and so on.

The stories D eanna tells next attend to the moments within our work where we grapple with the complexities of listening to an assemblage of clay, stones, dirt, sticks, sound, and, and, and. Deanna's stories are not a linear description of our project. We seek out and follow the diverse relationalities that listening takes us into. We move between Deanna's stories and theories to begin to complexify listening, to provoke new thinking and ask new questions in our practices. We begin by telling stories and theories of listening as being shaped through spaces, and we work to complicate the voices we attempt to listen to. Next, we attend to our responses to the sound, and we wonder about our failed replies and the resistances of silence. We then point to an ethics of listening that focuses on difference. Finally, we provide concluding remarks.

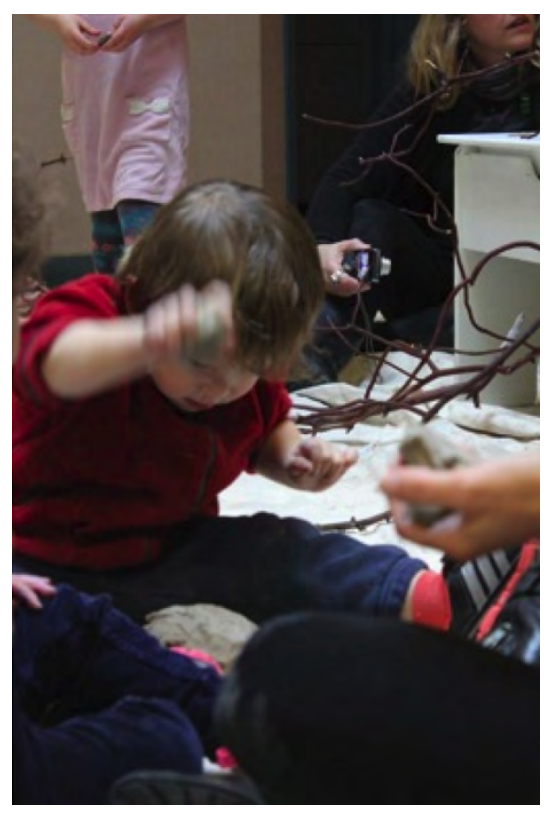

Figure 1. Children and educator engaging stones and clay.

\section{Telling Stories}

Listening Spaces

The educators, children, and researchers are in the atrium located in the centre of the childcare centre's three buildings. This area connects management, reception, two rooms for 3- to 5-yearolds, and one toddler room. We are seated on canvas that covers the floor in the atrium. The clay is resting in Shira's hand as she says, "Lets make the crackle sound." She picks up and invites sticks, leaves, and other objects into the clay. I sit silently beside her as she bangs, squishes, and drops the materials into one another. We listen, but it's not the crackle sound. Eventually she recalls that we need rocks to find the sound. We ask Ty what the name of the sound is, and he reminds us that it's the crackle sound. Shira walks as I crawl along the floor next to her searching for the rocks. We find a few. They are big, and Shira taps one onto the other. The crackle "speaks" quietly and quickly. Shira drops the rocks. Her visit is over.

The story above makes us think about listening as being shaped by our location, what is in the room, what is in the air, what ways we understand and can't understand. The clay, sticks, leaves, stones, the sound, the children, we, and our thoughts and questions are continually relating and come to matter in this complex space. How and why all these bodies relate and come to matter is never natural, innocent, or equal; it involves structures of power. We notice these power structures through the design of the buildings we are in, separating us by age and number of bodies, by the languages that are typically spoken in our childcare spaces, by the bodies that are present and the bodies that are absent, by the ways we typically think and act in our childcare setting and the ways of thinking and acting that become extinguished. These are the spaces of listening, and where listening takes shape (B irla, 2010; Byrd \& R othberg, 2011).

We are deliberately experimenting by engaging listening in the atrium - an area of connection within the diverse structures of power. The sound from the clay and bits of sticks, leaves, and other objects and the sound from the rocks make "noise." We and the children listen, searching for the familiar sound, the sound we have come to know and like. Listening takes shape and produces us unequally (B irla, 
2010) as the "noisy" more-than-human others and human listeners. We make no claims for our bodies and the land to be one (Watts, 2013). Instead, we are interested in the contact zones (Pratt, 1992), the spaces that shape us in contact with rocks, clay, dirt, and sticks. These spaces, fraught with complex histories, hold our attention.

We continue to listen with another story we tell to take these spaces of listening further so that we might think about voice.

\section{Complicating Voice}

Who notices the sound first? Is it me, Ty, Shira, or Sam? Either way, it pulls us all in together. We lean into it. We cradle it beside our ears. It makes us wonder. It makes us laugh. Maybe it's a little funny. It invited others to listen. I wonder what it wanted to tell us. Is it telling the story of how we created this bowl, or is it more? Is it asking us to find others to play? An invitation by something unliving, yet finding a way of speaking. It was heard. Was it understood? Bella brings her head close to the sound. "I want to hear," she says. Whatever the sound is telling us it brings with it wonder, smiles, and movement. Dressed in rain gear, I sit on the forest floor covered in water, mud, and clay. My hands are tired, cold, wet, and covered in a mix of dry, paste-like clay. My hands say they are finished. I ignore them. I lift my arms into the air near the children's ears and squeeze the clay-rock-water assemblage, creating the sound. The children jump, stomp their feet, and shake their hips while my upper body moves along with them. We dance around the sound. Maybe it knows some of our songs.

The story above makes us think deeply about hearing, and about the ways we understand what we listen to. In these intricate listening relationalities, we specifically select Spivak's (2010) concept "failure of hearing" instead of "failure of speaking" to suggest that the responsibility and work of understanding resides more with those more powerful. Spivak's (2010) understanding of "failure of hearing" is extremely complex and involves the notion of voice. Birla (2010) brings forward the issue of an "authentic voice." She is cautious about the notion that we are able to understand a "voice" without mediation. In other words, we cannot have direct access to a voice without some way of understanding the voice. Children and we want to listen in the story above, but we wonder if we understand. What ways of understanding are shaping our listening to the sound? In this sense, we are interested in the generative possibilities of considering our responsibilities in hearing and understanding and all the messiness that comes along with the voice we attempt to listen to. Indeed, our hands and bodies are messy, covered in clay, as we attempt to listen. Listening takes effort, as our bodies become tired and cold and our hands ache. Listening is physical. We move and get into the clay.

We also wonder about our actions and responses within the listening spaces that continue to shape us. B el ow we continue with another story of listening from our practices with children as we attempt to grapple with an ethics of responding.

\section{Responding to Sound}

The assemblage of clay, stones, and sound is in the forest. I am sitting on the forest floor, legs crossed in front of me. The outside edges of my hands press together as I cradle the now formed clump of clay, stones, pine needles, earth, and water. The children add to the clay bowl, filling it with dirt, small stones, and water, then I fold the bowl into itself. At first the clay is quick to move through my hands, giving in to me easily, gliding in my fingers with no protest. As more stones merge with the clay it becomes firm, resisting my hands and forcing me to work harder and harder. The stones are first hidden then take over the clay. I listen to the stones as they crash into each other through the clay. Reggio pedagogy suggests that listening is emotion. I wonder what the rocks are feeling. What are they telling me? Is the message important? Are they beginning to complain as they crush through the clay and into one another? The sound makes itself heard. Is it protesting or thanking me?

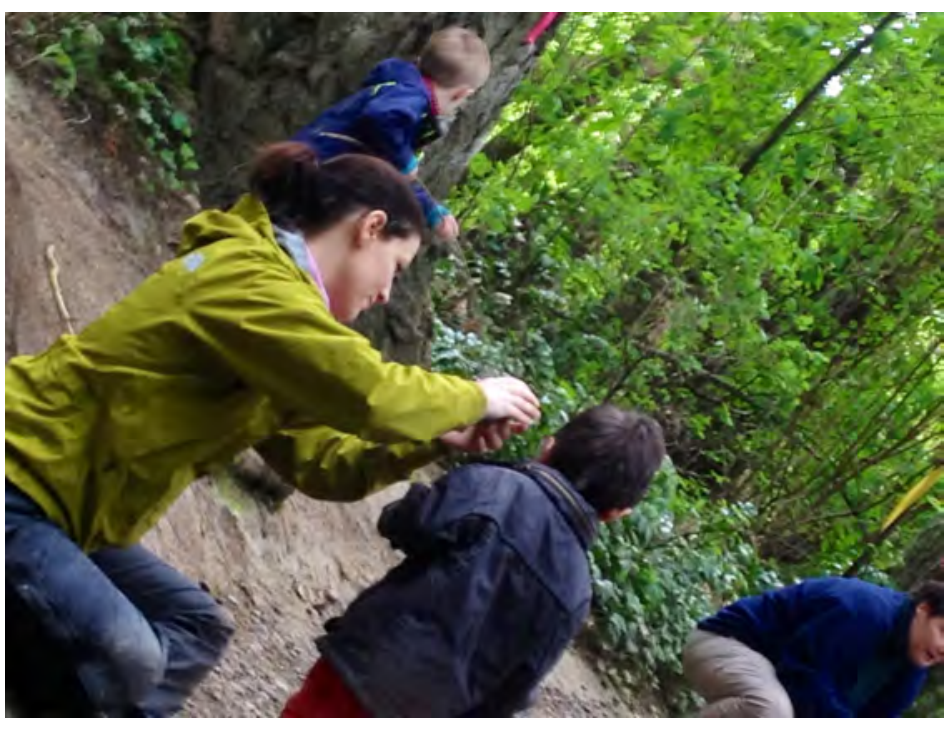

Figure 2. C hildren and educator in forest with clay.

Ty names the sound. It becomes the "crackle." It is important; we name things when they are important. Everyone hears the crackle. Are we understanding? It is lunch, we are cold and hungry, but the crackle asks us to stay, saying something to each of us before we leave it with Veronica and Vanessa in the forest. Luckily they carried it back for us. The bowl-clay-rocks-water-crackle found its way into our atrium. 
We are curious about listening when we might not understand what we hear. The story above makes us consider misunderstanding, and failing to hear the sound's message. What might we do when we cannot know what we hear? Have we heard the sound correctly? W hat are the consequences of thinking we have understood when we might not have? Part of the work of listening, Birla (2010) contends, is learning how to represent ourselves as those who are powerful. Representing ourselves is about learning to be responsive. Birla (2010) states:

In asking us to represent ourselves, Spivak asks us to supplement the benevolent intention of "speaking for" with an ethics of responsibility - in the sense of cultivating a capacity to respond to and be responsive to the other; without demanding resemblance as the basis of recognition. (p. 93)

A $n$ ethics of responsibility takes us away from demanding to know the crackle, to seeking out ways of fostering responses to what we hear. We are also interested in ways of responding when we might not understand the message. In the stories we have been telling, we continue to try to understand, to grapple with the complexities of the message, and to question ourselves. We and the children continue to stay and attend to the sound-the assemblage of "noisy" more-than-human others. We notice that the children continue to foster responses to the sound. What can we learn from them? What ways of understanding do the children draw from? We also consider that we all make mistakes and we continue to wonder, how we will know when our responses have failed? For example, can naming also be risky? W hat might naming "the crackle" do to it?

B elow we present another story as we continue to think through the complexities of listening.

\section{Failed Reception}

We find a few rocks on the floor. Sam brings one to me and asks me to "hide the rock." I lift the rocks from his hand and place them into the clay, folding the clay in. M ore rocks become hidden. The crackle whispers. Sam lifts another rock and bangs it into the clay-stone. The crackle is quiet. He bangs a few more times. It "speaks," loudly. "I found it!" He laughs. Is it telling a new joke, or repeating the old one? Sam piles rock-clay-rock-clay into a pile and begins smashing the tower over and over. The crackle is playing a game. It hides and "speaks" only when it's ready to jump out and surprise us. Isabella walks over to us and is introduced to the crackle. She listens. The crackle explains the game to her and she joins in.

Byrd and R othberg (2011) hel p us think about the idea of "the gap" in listening. We take this gap to be an intensely political space, where the message can get distorted between the sender and receiver. Translation by the sender to the receiver changes the message; it is an incommensurable relation. Byrd \& Rothberg (2011) state:

It is important to be precise about the kinds of non-reception at stake. F ailed reception can certainly mean a complete lack of reception, that is, a relegation of subaltern subjects to silence, absence, and non-recognition. But perhaps more invidious are forms of partial and distorted reception: reception that fails to acknowledge an incommensurable relation to the source of the message, an incommensurability that is not a "natural" product of cultural difference but derives from established power differentials. (p. 6)

We and the children, in the story above, draw on ways of understanding that are not a natural product of cultural differences. We listen to the sounds- the more-than-human assemblage of clay and rocks - within structures of power. In the story above, we hear the crackle and laugh; we play a game with the crackle. What would an ethic of attending to and responding to "lack of reception" (Byrd \& Rothberg, 2011, p. 6) be like? So, we attempt to pay attention to gaps, and to partial and distorted listening. We wonder where attending to these gaps might take us in our collaboration with the children. We notice gaps of sound when we sit silently and wait, gaps of searching and not finding the sound, gaps of space between bodies, rocks, clay, the floor, walls, and, and, and, gaps of understanding when we question ourselves, gaps of time waiting to get back to the sound, and, gaps in getting back to other moments in our day.

N ext we tell another story of a gap in sound to take us deeper into the ethics of listening.

Silence and Refusing to be Heard

We are seated on the atrium floor surrounded by sticks, ivy, rocks, and dry and damp clay. There is a buzz of activity in the room with fellow researchers of various ages moving fast, moving slow, or resting. The area is loud with everyone engaged in various levels of conflicting yet collective work. Ty is seeking the crackle. He walks over to two hard balls of clay. I notice the clay balls look like rocks. Ty collects a few balls and bangs them together. The crackle's voice has changed. Is it telling a similar story? Ty and I are both interested. As Ty bangs the clay balls, the balls bounce off each other, and this time knock a small piece to the floor. We notice it falls beside bits of dried clay clinging to the canvas. He picks it off. Someone brings a few rocks and places them on the floor. Ty and I pick up the rocks 
and begin to smash the clay with the rocks. The crackle breaks. It becomes dust. The dust begins to grow as we continue to smash the clay. It is suddenly silent.

Razack (1998) describes the unsettling idea of silence when we engage with spaces of listening. The story above makes us wonder about the sound's ability and power to refuse to be heard. A lthough we may seek it out and try to engage it, the sound becomes silent. Silence reminds us that we are not all-powerful in listening. The sound refuses to be heard: it transforms, it breaks, it becomes dust and resists our recognition.

In the stories we have been telling, the sound is difference (Hall, 1990). We search for the familiar sound, but sometimes we find a different sound, the sound speaks quietly, it surprises us, and it is silent. We wonder how familiar the sound is. We notice that the spaces of listening continually shift in the stories we tell. W hat does this mean for the becoming of the "voice" we attempt to listen to? What does this mean for us as listeners?

We continue with another story of engaging with the difference of the sound.

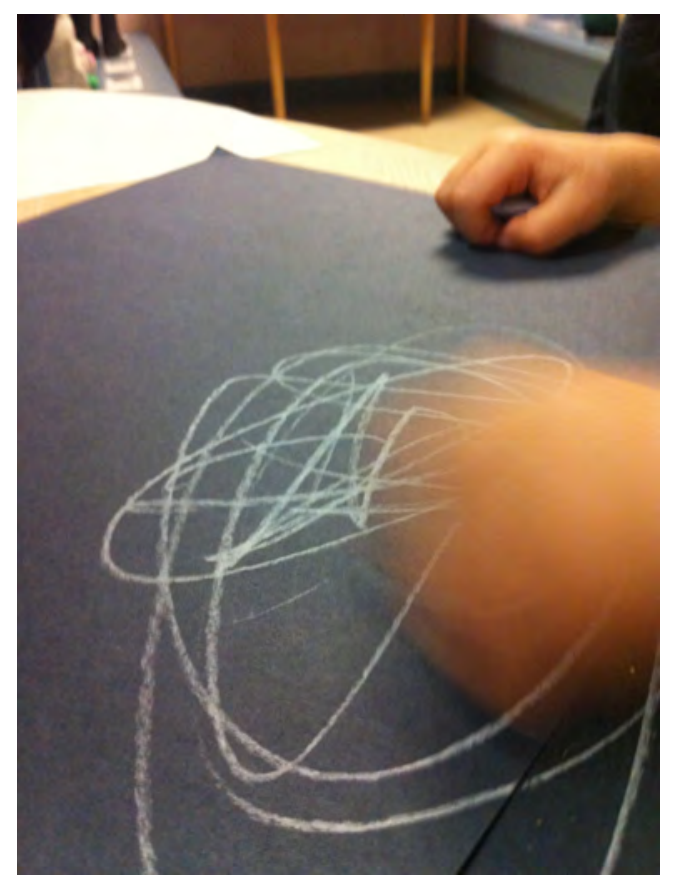

Figure 3. Child drawing.

Becoming Seen

Vanessa has sparked a curious question by asking if the crackle can be seen. Sam is washing his hands in the bathroom. I ask if he thinks the crackle could be a colour. He said "yes" and chooses white. I asked if he would like dark paper and white pens in the morning to draw it. He says "yes." Next morning, I set up a table with white and black paper along with graphite and white charcoal. When Sam arrives I remind him about our discussion and wait patiently for his invitation to show me the crackle. We sit at the table as Sam lifts the white charcoal, his hand racing over the black paper. Circles form quickly on the paper. I hear the brush of charcoal over paper in the silent room. "There it is!" he exclaims. He switches to the graphite on white paper. The motion and image is similar, so I ask if both are pictures of the crackle. He says, "No, just the white charcoal is the crackle."

Ashlynne enjoys quiet time with the crackle. She moves away from the group seeking distance and intimacy with the sound. Her movements are slow and purposeful, her conversations quiet. Without showing her the image or telling her the colour, I share with her the story of Sam drawing the crackle. She tells me the crackle is red. We walk together gathering white paper and red pencil crayons and find a spot on the floor next to the light table. The paper brightens as we place in on the table. I ask what the crackle looks like and Ashlynne replies, "I'Il show you." Her right hand grips the pencil as her body gently leans over the paper on the light table. She slowly draws a small circle on the paper. She tells me it is a small one, and then draws a big one. O ther children join us. Once again, the crackle has called them to play.

In the story above, the sound is becoming again. The sound is white, it is red, it is fast circles, it is a small gentle circle, it is a big circle. We wonder how to continue engaging ethically with listening, with the sound, when it is difference, when it is becoming. Can we continue to seek the otherwise, while at the same time engaging in these intense spaces of contact with difference?

\section{Conclusion}

The stories we have told help us move toward communities of listening, which centre more-than-human others as "speakers." We grapple with the complex spaces of power and ethics as listeners - who are both powerful and humbled by the power of the message. Our ethics engage with difference and we considered our responsibilities and accountabilities in responding. Where might such an ethics of listening take us in our practices with children?

\section{R eferences}

Birla, R. (2010). Postcolonial studies: Now that's history. In G. C. Spivak \& R. C. M orris (Eds.), Can the subaltern speak? Reflections on the history of an idea (pp. 87-99). N ew York, NY: Columbia University Press. 
Byrd, J. Rothberg, M . (2011). Critical categories for postcolonial studies. Interventions, 13(1), 1-12. doi:10.1080/1369801X.2011.545574

Gandini, L. (1998). Educational and caring spaces. In C. Edwards, L. Gandini, \& G. Forman (Eds.), The hundred languages of children: The Reggio E milia approach to early childhood education -Advanced reflections (pp. 161-178). Norwood, NJ: Ablex.

Garforth, S. (2009). Attention and listening in the early years. London, UK : J essica Kingsley.

Hall, S. (1990). Cultural identity and diaspora. In J. Rutherford (Ed.), Identity: Community, culture, difference (pp. 222-237). London, UK: Lawrence \& Wishart.

Hill, S. M. (2008). "Travelling down the river of life together in peace and friendship, forever": Haudenosaunee land ethics and treaty agreements as the basis for restructuring the relationship with the B ritish Crown. In L. Simpson (Ed.), Lighting the eighth fire (pp. 23-45). Winnipeg, MB: Arbeiter Ring.

M acN aughton, G. (2003). Shaping early childhood: Learners, curriculum, and contexts. Berkshire, UK : Open University Press.

Mosley, J., \& MyiLibrary. (2005). Circle time for young children. New York, NY: Routledge.

Pratt, M . L. (1992). Imperial eyes: Travel writing and transculturation. London, UK : Routledge.

Razack, S. (1998). Looking white people in the eye: Gender, race, and culture in courtrooms and classrooms. Toronto, ON: University of Toronto Press.

Rinaldi, C. (2001). The pedagogy of listening: The listening perspective from Reggio Emilia. Innovations in early childhood education: The international Reggio Exchange, $8(4), 1-4$.

Rose, D. B. (2004). Reports from a wild country: Ethics for decolonization. Sydney, A ustralia: University of N ew South Wales Press.

Spivak, G. C., \& M orris, R. C. (2010). Can the subaltern speak?: Reflections on the history of an idea. N ew York: Columbia U niversity Press.

Taylor, A ., \& Guigni, M. (2012). Common worlds: Reconceptualising inclusion in early childhood communities. Contemporary Issues in Early Childhood, 13(2), 108-119. http://dx.doi.org/10.2304/ciec.2012.13.2.108

Watt, V. (2013). Indigenous place-thought \& agency amongst humans and non-humans (First Woman and Sky Woman go on a European world tour!). Decolonization: Indigeneity, Education, \& Society, 2(1), 20-34.

Yifat, R., \& Zadunaisky-Ehrlich, S. (2008). Teachers' talk in preschools during circle time: The case of revoicing. J ournal of Research in Childhood E ducation, 23(2), 211-226. doi: $10.1080 / 02568540809594656$

Zaghlawan, H. Y., \& Ostrosky, M. M. (2011). Circle time: An exploratory study of activities and challenging behavior in head start classrooms. Early Childhood Education J ournal, 38(6), 439-448. doi:10.1007/s10643-010-0431-z 


\title{
Book Review: Conversations: Behind Early Childhood Pedagogical Documentation
}

\author{
E dited by A Ima Fleet, Catherine Patterson, and J anet Robertson \\ Review ed by Sydney Gurewitz Clemens
}

Sydney Gurewitz Clemens has been teaching young children and their teachers for almost 60 years. She is focused on "hot cognition" in the work of Sylvia A shton-Warner, Vivian Gussin Paley, and Reggio Emilia practice. Her most recent book, Seeing Young Children with New Eyes: What we Learned from Reggio E milia About Young Children and Ourselves, written with Leslie Gleim, was published in August 2014 and is available from iTunes and Lulu.com. Email: sydney@eceteacher.org

I haven't felt this excited by a teaching book in some years! The thoughtful, critically minded authors gathered in this book present nontrivial thinking about what we're learning from Reggio Emilia. As a person who lives in the United States, I found some of the A ustralian context unfamiliar, but the struggles with issues of racism and cultural diversity and the search for authentic growth in teaching were what I have learned, much of it from the Reggiani, to think about, too.

Each reader may approach this book in his or her own style. You may wish to "dip into" pieces that reflect your interests and concerns, which is the way this review is organized, or you may be more systematic. The editors have a logic in their sequence of chapters which moves from ideas that are more foundational (e.g., the first section on "opening the conversation") to confront some of those early ideas with others that bring more balance and choice to the story (e.g., the final section on "disrupting the conversations"). In any case, whereas you might be tempted to skim over the collegial "responses" at the end of each section, they are, in fact, integral because they invite conversations from other readers - friends and colleagues - with important ideas to share.

Many things intrigue me about this book, which opens with editors Alma Fleet and Catherine Patterson defining the scope of this big book and the role of pedagogical documentation in the life of the program for young children. Next comes the remarkable critique by B ritt and Rudolph in chapter 2. They raise many questions about "normalized" conceptualizations of pedagogy:

Why, for instance, does the majority of 'learning' or 'work' time seem to take place indoors?

Why does 'learning' seem to need to happen sitting down?

Why are children ranked against each other as if they are quantifiable data?

Why is strength in some subject areas seen as 'intelligence' but not in others? (Britt \& Randolph, 2012, p. 25)

And later:

The distrust and narrow accountability measures applied to teachers also creates an environment in which teachers are expected to be factory-like technicians assuming a standardized product (the student, and one form of pedagogy) rather than creative, flexible, critical researchers interested in discovering more about the best ways their unique group of students learn and relate in the world. (Britt \& Randolph, 2012, p. 25)

And still later:

It is important, however, to remember that these ways of thinking about and practicing pedagogy in primary school are not necessarily fixed, stable or inevitable (citing St. Pierre \& Pillow, 2000)... . There is still potential for hope to be offered in disrupting that which is taken as stable/unquestionable truth' . . . to create new trajectories.' (B ritt \& Randolph, 2012, p. 26)

Illustrating these ideas, the authors offer us a documentation panel (pp. 32-35) showing six- and seven-year-old children's photographs, paintings, and language about how their hands are voices, their hands, moving, a language. 
A child is quoted saying: "If our hands went to the circle we could pretend that they were littler thoughts and when we put them all together they are one big thought. If we put them together in the circle we are one big community and we work together." (Britt \& Randolph, 2012, p 35)

As a reader I found this rich conversation among young children about community extraordinary and wonderful. I imagine the children and teachers cited had similar feelings.

In another section, Doranna Wong, studying in A ustralia but coming from Singapore, writes about the cyclical process of observation: discussing, planning, and documenting, then moving on to observation once again. She says:

The learning from the constant listening and talking could communicate the voices of the children and of me. It made all the listening worthwhile as it was not just an exercise. ... Documenting grounded me as it meant the end of one cycle of listen-review-plandocument and the start of the same cycle again. ... Each discussion resulted in many 'un-doings' of my image of the child and a better understanding of myself - finding a balance between how I was as a teacher in the Australian context and wondering how I would be when I went back to Singapore. (Chng \& Wong, 2012, p. 50)

She says later:

I often felt I had to 'deny' a part of who I was to fully embrace who I wanted to become by working in this way. ... I had to choose between acknowledging the value placed on the education of children from my culture (primarily children's knowledge and success in the academics) or advocating for a change in this value, this way of thinking and being with children in my work. This also meant a change in the way my relationships developed with children. The most uncomfortable aspect of this way of working with families was the notion that I was learning with the children rather than structuring what they were to learn. (Chng \& Wong, 2012, p. 52)

Doranna's fellow student and writing partner, A ngela Chng, who is also from Singapore, writes:

I considered how this new way of thinking could be applied in an entirely different culture and context. What was going to be relevant? What could be implemented immediately and what would take time? ... Pedagogical documentation had shaped my philosophy. It felt strange, it was viewing how things were done in a very familiar and yet unfamiliar fashion, striking at the core of my understandings of the Singapore context with newfound eyes. It was never about abandoning one pedagogy for another, but in essence developing a deeper understanding of why things were the way they were and what I could do from there. (Chng \& Wong, 2012, p. 55)

Conversations is a brave book. For example, in the chapter "G et Over Yourself: The E thics of Respect," J anet Robertson asks and begins to answer an important question:

How do white people, couched in Western thinking, engage in conversations to gather information about local Aboriginal culture? How do we learn about the dance of questions and answers, where the Western cultural mores of an entitlement to an answer, and the Aboriginal value of censoring a reply depending on gender, wisdom and the relationship, shapes a conversation? The sensitive nature of some material, values, and expectations require some conversations to be choreographed and rehearsed. The most salient point is that if we, the second Australians, don't ask about Aboriginal culture, we will remain ignorant and that it is more offensive not to ask than to risk asking an inappropriate question. (Cave, Connerton, Honig, \& Robertson, 2012, p. 61)

The lengthy discussion of this question is important, not only to A ustralians, but also to A mericans and Canadians, to people in N ew Zealand and Hawaii and South Africa. While the people who were colonized have different stories and different ways of expressing and protecting their culture, the second comers, whoever we are, need to learn to find out how to live together with the first.

In the book’s second section, “Locating the Conversations," New Zealanders Slavica Jovanovic and John Roder write:

0 ur taken-for-granted assumptions, however, need to be continually re-visited; to be unpacked and taken to deeper levels, in order to know what it entails to understand a person. M aking 'the other' visible through cultural days, songs and stories, pictures, language and other ways of representing culture has its place, but does this tell us a story about who this cultural 'other' really is or how the very same 'other' made us change? It if does, what then is this story? How do we know we have created the space for him/her to be and to become, and offered a place in our hearts because it is there that our teaching starts? (J ovanovic \& Roder, 2012, p. 129) 
This matter of questioning our assumptions builds thoughtful teaching practices. Its absence is deadening to the classroom. There are continuing instances in this wonderful book of the questions of protecting agency in the children, a deep and important question from Reggio Emilia for us to take home to our countries, since each country has its own ways of snuffing out the spontaneity of children and their creativity.

In the same piece the authors say:

Pedagogy should not only be directed towards children and their learning, but also be an important transformative force in our own learning, learning about our own 'self'. This learning is not so much about 'being', but about being that is always 'becoming'. It is our reflective being that leads to action revealing another possible 'self' and impacting on our values and belief systems. (J ovanovic \& Roder, 2012, p. 130)

As I write this review, I tell myself that I'm quoting too much, and yet I don't stop myself - the quotations give the flavour of this book, a rare flavour, worth my five-star review. How could I find the audacity to reframe Slavica's statement that "there is no boundary between what the child is and what the child is continuously becoming. I feel it is the same for the teacher" (Jovanovic \& Roder, 2012, p. 135)?

Pamela Wallberg, similarly, gives us this:

Educators give voice to tensions that arise through day-to-day interactions, and will often provoke conceptual tensions by introducing a binary dilemma that the children must somehow find a third solution to. I believe this kind of problematization matters to Reggio Emilia thinking, to hel ping children exercise agency, and to mental health at a fundamental level. (Wallberg, 2012, p. 135)

This attention to problematization is an important facet of Reggio Emilia thought, and is well presented here.

In section 3, "M aterials M atter: A Conversation on M atters $M$ aterial" by L ouisa Schwartz and J anet Robertson takes a strong look at materialism in the program for young children, arguing for materials that have possibilities rather than ones that dictate how they are used. In their writing they raise, and interestingly answer, a question borrowed from L enz Taguchi (2010): "Is it possible to think of the material in early childhood practices as having agency of its own?" This chapter reminded me strongly of A ndy Goldsworthy's work, and of how children approach tape, paper, glue, and other materials if they aren't told how to use them. Robertson asks us:

If pedagogy and its materials always supply answers, then what problems do children encounter? We shape our pedagogy to create problems that can be solved. Thus the solution is our way of making thinking complicated. F rom these complications we often derive the kernel of a piece of pedagogical documentation. (Schwartz \& Robertson, 2012, p. 177)

$M$ any of the authors are connected with $\mathrm{M}$ ia $\mathrm{M}$ ia, the early childhood centre at M acquarie U niversity. One of the themes of the faculty there is that they should resist "the normalization of practice and working conditions" (Schwartz \& Robertson, 2012, p. 223). I found this idea exciting, since many fine practitioners I've know have been hamstrung by conditions that seemed permanent and would oppress their work for all of their future in that institution. We read stories in the book about changes that were needed and brought to fruition. As I think about the history of the schools of Reggio E milia, they have these stories also, important stories to fuel our own struggles about issues of naming the program, of making part-time attendance a thing of the past, of attending to an outdoor program, and of changing relationships with families of the children.

Conversations is full of metaphors, but my favourite one is to seek the stone in your shoe, which means interrupting the ordinary to pause and refocus and gather your thoughts. This metaphor comes from Robertson, and I, for one, am grateful for it.

When I briefly worked with teachers in Australia, they kept referring to each other as "girls" and I kept correcting them, annoying them in the process. On the last day I was there, one young woman challenged me: "W hy do you insist on our calling each other 'women'?"

I told her that her work was important and difficult, and that we don't give hard, important work to children, but to adults. And that she should model that respect to anyone coming through the childcare centre. This book includes the idea that we must give ourselves "permission to regard our work in early childhood education programs as important and worthy of attention and respect" (Schwartz \& Robertson, 2012, p. 241).

Toward the end of the book we are told that "a skilled person 'lives his/her knowledge' which is different to how a skilled person 
"lives his/her skills", (Semann, Proud, \& Martin, 2012, p. 255). If you are wanting to live your skills in an early childhood context, Conversations is a strong companion for your journey. This book isn't for the introductory R eggio Emilia class but for a grown up and mindful mature exploration of how we bring the best strategies and ideas of the Reggiani into our daily lives with children. Get your library or your school to order it. It is expensive, but not so costly that its riches can be skipped.

\section{R eferences}

Davies, B. (2004). Introduction: Poststructuralist lines of flight in Australia. International J ournal of Qualitative Studies in Education, 17(1), 3-9.

Lenz Taguchi, H. (2010). Going beyond the theory/practice divide in early childhood education: Introducing an intra-active pedagogy. London, UK: Routledge. 


\title{
Call for Contributions
}

\author{
Special Issue on 'The Visual Arts in Early Childhood Education' \\ F or Canadian Children, 2016 On-line edition \\ Guest E ditor: Dr. Sylvia Kind, Capilano U niversity
}

Children's artistic engagements are increasingly taken seriously as investigative, relational, and meaning making processes involving various fabrications and compositions and multiple ways of knowing. This is a shift from thinking about children's artistic engagements as primarily individual, self-expressive, emotional representations. Rather, artistic engagements are understood as complex, intertextual, performative, material practices that produce particular worlds and meanings.

As such, we are interested in what art is, what it does, and how it matters in early childhood educational settings. We invite submission of papers that address the visual arts in early childhood from a variety of perspectives, particularly those that offer an alternative to conventional understandings of children's art making. In addition we are interested in contributions that:

a. Propose innovative ways of thinking about the visual arts in early childhood education.

b. Conceptualize children's artistic engagements and experimentations through relational-materialist, Deleuzian, and Indigenous perspectives.

c. Explore the interconnections of contemporary art/artists and early childhood contexts.

d. Experiment with visual/textual forms of representing children's artistic experimentations and forms of worldmaking.

Educators, researchers, and artists are invited to submit a 250 word abstract for this issue of Canadian Children focused on Visual Arts in Early Childhood Education to Sylvia Kind by August 15, 2014. If the abstract is accepted, the manuscript is due by January 31,2015 . Once the review process has been completed, accepted papers must be resubmitted by July 31, 2015.

A bstracts and papers can be submitted via email to Sylvia K ind (skind@ capilanou.ca)

\section{GUIDELINES FOR AUTHORS}

Canadian Children is the journal of the Canadian Association for Young Children (CAYC), a national association specifically concerned with the well-being of young children in Canada. The journal is published in print twice yearly and online once a year. Canadian Children contains invitational articles, peer-reviewed articles, articles from professionals in early childhood related fields, and reviews of books and other resources.
Canadian Children is a multidisciplinary journal. A uthors from across Canada, and el sewhere, are invited to submit articles and book reviews which reflect the variety and extent of both research and practice in early childhood education and child well-being.

Submissions should appeal to an audience that includes professionals in the field of childhood education and other child related fields, as well as researchers.

We welcome manuscripts between 4000-6000 words for the Invitational \& Child Study sections, and between 1500-3000 words for the Directions and Connections section.

\section{Form, Length and Style:}

- Articles may be of varying length, written in a readable style. Style should be consistent with the Publication M anual of the A merican Psychological A ssociation (6th Edition).

- Articles should be sent as an e-mail attachment to the email address below.

- All submissions should be accompanied by a copy of the signed permission form available on the website.

- Authors are to obtain releases for use of photographs prior to submitting the manuscript via e-mail. Signed permissions need to be included in the submission.

- Please include a brief biographical sketch (4-5 sentences) including the author(s) full name, title, professional affiliation, and other relevant information.

- An abstract should be included at the start of the manuscript and not exceed 100 words.

- 4-5 keywords should be included following the abstract

- Footnotes should not be used. Endnotes need to be located in the text by numbers.

- In order to enable blind review, manuscripts must be anonymized. No author information should be included in the manuscript.

- All author information (including full name, mailing address and biographical information) must be included in a separate document.

- It is expected that authors will not submit articles to more than one publisher at a time.

\section{Submission email address:}

To submit a manuscript, email to cdnchildren@ gmail.com, copied to Sylvia Kind (see below).

\section{Contact Information:}

For further information or inquiries, please contact special issue guest editor directly:

Sylvia Kind, skind@ capilanou.ca 


\section{CAYC BOARD OF DIRECTORS}

\section{National Directors}

\section{President}

Rebecca Kelly

Alberta

\section{Director}

Peggie Olson

Saskatchewan
Director/Vice President Angela Woodburn

Ontario
Secretary

Melanie Janzen

Manitoba
Technology Integration

Chair

Karyn Callaghan

Ontario
Publications Chair Iris Berger

British Columbia
Treasurer, Membership

Chair

Lynda Noble

Nova Scotia

\section{Pravincial Directors}

\section{British Columbia}

Kathleen Kummen
Alberta

Sherry Moores
Saskatchewan

Darlene Dixon

Beth Warkentin

\section{Ontario}

Anne Marie Coughlin

Nova Scotia

Sherry Riggs
Quebec

Sara latauro
New Brunswick

Vacant

Newfoundland/

Labrador

Vacant

\section{Nunavut}

Vacant

\section{Yukon}

Vacant
Prince Edward Island Vacant

Northwest Territories

Vacant

\section{MEMBERSHIP SERVICE}

Vicki Brown

31 Pinedale Drive

Prospect Bay, Nova Scotia B3T 1 Z6

Phone: 902-852-2954

Email: membership@cayc.ca
THE JOURNAL - Editors' Desk

Co-Editors,

Laurie Kocher and

Veronica Pacini-Ketchabaw cdnchildren@gmail.com 


\section{Consider a \\ CAYC Membership GIFT}
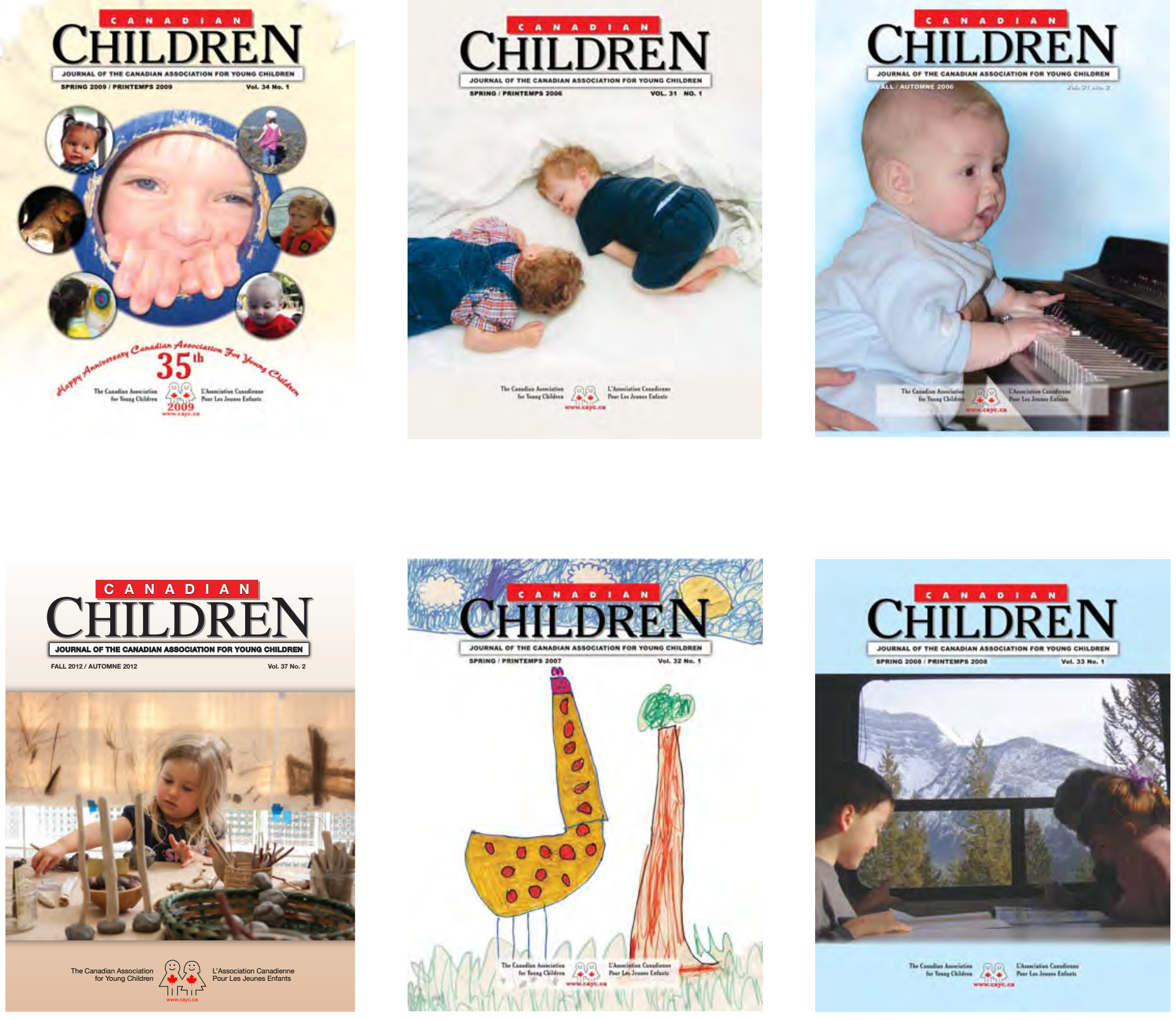

...for the education students OR graduates in your life Refer to our website www.cayc.ca 